\title{
Comparative Advantage in Innovation and Production
}

Somale, Mariano

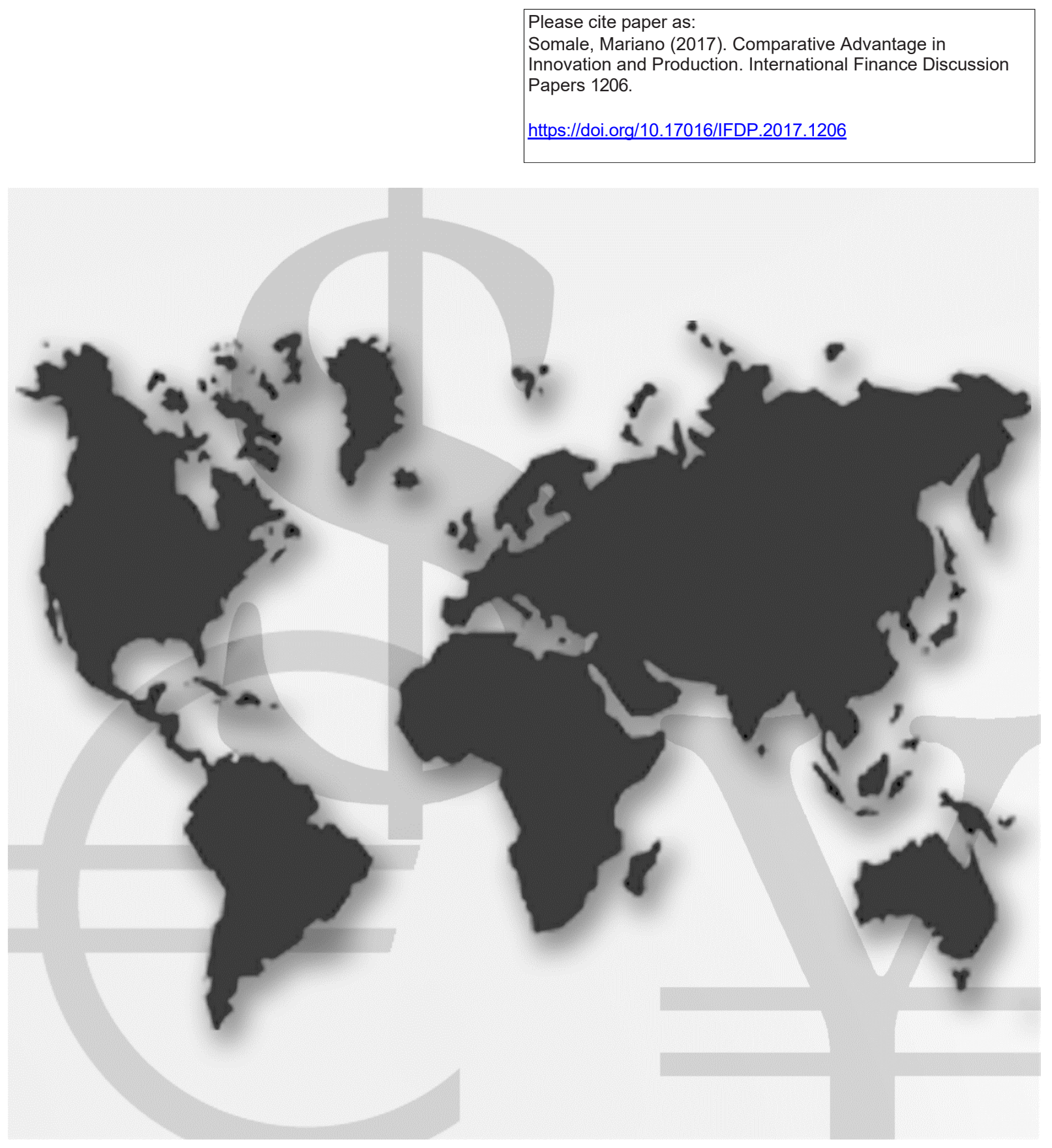

\section{International Finance Discussion Papers}

Board of Governors of the Federal Reserve System

Number 1206

May 2017 
Board of Governors of the Federal Reserve System

International Finance Discussion Papers

Number 1206

May 2017

\title{
Comparative Advantage in Innovation and Production
}

\author{
Mariano Somale
}

NOTE: International Finance Discussion Papers are preliminary materials circulated to stimulate discussion and critical comment. References in publications to International Finance Discussion Papers (other than an acknowledgment that the writer has had access to unpublished material) should be cleared with the author or authors. Recent IFDPs are available on the Web at https://www.federalreserve.gov/econres/ifdp/. This paper can be downloaded without charge from Social Science Research Network electronic library at http://www.sssrn.com. 


\title{
Comparative Advantage in Innovation and Production*
}

\author{
Mariano Somale
}

\begin{abstract}
This paper develops a multi-country, general equilibrium, semi endogenous growth model of innovation and trade in which specialization in innovation and production are jointly determined. The distinctive element of the model is the ability of the agents to direct their research efforts to specific goods, in a context of heterogeneous innovation capabilities across countries and contemporaneous decreasing returns to $\mathrm{R} \& \mathrm{D}$. The model features a two-way relationship between trade and technology absent in standard quantitative Ricardian trade models. I calibrate the model using a sample of 29 countries and 18 manufacturing industries and quantify the importance of endogenous adjustments in technology. I find that endogenous adjustments in technology due to directed research can account for up to $52.8 \%$ of the observed variance in comparative advantage in production. In addition, the model suggests that standard Ricardian models overestimate the reductions in real income from increases in trade costs and underestimate the increment in real income due to trade liberalizations.
\end{abstract}

Keywords: Trade, innovation, directed research, quantitative models.

JEL codes: F10, F11, 030.

*I am indebted to Stephen Redding, Esteban Rossi-Hansberg and Gene Grossman for guidance, encouragement and support. I also benefited from conversations with Eduardo Morales, Ferdinando Monte, Sebastian Sotelo and Jing Zhang. I would like to thank the International Economics Section at Princeton University for financial support.

${ }^{\dagger}$ The author is a staff economist in the Division of International Finance, Board of Governors of the Federal Reserve System, Washington D.C. 20551 U.S.A. The views in this paper are solely the responsibility of the author and should not be interpreted as reflecting the views of the Board of Governors of the Federal Reserve System or of any other person associated with the Federal Reserve System. 


\section{Introduction}

In this paper I develop a quantitative model of innovation and trade to study the interactions between trade and technology in a context of endogenous innovation and in which agents can direct their research efforts to specific goods in the economy. Ever since the writings of David Ricardo, the relationship between technology and trade has featured prominently in economic analysis. Traditional Ricardian trade theories have emphasized the role of technological differences across countries as the main determinants of specialization patterns in production and trade. The literature following this tradition has typically taken these technological differences as exogenous and used static models to analyze topics such as the patterns of production and trade, the welfare gains from trade, the effects of exogenous technological progress and the effects of the diffusion of technology. ${ }^{1}$ Moreover, since the seminal contribution of Eaton and Kortum (2002), we have a rich set of quantitative trade models incorporating the main Ricardian insights in a context of many goods and many countries, allowing the researcher to go beyond the qualitative analysis that previous models permitted. ${ }^{2}$

Treating technological differences as exogenous, as in a typical static Ricardian model, presumes that the direction of technical change is not affected by trade. However, this is not the case in the presence of endogenous innovation and directed research. Economists have long emphasized the economic nature of innovation activity and the role of expected profits in shaping the amount and direction of innovation efforts. In the words of Schmookler: "...invention is largely an economic activity, which like other economic activities, is pursued for gain." 3 Then, in an economy in which research efforts can be directed to specific goods, trade can affect innovation and technology through the changes it induces in the expected market size for inventions. These trade-induced changes in market size affect the relative expected profitability of innovation across goods and generate reallocations of research efforts from those goods for which the market contracts towards those goods for which the market expands, ultimately affecting the distribution of technology across goods and countries.

These effects of market size and trade on innovation are not mere theoretical possibilities. Empirical evidence on the effect of market size on innovation goes back to at least the times of Schmookler. In his seminal work on technical change in various capital good industries, Invention and Economic Growth (1966), Schmookler provides evidence about the importance of demand and the expected market size for an innovation as determinants of invention activity. More recently, Newell, Jaffee and Stavins (1999) show that the type of innovation on the typical air conditioner sold at Sears shifted from innovations that reduced their in the period 1960-1980 to innovations that made them more energy-efficient in the period 1980-1990, which they argue was the consequence of the rise in energy prices in the later period. Using changes in demographic trends as a source of exogenous variation in the market size of different types of drugs, Acemoglu and Linn (2004) find economically important effects of these changes in market size on innovation. Recent studies also provide evidence supporting the effects of trade on innovation discussed above. Bustos (2011) shows that technology spending increased faster on those Argentinean

\footnotetext{
${ }^{1}$ Grossman and Helpman (1995) survey the literature that follows this tradition.

${ }^{2}$ Eaton and Kortum (2012) survey the quantitative trade literature building on Eaton and Kortum (2002).

${ }^{3}$ Schmookler, Invention and Economic Growth, 1966, p. 206.
} 
industries facing higher reductions in Brazil's tariffs in the context of MERCOSUR trade liberalization. Lileeva and Trefler (2010) show that Canadian plants that received preferential access to U.S. markets under the terms of the Canada-U.S. Free Trade Agreement raise their labor productivity by investing in productivity-enhancing activities. This micro-level evidence suggest that current quantitative Ricardian models may be missing an important margin of adjustment in not allowing for trade to affect technology through its impact on the direction of technical change.

The purpose of this paper is to study the two-way relationship between trade and technology that emerges in a context of endogenous innovation and directed research, and to assess qualitatively and quantitatively the macro-level implications of directed research for innovation, production and trade. To that end, I build on Eaton and Kortum (2001) and on recent developments in the static quantitative trade literature to develop a multi-country, general equilibrium, semi-endogenous growth model of innovation and trade in which specialization in innovation and production are jointly determined. The distinctive element of the model is the ability of agents to direct their research efforts to specific industries in a context in which countries differ in their exogenous innovation capabilities; this new element builds into the model the two-way relationship between trade and technology that is the focus of this paper. The semi-endogenous nature of technical change in this model implies that all the effects of directed research are reflected in the levels of the variables of interest in the balanced growth path (BGP), with no effect on BGP-growth rates. These level effects are the focus of this paper. I use the model to assess the effects of trade on technology and to study questions that standard Ricardian quantitative models and reduced-form approaches are not suitable to answer. How important is the feedback from demand and market size to technology? How is comparative advantage in production determined in this context? How are the specialization patterns of innovation, production and trade determined? How does this additional margin affect our conclusions regarding the effects of trade liberalization on production, trade flows and welfare?

The model features contemporaneous decreasing returns in R\&D, which are parsimoniously captured by a single parameter, $v$, common to all countries and industries. This parameter can take values on the interval $(0,1)$, with the lower and upper limits of this interval corresponding to the cases of no innovation and constant returns, respectively. Decreasing returns in R\&D are an important element of the model since they control the importance of the additional margin of adjustment introduced by directed research; the weaker the decreasing returns in $\mathrm{R} \& \mathrm{D}$, the stronger the endogenous adjustment in technology in response to changes in the environment. This feature of the model has two implications. First, under the structure of the model, quantifying the strength of technology adjustments reduces to the determination of the value of the parameter $v$ capturing the decreasing returns in R\&D. Second, higher values of $v$ admit richer interactions between trade and technology. In particular, I show that if $v$ is greater than $1 / 2$, then the adjustments in technology are strong enough to allow for the possibility of home market effects and potential reversals in the exports profile of countries as trade costs decline.

The structure of the model facilitates its quantitative implementation. In the BGP, the model nests the benchmark Ricardian model with no innovation as a special case. More specifically, when R\&D possibilities are eliminated, the model reduces at the aggregate level to a multi-industry version of Eaton 
and Kortum (2002) (henceforth EK model), and shares with the later the same structure in the crosssection. ${ }^{4}$ This feature of the model has two implications. First, many of the methods developed in the literature to estimate multi-industry versions of the EK model can also be applied to this model. In particular, I use the methods developed in Costinot, Donaldson and Komunjer (2011) to estimate comparative advantage in production from trade flows, a variable that is at the center of the analysis of this paper. Second, the models with and without innovation perform equally well in matching trade and production data in the cross-section. Moreover, both models can be estimated to match exactly the data and to share all exogenous parameters and manufacturing technologies. Nevertheless, even if the two models are set up in this way, they still differ in their counterfactual predictions regarding the changes in trade flows, manufacturing technology and welfare associated with different shocks, all of which are relevant dimensions for policy analysis.

Relative to the benchmark Ricardian model with no innovation, the present model adds only one additional parameter to the total number of parameters needed to be estimated to evaluate counterfactual predictions across BGPs. Moreover, armed with an estimate of the parameter $v$ capturing the decreasing returns in R\&D, any method used to estimate the countries' manufacturing productivities in the model with no innovation can be used to recover countries' innovation capabilities. Consequently, all the additional estimation burden imposed by the introduction of directed research relies on the estimation of decreasing returns to $\mathrm{R} \& \mathrm{D}$.

I estimate the decreasing-returns parameter $v$ using production and trade data from 2006 for a sample of 29 countries and 18 manufacturing industries. The estimation strategy is based on a structural equation of the model that reflects the main factors affecting the direction of technical change in the presence of directed research, i.e., it expresses countries' relative manufacturing technology in the BGP as a function of exogenous relative innovation capabilities and endogenous relative market shares, with the importance of the later controlled by $v .{ }^{5}$ Due to the two-way relationship between trade and technology in the model, estimating said equation by OLS yields an upward biased estimator of $v$. To address this endogeneity problem, I instrument relative market shares with industry preference parameters, under the assumption that the later are uncorrelated with comparative advantage in innovation. Following this strategy I provide a consistent estimator of $v$ under the baseline assumption of Cobb-Douglas preferences across industries, an assumption that is pervasive in the quantitative trade literature. I also show that this estimator is biased if the elasticity of substitution across industries, $\sigma$, is incorrectly specified. Then, to address concerns of overestimation of $v$ due to potential upward deviations from the baseline unitary-elasticity assumption, I derive two estimators that provide upper and lower bounds for $v$ under the weaker assumption that $\sigma$ is greater than or equal to one. The estimated range of possible values for $v$ obtained from these estimators, $[0.706,0.811]$, fits in the $(0,1)$ interval proposed in the theory and lies completely above the threshold value of $1 / 2$ discussed above, indicating significant endogenous adjustments in technology.

When performing counterfactual analysis across BGPs, I extend the approach popularized by Deckle,

\footnotetext{
${ }^{4}$ More specifically, the model reduces to a multi-industry version of Bernard, Eaton, Jensen and Kortum (2003). However, these models have equivalent reduced-forms at the aggregate level in terms of the determination of wages, production and trade flows.

${ }^{5}$ In this equation, market shares reflect the interactions between market size and innovation discussed above.
} 
Eaton and Kortum (2007) (henceforth DEK) to include the effect of innovation and directed research and solve the BGP of the model in changes. When the model is solved in changes, only a subset of parameters is needed to perform any given counterfactual evaluation. In particular, this approach does not rely on estimates of unobserved structural parameters such as innovation capabilities or trade costs. In addition, the system of equations of the model in changes encompasses the system of equations corresponding to a multi-industry EK model as a special case. This implies that armed with an estimate of the parameter capturing the decreasing returns in $\mathrm{R} \& \mathrm{D}$, performing counterfactual analysis in the model with directed research does not impose any additional data requirement over the benchmark model with no innovation.

I calibrate the model for the same sample of countries and industries used in the estimation of $v$, and use it to quantify the importance of directed research on technology, production and trade flows. I decompose manufacturing comparative advantage in the observed open equilibrium in 2006 into exogenous and endogenous components. For the baseline calibration of the decreasing returns in R\&D, I find that the endogenous adjustments in technology due to directed research can account for up to $52.8 \%$ of the observed variance in comparative advantage in production, a share that is robust with respect to the value of the parameter $v$ in the estimated range of possible values. To assess the importance of tradeinduced adjustments in technology, I analyze how these results are affected by trade costs. Specifically, I use the model to compute a similar variance decomposition for the cases of frictionless trade and autarky. Moving from autarky to the observed equilibrium in 2006 increases the share of the endogenous component from $26.2 \%$ to $52.8 \%$, implying that trade is responsible for about a fourth of the total variance of manufacturing comparative advantage in the observed equilibrium in 2006. In addition, the share of the endogenous component increases to $94.1 \%$ in the frictionless trade equilibrium, suggesting that there is plenty of room for further adjustments in technology as trade frictions decline.

I use the model to explore quantitatively two counterfactual situations:

(i) I explore the changes in real income as countries move to autarky. The model shows that all countries suffer a reduction in their real income. Relative to the model with directed research, the standard model with no innovation tends to overestimate the reductions in real income, although the differences between models appear modest. On average, the reductions in real income predicted by the model with directed research represent $93 \%$ of those predicted by the model with no innovation. The main reason for the modest differences in the predicted changes in real income is the presence of high trade frictions in the observed open equilibrium, which reduces the scope for specialization in innovation.

(ii) I examine the effects of a $25 \%$ reduction in trade costs. The introduction of directed research has relatively important effects on the model's predictions regarding the changes in trade flows and market shares. The predicted changes in trade flows in the model with no innovation can explain a little more than a third of the variation in the corresponding changes in the model with directed research. In addition, the model with no innovation tends to underestimate the magnitude of the changes in market shares. According to the model, all countries enjoy an increase in their real income. Relative to the model with directed research, the standard model with no innovation tends to underestimate the increases in real income, although the differences are also modest in this case. The increases in real income in the presence of directed research are on average $2 \%$ higher than in the case of no innovation. 
This paper contributes to the rapidly growing quantitative trade literature that uses static, multiindustry Ricardian models that build on Eaton and Kortum (2002). Among these studies we can mention Arkolakis, Costinot and Rodriguez-Clare (2012), Caliendo and Parro (2014), Chor (2010), Costinot, Donaldson and Komunjer (2012), Donaldson (2012), Levchenko and Zhang (2014a, 2014b), Shikher (2011). Relative to this literature, in which production technology is exogenous, this paper introduces dynamics, endogenous innovation and directed research into the picture, resulting in an endogenous distribution of production technology across industries that is affected by trade.

This paper is related to the large endogenous and semi-endogenous growth literature analyzing the effects of trade on the pace of endogenous technical change. Among these studies we can mention Grossman and Helpman (1989, 1990, 1991), Rivera-Batiz (1991), Taylor (1993), Jones (1995), Eaton and Kortum (2001). This paper's main departures from this literature are the introduction of directed research and its quantitative focus. Within this literature, this paper is closest to Eaton and Kortum (2001), which studies the interactions between trade and technology in a single-industry version of the model in this paper. In that context, the authors show that trade has no effect on the BGP-level of technology as it brings about two opposing effects that cancel each other out: firms have easier access to foreign markets but also face stronger competition in their domestic markets. In contrast, with multiple industries and directed research, as in the present paper, these two effects of trade do not cancel out at the industry level, leading to a reallocation of innovation efforts that is ultimately reflected in the distribution of production technology.

This paper is also related to Arkolakis, Ramondo, Rodriguez-Clare and Yeaple (2013). They develop a quantitative single-industry model of multinational production and trade in which countries differ in their manufacturing and innovation productivities and in which firms can separate the location of their innovation and production activities. They use the model to study the effects of openness on the specialization in innovation or production patterns and they analyze the role of multinational production as a vehicle through which this international specialization takes place. In contrast, in this paper countries can direct their research efforts to different goods in the economy but cannot separate their innovation and production locations. In a context in which countries differ in their innovation capabilities across the different goods in the economy, I analyze the effects of trade on the innovation and production specialization patterns across the goods in the economy.

In a working paper released after the first draft of this paper was circulated, Kucheryavyy, Lyn and Rodriguez-Clare (2016) explore the consequences of introducing external economies in a multi-industry version of Eaton and Kortum (2002) and obtain a system of equations characterizing the equilibrium of their model that is similar to the one characterizing the balanced growth path of the model in this paper. Although they make some related points to the ones I make here regarding the gains from trade, the main purpose of their paper it to prove existence and uniqueness of the equilibrium. In contrast, this paper is a quantitative study of the importance of endogenous adjustments in technology and its macrolevel consequences for production, trade flows and welfare. As such, an important contribution of this paper is to provide an estimation strategy for the parameter $v$ controlling the strength of the endogenous adjustments in technology. 


\section{The Model}

In this section I build on Eaton and Kortum (2001) to develop a multi-country, dynamic, general equilibrium model of innovation and trade in which specialization in innovation and production are jointly determined. The distinctive element of the model is the ability of the agents in any country to direct their research efforts to specific goods in a context in which innovation capabilities vary across goods and countries. The model is a semi-endogenous growth model and as such, aggregate growth rates in the balanced growth path (BGP) are not affected by trade or standard policies such as taxes and R\&D subsidies; this implies that all of the new endogenous adjustments in the innovation process induced by directed research are reflected in the levels of manufacturing technology in the BGP.

In the rest of this section I describe the components of the model and I provide a characterization of the market equilibrium, leaving for the next section the analysis of the BGP.

\subsection{Basic Environment}

Time is continuous and is indexed by $t \in[0, \infty)$. The world consists of $N$ countries. Country $i$ is populated by a continuum of identical and infinitely lived households, each of them with $L_{i t}$ members at time $t$. The mass of households is normalized to one such that $L_{i t}$ also represents total population at time $t$. The representative household in every country grows at the exogenously given rate $n$, i.e., $L_{i t}=L_{i 0} e^{n t}$. Labor is the only factor of production and its total inelastic supply at time $t$ is given by the population size $L_{i t}$.

There are two sectors in the economy, manufacturing and research. The manufacturing sector produces a fixed set of final goods taking the level of technology as given, while the research sector invests in R\&D to improve the technology of final goods. ${ }^{6}$ Labor is perfectly mobile across sectors within a country but is immobile across countries.

$\boldsymbol{R} \mathscr{G} D$ and Productivity. - Firms in the research sector invest in R\&D to obtain more efficient production techniques for final goods. To capture the idea of directed research, I divide the set of final goods in industries and allow countries to direct their research efforts toward specific industries. Formally, there is a fixed set $\Omega$ of industries with a continuum of goods in each industry. A final good in the economy is identified by the pair $(z, \omega) \in[0,1] \times \Omega$, where $\omega$ identifies the industry to which the good belongs and $z$ identifies the good within the industry. Country $i$ can direct its research efforts to any industry, but not to any specific good within the industry. I assume that countries differ in their research productivities across industries. Specifically, ideas regarding new techniques arrive to individual firms in country $i$ targeting industry $\omega$ as a Poisson process with arrival rate $\iota_{i}^{\omega}\left(l_{t}^{R, \omega}\right)^{v}$, where $\iota_{i}^{\omega}$ is a parameter representing the industry specific research productivity of country $i, l_{t}^{R, \omega}$ is the total number of researchers employed by the representative firm and $v \in(0,1)$ is a parameter that captures the extent of contemporaneous decreasing returns in research. I assume that there is a fixed set of research firms targeting industry $\omega$ and I normalize the mass of this set to one.

A few comments about the particular functional form assumed for the arrival rate of $\mathrm{R} \& \mathrm{D}$ are in

\footnotetext{
${ }^{6}$ Alternatively, R\&D could improve the quality of the product. Both specification are equivalent for the purposes of the present paper.
} 
order. First, contemporaneous decreasing returns in $R \& D$ are parsimoniously captured by $v$. Second, the Inada condition together with no free entry guarantee that all industries are targeted in equilibrium in any country $i .^{7}$ However, the case of constant returns to scale and free entry can be obtained as the limit $v \rightarrow 1$. And third, as becomes clear later, the parameter $v$ controls the strength of the endogenous adjustment in technology introduced by directed research, with higher values of $v$ associated with stronger adjustments. ${ }^{8}$ For these reasons, the parameter $v$ is a central element of the analysis.

An idea is the realization of two random variables $Z$ and $X$. The realization of $Z$ indicates the good $z$ within industry $\omega$ to which it applies, while the realization of $X$ indicates the efficiency $x$ of the new technique, defined as the number of units of final output that are obtained per unit of labor input, i.e., $q=x l$. Throughout the rest of the analysis I assume that $Z$ has a uniform distribution over $[0,1]$ and $X$ has a Pareto distribution with cdf $H(x)=1-x^{-\theta}$.

As the result of the $\mathrm{R} \& \mathrm{D}$ process described above, the arrival of ideas regarding new production techniques for any final good $(z, \omega)$ in country $i$ has the following characteristics: (i) it follows an inhomogeneous Poisson process $\mathcal{P}(z, \omega, i)$ with arrival rate $\iota_{i}^{\omega}\left(L_{i t}^{R, \omega}\right)^{v}$, where $L_{i t}^{R, \omega}$ denotes the total number of researchers targeting industry $\omega$ at time $t$; (ii) for any pair $(z, \omega, i),\left(z^{\prime}, \omega^{\prime}, i^{\prime}\right)$ such that $(z, \omega, i) \neq\left(z^{\prime}, \omega^{\prime}, i^{\prime}\right)$, $\mathcal{P}(z, \omega, i)$ and $\mathcal{P}\left(z^{\prime}, \omega^{\prime}, i^{\prime}\right)$ are independent. The total number of techniques for good $(z, \omega)$ discovered up to time $t$ in country $i$ is then a random variable distributed Poisson with parameter

$$
T_{i t}^{\omega} \equiv \iota_{i}^{\omega} \int_{-\infty}^{t}\left(L_{i s}^{R, \omega}\right)^{v} d s
$$

The efficiency of the best and second best techniques up to time $t$ for a good in industry $\omega$ are random variables $X_{i t}^{\omega,(1)}, X_{i t}^{\omega,(2)}$ with joint cdf given by ${ }^{9}$

$$
\begin{aligned}
F_{i t}^{\omega}\left(x_{1}, x_{2}\right) & =\operatorname{Pr}\left(X_{i t}^{\omega,(1)} \leq x_{1}, X_{i t}^{\omega,(2)} \leq x_{2}\right) \\
& =\left[1+T_{i t}^{\omega}\left(x_{2}^{-\theta}-x_{1}^{-\theta}\right)\right] e^{-T_{i t}^{\omega} x_{2}^{-\theta}} \text { for } x_{1} \geq x_{2} \geq 1
\end{aligned}
$$

Assuming a law of large numbers across the continuum of goods within each industry, $F_{i t}^{\omega}$ also represents the cdf of the joint distribution of the best and second best techniques across goods within industry $\omega$ in country $i .{ }^{10}$ Given its definition and its role in (2), throughout the paper I will refer to $T_{i t}^{\omega}$ interchangeably as the stock of ideas or the level of manufacturing technology of country $i$ in industry $\omega$.

Preferences.- The representative household's preferences over streams of per-capita consumption

\footnotetext{
${ }^{7}$ No free entry in R\&D implies that research firms make positive profits in equilibrium. However, the presence of profits per se does not affect the results of the paper. Alternatively, I could have assumed free entry and that R\&D requires the combination of labor and a fixed factor that is specific to each country and industry. With these modifications, the profits in the model presented in the text would become rents of the specific factors in the alternative model.

${ }^{8}$ In the extreme case of $v=0$ no innovation takes place and the additional margin of adjusment is not opperational.

${ }^{9}$ See Appendix C.1.1 for a proof.

${ }^{10}$ Throughout the analysis I assume that $T_{i 0}^{\omega}$ is sufficiently high for all $\omega$ and $i$, such that we can safely consider that (2) is valid for $x_{1} \geq x_{2} \geq 0$. All the results in the paper are derived under this assumption. In Appendix C.1.1 I show that the difference between $F$ above and a cdf $F^{\prime}$ given by (2) but with support $x_{1} \geq x_{2} \geq 0$ becomes negligible as $T_{i t}^{\omega} \rightarrow \infty$.
} 
are

$$
U_{i}=\mathbb{E}_{0}\left[\int_{0}^{\infty} e^{-\bar{\rho} t} L_{i t} \frac{\left(C_{i t} / L_{i t}\right)^{1-\eta}}{1-\eta} d t\right]=\mathbb{E}_{0}\left[\int_{0}^{\infty} e^{-\rho t} \frac{C_{i t}^{1-\eta}}{1-\eta} d t\right]
$$

where $\eta$ is the inverse of the intertemporal elasticity of substitution, $\rho=\bar{\rho}-n \eta$ is the effective rate of time preference,

$$
C_{i t}=\exp \left\{\int_{\Omega} \alpha_{i}^{\omega} \log \left[\frac{C_{i t}^{\omega}}{\alpha_{i}^{\omega}}\right] d \omega\right\}
$$

and

$$
C_{i t}^{\omega}=\left[\int_{0}^{1} c_{i t}^{\omega}(z)^{\frac{\sigma^{\omega}-1}{\sigma^{\omega}}} d z\right]^{\frac{\sigma^{\omega}}{\sigma^{\omega}-1}}
$$

for $\sigma^{\omega}>0$.

Market Structure and Geography.- Although the details of the market structure in both sectors and its consequences are analyzed later, here I provide an overview that serves as a guide through the exposition. All the assumptions regarding the market structure are completely standard in the literature.

At any given moment in time there are many alternative techniques in each country to produce a given final good $(z, \omega)$ that differ in their respective efficiencies. The owners of these techniques around the world engage in price competition in the market of good $(z, \omega)$ in each country $i$. As the result of this competition, the producer with the lowest marginal cost of serving that market becomes the sole supplier of the good to that market and charges the minimum between the monopoly price and the maximum price that keeps competitors at bay. ${ }^{11}$ In sum, the manufacturing sector is characterized by Bertrand competition in the market of each final good, and monopolistic competition among producers of final goods within an industry.

Entrepreneurs in the research sector finance their R\&D activity issuing equity claims that pay nothing if research efforts fail to improve upon the state of the art technique for some good, but entitle their holders to the stream of future monopoly profits if research succeeds. I assume that production techniques generated by the R\&D activity can be used only in the manufacturing sector of the country where they were developed, ruling out international licensing and multinational corporations.

In order to abstract from issues regarding intertemporal trade and foreign ownership of domestic firms, I assume that financial assets are not traded. This assumption implies that each country must finance all R\&D that takes place within its borders from domestic savings, and that trade is balanced every period. ${ }^{12}$ However, consumers of country $i$ can freely borrow and lend at the risk free domestic interest rate $r_{i t}$.

Geographic barriers are modeled in the standard iceberg formulation, whereby $\tau_{i j}^{\omega}$ units of a good must be shipped from country $i$ in order for 1 unit to arrive to country $j$, with $\tau_{i j}^{\omega}>1$ if $i \neq j$ and $\tau_{i i}^{\omega}=1$.

Throughout the analysis I use $w_{i t}$ to denote the wage of country $i$ in period $t$ and set the wage of some country $j$ as the numeraire, $w_{j t}=1$ for all $t$.

\footnotetext{
${ }^{11}$ The monopoly price is the optimal price charged by a monopoly that faces the residual iso-elastic demand corresponding to $\operatorname{good}(z, \omega)$.

${ }^{12}$ Exogenous trade deficits/surpluses can be introduced without affecting the qualitative results presented in the paper.
} 


\subsection{Market Equilibrium}

\subsubsection{Demand}

The representative household in country $i$ maximizes its preferences subject to its budget constraint. Given that preferences are additively separable over time, we can divide the consumer's problem into a static and a dynamic problem. The static problem in each period $t$ involves the optimal allocation of total expenditure $E_{i t}$ among the different goods in the economy. For a given level of expenditure $E_{i t}^{\omega}$ allocated to industry $\omega$, the expenditure on individual goods within that industry implied by the CES lower tier utility function is

$$
E_{i t}^{\omega}(z)=E_{i t}^{\omega}\left[p_{i t}^{\omega}(z) / P_{i t}^{\omega}\right]^{1-\sigma^{\omega}}
$$

where $P_{i t}^{\omega} \equiv\left[\int_{0}^{1} p_{i t}^{\omega}(z)^{1-\sigma^{\omega}} d z\right]^{\frac{1}{1-\sigma^{\omega}}}$ is the ideal price index of goods in industry $\omega$.

The upper tier Cobb-Douglas utility function implies that the share of total expenditure allocated to industry $\omega$ in country $i$ is $\alpha_{i}^{\omega}$, i.e.,

$$
E_{i t}^{\omega}=\alpha_{i}^{\omega} E_{i t}
$$

Given the price indices of each industry $\omega$, the aggregate price index is

$$
P_{i t}=\exp \left\{\int_{\Omega} \alpha_{i}^{\omega} \log P_{i t}^{\omega} d \omega\right\}
$$

From the dual problem of the static problem we get

$$
E_{i t}^{\omega}=C_{i t}^{\omega} P_{i t}^{\omega}, E_{i t}=C_{i t} P_{i t}, \text { and } E_{i t}=\int_{\Omega} E_{i t}^{\omega} d \omega
$$

The dynamic problem involves the optimal allocation of expenditure across time subject to an intertemporal budget constraint. The solution to this problem is characterized by the familiar Euler equation

$$
\widetilde{C}_{i t}=\frac{1}{\eta}\left[r_{i t}-\widetilde{P}_{i t}-\rho\right]
$$

where $\widetilde{X}_{t} \equiv d \log \left(X_{t}\right) / d t$, together with transversality conditions on bonds holdings.

\subsubsection{Manufacturing Sector}

The problem of the firms in the manufacturing sector is static: at any time $t$ firms hire labor, produce, set prices and make their export decisions taking as given the level of technology and the demand conditions at the time. At any moment in time, the demand, the market structure and the distribution of manufacturing productivities in each industry are as in Bernard, Eaton, Jensen and Kortum (2003) (henceforth BEJK.) This implies that, in the cross-section, the structure of costs, markups and prices at the industry level are also as in BEJK. For this reason, when describing the structure of the model within an industry, I describe those aspects of the model that are central to the purpose of this paper, relegating nonessential 
derivations and proofs to the appendix. ${ }^{13}$

Trade Shares and Prices. Bertrand competition implies that country $i$ buys each good from the cheapest source around the world. The cost distributions I.1 in Appendix C.1.2 imply that the fraction of goods from industry $\omega$ that country $j$ buys from country $i$ at time $t, \lambda_{i j t}^{\omega}$, is

$$
\lambda_{i j t}^{\omega}=\frac{T_{i t}^{\omega}\left(w_{i} \tau_{i j}^{\omega}\right)^{-\theta}}{\Phi_{j t}^{\omega}} .
$$

In the previous expression, $\Phi_{j t}^{\omega}$ is a cost parameter that summarizes how manufacturing technology, wages and trade costs around the world govern the distribution of the cost of serving market $\omega$ in country $j$; it is given by

$$
\Phi_{j t}^{\omega}=\sum_{k=1}^{N} T_{k t}^{\omega}\left(w_{k} \tau_{k j}^{\omega}\right)^{-\theta} .
$$

The cost distributions imply that the distribution of prices in each industry is independent of the source country. ${ }^{14}$ Then, (11) also represents the fraction of country $j$ 's total expenditure in industry $\omega$ that is allocated to goods from country $i$.

Finally, the exact price index for industry $\omega$ in country $i$ is

$$
P_{i t}^{\omega}=B_{P}^{\omega}\left(\Phi_{i t}^{\omega}\right)^{-\frac{1}{\theta}}
$$

where $B_{P}^{\omega}$ is a constant that depends only on parameters. ${ }^{15}$

Cost Share in Revenues. In any industry $\omega$, the share of total production costs (including trade costs) in country $j$ 's total expenditure is $\theta /(1+\theta) .{ }^{16}$ Intuitively, a lower value of $\theta$ corresponds to a fatter upper tail of the Pareto distribution from which the efficiency of a new technique is drawn. This implies that, on average, the cost reductions associated with a successful new technique are higher for lower values of $\theta \cdot{ }^{17}$ Consequently, low values of $\theta$ translate into higher average markups and a higher (lower) share of profits (costs) in total revenue.

Given that the distribution of costs and markups is independent of the source country, the share of total production costs in country $i$ 's sales to country $j$ is also given by $\theta /(1+\theta)$. Since this is true for any destination country $j$, we obtain

$$
w_{i t} L_{i t}^{q, \omega}=\frac{\theta}{1+\theta} R_{i t}^{\omega}
$$

where $L_{i t}^{q, \omega}, R_{i t}^{\omega}$ are the total number of workers employed and the total revenues/sales generated by country $i$ 's manufacturing firms in industry $\omega$, respectively.

Finally, market clearing at the industry level implies that the total revenue of country $i$ 's manufacturing

\footnotetext{
${ }^{13}$ See Appendix C.1.2 for a discussion of the determination of costs, markups and prices.

${ }^{14}$ See Appendix C.1.2 point I.3.

${ }^{15}$ Specifically, $B_{P}^{\omega} \equiv\left\{\Gamma\left(\frac{1-\sigma^{\omega}+2 \theta}{\theta}\right)\left[1+\bar{m}\left(\sigma^{\omega}\right)^{-\theta} \frac{\left(\sigma^{\omega}-1\right)}{\left[\theta-\left(\sigma^{\omega}-1\right)\right]}\right]\right\}^{\frac{1}{1-\sigma^{\omega}}}$. See Appendix C.1.3 for a derivation of (13).

${ }^{16}$ See Appendix C.1.4 for a proof.

${ }^{17} \mathrm{~A}$ new technique is successful if it becomes the most efficient technique to serve the domestic market.
} 
firms in industry $\omega, R_{i t}^{\omega}$, equals the world expenditure on industry- $\omega$-goods produced in country $i$,

$$
R_{i t}^{\omega}=\sum_{j=1}^{N} \lambda_{i j t}^{\omega} E_{j t}^{\omega}
$$

\subsubsection{Research Sector}

Firms in the research sector invest in $R \& D$ to obtain new production techniques that improve the production efficiency of final goods. Research firms finance their R\&D activity issuing equity claims that pay nothing if research efforts fail to improve upon the state of the art technique for some good, but entitle their holders to the stream of future profits if research succeeds. Given that no financial assets are traded, the savings of domestic households are the only source of financing for research firms.

Given that there is a continuum $[0,1]$ of identical firms directing their research efforts to industry $\omega$, and that the risks associated with the $\mathrm{R} \& \mathrm{D}$ efforts are independent across firms, well-diversified equity holders can obtain a deterministic return from their equity investment. Consequently, the equilibrium price of the equity claims issued by the research firms equals their expected return.

Let $V_{i j t}^{\omega}$ denote the expected present value at time $t$ of the stochastic future stream of profits generated by an idea from country $i$ in country $j$, conditional on the idea beating the state of the art in country $j$ at time $t$. Then

$$
V_{i j t}^{\omega}=\mathbb{E}_{t}\left[\int_{t}^{\infty} e^{-\int_{t}^{s} r_{i u} d u} \pi_{j s}^{\omega}(z) d s\right],
$$

where $\pi_{j s}^{\omega}(z)$ are the profits at time $s$ of the firm producing good $(z, \omega)$ in country $j$. Notice that the expected profits generated in country $j$ at any future time $s>t$ are equal to average profits at $s$, multiplied by the probability at time $t$ that the idea is still the state of the art in that country at time $s$, with this probability given by $\Phi_{j t}^{\omega} / \Phi_{j s}^{\omega}{ }^{18}$ Using this together with the fact that the share of profits in the sales to country $j$ is $1 /(1+\theta)$, the last expression becomes $^{19}$

$$
V_{i j t}^{\omega}=\int_{t}^{\infty} e^{-\int_{t}^{s}\left[r_{i u}+\widehat{\Phi}_{j u}^{\omega}\right] d u} \frac{E_{j s}^{\omega}}{1+\theta} d s .
$$

As the last expression shows, in evaluating $V_{i j t}^{\omega}$, future average profits must be discounted at the augmented rate $r_{i u}+\widehat{\Phi}_{j u}^{\omega}$. As more ideas are discovered and the technological frontier in country $j$ grows, some of the firms serving that market at time $t$ are driven out of business by more efficient firms. This endogenous termination probability that reduces the expected value of profits of any firm producing at time $t$ is captured by the additional term $\widehat{\Phi}_{j u}^{\omega}$ in the discount rate.

Given that the price of an equity claim issued by a research firm equals its expected value, any research firm maximizes the expected returns from the R\&D activity. On the one hand, for any firm in country $i$ using $l_{t}^{R, \omega}$ researchers to target industry $\omega$, the expected benefit over the interval $d t$ is

\footnotetext{
${ }^{18}$ See Appendix C.1.5 for a proof.

${ }^{19}$ From the analysis of the costs share in revenues we know that the total production costs in country $i$ 's sales to country $j$ is given by $\theta /(1+\theta)$, which implies that the share of profits is $1 /(1+\theta)$.
} 
$\frac{\iota_{i}^{\omega}\left(l_{t}^{R, \omega}\right)^{v}}{T_{i t}^{\omega}}\left[\sum_{j=1}^{N} \lambda_{i j t}^{\omega} V_{i j t}^{\omega}\right] d t$, where $\iota_{i}^{\omega}\left(l_{i t}^{R, \omega}\right)^{v} d t$ is the probability of having and idea in the interval $d t$, $1 / T_{i t}^{\omega}$ is the probability that the idea beats the technological frontier in country $i$ and $\lambda_{i j t}^{\omega}$ is the probability of beating the state of the art technique in country $j$ conditional on beating the frontier in country $i$. On the other hand, the costs for the firm are simply the wages paid to researchers $w_{t} l_{t}^{R, \omega}$. The first-order condition that characterizes the solution to this problem for each individual firm yields the aggregate research profit maximization condition

$$
w_{i t}=\frac{\iota_{i}^{\omega} v\left(L_{i t}^{R, \omega}\right)^{v-1}}{T_{i t}^{\omega}}\left[\sum_{j=1}^{N} \lambda_{i j t}^{\omega} V_{i j t}^{\omega}\right]
$$

for all $\omega$, where $L_{i t}^{R, \omega}$ is the total number of researchers targeting industry $\omega$.

It is worth mentioning that, in this setting, research firms make positive profits in equilibrium. However, the presence of these profits does not affect the households' saving decisions nor the direction of innovation efforts in the economy.

\subsubsection{Closing the Model and Definition of Equilibrium}

Balanced Trade. - Since there is no trade in financial assets, households in country $i$ can save only in equity claims issued by the domestic research sector. Consequently, at any moment in time, total income is equal to the sum of total expenditure in final goods and total purchases of domestic equity claims

$$
R_{i t}+\int_{\Omega}\left[\Pi_{i t}^{R, \omega}+w_{i t} L_{i t}^{R, \omega}\right] d \omega=\int_{\Omega} I_{i t}^{\omega} d \omega+E_{i t},
$$

where $R_{i t} \equiv \int_{\Omega} R_{i t}^{\omega} d \omega$ is the total revenue generated by manufacturing firms, ${ }^{20} \Pi_{i t}^{R, \omega}$ are the total profits generated by the research firms in industry $\omega$, and $I_{i t}^{\omega}$ is the total value of household's purchases of equity claims issued by research firms in industry $\omega$. Noticing that by definition, the total revenue of research firms in industry $\omega$ equals $I_{i t}^{\omega}$, and so the last expression implies that trade is balanced every period ${ }^{21}$

$$
R_{i t}=E_{i t}
$$

Labor Market Clearing. - The labor market clearing condition requires that the sum of the total number of production workers and researchers allocated to all industries equals the total endowment of labor at each moment in time. Recalling that $L_{i t}^{q, \omega}$ represents the production workers employed in industry $\omega$ and that $L_{i t}^{R, \omega}$ denotes the total number of researchers directing their research efforts to the same industry, the labor market clearing condition can be written as

$$
L_{i t}=\int_{\Omega}\left[L_{i t}^{q, \omega}+L_{i t}^{R, \omega}\right] d \omega .
$$

\footnotetext{
${ }^{20}$ Recall that $R_{i t}^{\omega} \equiv \Pi_{i t}^{q, \omega}+w_{i t} L_{i t}^{q, \omega}$, where $\Pi_{i t}^{q, \omega}$ are total profits generated by manufacturing firms in class $\omega$.

${ }^{21}$ Trade is not required to be balanced in each industry $\omega$, implying that in general $R_{i t}^{\omega} \neq E_{i t}^{\omega}$.
} 
In the rest of the paper I use $L_{i t}^{\omega}, L_{i t}^{q}, L_{i t}^{R}$ to denote total workers devoted to industry $\omega$, total workers employed in the manufacturing sector and total workers employed as researchers respectively, i.e.,

$$
L_{i t}^{\omega}=L_{i t}^{q, \omega}+L_{i t}^{R, \omega}, \quad L_{i t}^{q}=\int_{\Omega} L_{i t}^{q, \omega} d \omega, \quad L_{i t}^{R}=\int_{\Omega} L_{i t}^{R, \omega} d \omega .
$$

Having described all the components of the economy, we can now state a formal definition of the equilibrium.

Definition 1 A market equilibrium is a set of functions $r_{i t}, w_{i t}, P_{i t}, R_{i t}, E_{i t}, C_{i t}:[0, \infty) \rightarrow \mathbb{R}_{+}$and $C_{i t}^{\omega}, P_{i t}^{\omega}, R_{i t}^{\omega}, E_{i t}^{\omega}, V_{i t}^{\omega}, L_{i t}^{q, \omega}, L_{i t}^{R, \omega}, T_{i t}^{\omega}: \Omega \times[0, \infty) \rightarrow \mathbb{R}_{+}$for each country $i=1, \ldots, N$ such that conditions (1),(6)-(19) hold.

\section{Balanced Growth Path}

In this section I will focus on the balanced growth path of the economy in which $P_{i t}, R_{i t}, E_{i t}, C_{i t}, C_{i t}^{\omega}$, $P_{i t}^{\omega}, R_{i t}^{\omega}, E_{i t}^{\omega}, V_{i t}^{\omega}, L_{i t}^{q, \omega}, L_{i t}^{R, \omega}, T_{i t}^{\omega}$ grow at constant rates for all countries $i$ and industries $\omega$. As a general rule, throughout the rest of the paper I omit the subscript $t$ when referring to the BGP-level of variables that are constant in the BGP. Finally, all derivations are relegated to appendix C.2.

\subsection{Solving for the BGP}

In the model presented in the last section, growth rates in the BGP depend only on the exogenous rate of population growth and technological parameters. In particular, BGP-growth rates are not affected by trade or standard policies such as taxes and $\mathrm{R} \& \mathrm{D}$; a feature that is common to semi-endogenous growth models. This means that the effects of trade through the new margin of adjustment introduced by directed research will only affect the BGP-levels of variables of interest such as technology, consumption, price level, etc. For this reason, in this section I focus on these level-effects of directed research and relegate the analysis of growth rates to Lemma 5 in appendix C.2.1.

Directed Research and Endogenous Manufacturing Technology. - R\&D investment decisions are made by profit maximizing firms who weigh the costs and the expected benefits from those investments. A factor affecting the expected benefits of $R \& D$ is the expected size of the market for a future innovation. For this reason, a key variable in the study of the determinants of country $i$ 's BGP-levels of technology is its market share in industry $\omega, \beta_{i}^{R, \omega}$, defined as the ratio of country $i$ 's total sales in industry $\omega, R_{i t}^{\omega}$, to the world expenditure in the same industry, $E_{t}^{\omega} \equiv \sum_{i=1}^{N} E_{i t}^{\omega}$, i.e., $\beta_{i}^{R, \omega} \equiv R_{i t}^{\omega} / E_{t}^{\omega}$. As shown later, $\beta_{i}^{R, \omega}$ is constant in the BGP, and consequently it also represents the fraction of present and future profits generated by world expenditure on industry $\omega$ accruing to firms in country $i$.

Combining Lemma 5.iii, equation (17) and the definitions of $\widetilde{T}_{i t}^{\omega}$ and $\beta_{i}^{R, \omega}$ we obtain the following equilibrium relationship in the BGP,

$$
T_{i t}^{\omega}=B_{T} \iota_{i}^{\omega}\left[\beta_{i}^{R, \omega} V_{t}^{\omega} / w_{i}\right]^{v}
$$


where $B_{T} \equiv n^{v-1} v^{2 v-1}$ is a constant and $V_{t}^{\omega}$ is the present value of the profits generated by the stream of world expenditure $\left\{E_{s}^{\omega}\right\}_{s \geq t}$ in the industry. The last equation identifies the research productivity $\iota_{i}^{\omega}$, the market size captured by country $i$ 's firms $\beta_{i}^{R, \omega} V_{t}^{\omega}$, and the cost of researchers $w_{i}$, as the only aggregate channels through which all exogenous parameters of the model can affect manufacturing productivity. ${ }^{22}$ In particular, factors such as openness, comparative advantage in innovation, country size and home market effects, all affect $T_{i t}^{\omega}$ through their effect on $\beta_{i}^{R, \omega} V_{t}^{\omega}$ and $w_{i}{ }^{23}$

The effects of $\iota_{i}^{\omega}$ and $w_{i}$ on $T_{i t}^{\omega}$ are straightforward: everything else equal, a higher research productivity or lower R\&D-input costs induce more innovation that is ultimately reflected in a higher manufacturing productivity. Regarding the effect of the actual market size captured by country $i$ 's firms, notice that in the BGP, $\beta_{i}^{R, \omega} V_{t}^{\omega}$ also represents the expected present value of profits for an idea from country $i$ that surpasses the domestic frontier. ${ }^{24}$ Then, a larger market $\beta_{i}^{R, \omega} V_{t}^{\omega}$ induces more innovation leading to a higher $T_{i t}^{\omega}$.

To understand the effects of trade on technology in the presence of directed research it is instructive to compare the present model with the single industry case in which, by construction, no directed research takes place. I do this with the help of the equation (21) that relates industry manufacturing technology to the resources allocated to the industry. Letting $\delta_{i}^{\omega} \equiv L_{i t}^{\omega} / L_{i t}$ denote the share of the total labor force allocated to industry $\omega$, the definition of $\widehat{T}_{i t}^{\omega}$ and points iii and iv of Lemma 5 yield

$$
T_{i t}^{\omega}=B_{T}^{\prime} \iota_{i}^{\omega}\left[\delta_{i}^{\omega} L_{i t}\right]^{v}
$$

where $B_{T}^{\prime} \equiv(v n)^{-1} \kappa^{v}$ is a constant.

Eaton and Kortum (2001) show that in the single-industry case the degree of openness has no effect on the BGP-level of technology. This can be seen in equation (21) noting that in this case all the resources must be allocated to the sole industry in the economy regardless of the degree of openness, i.e., $\delta_{i}^{\omega}=1$. The reason for this is that for any country, openness brings about two opposing effects on innovation that cancel each other out: on the one hand, there is a positive effect on innovation granted by the easier access to foreign markets experienced by domestic firms; on the other hand, there is a negative effect on innovation caused by the increased competition faced by those same firms in their domestic markets. Then, in the single-industry case, the BGP-level of technology of a country depends only on its research productivity and on the size of its labor force, $T_{i t}^{\omega}=B_{T}^{\prime} \iota_{i}^{\omega} L_{i t}^{v}$, and it is not affected by trade.

In contrast, in the multi-industry case, when a country opens up to trade it reallocates its research efforts towards those industries that present more profitable investment opportunities. As a result, the two opposing effects on innovation described above do not cancel out at the industry level, so openness has an effect on the distribution of manufacturing technology in the BGP. This is captured in equation (21) by the endogenous trade-induced adjustments of industry labor-shares $\delta_{i}^{\omega}$.

The effects of specialization and trade on the allocation of resources across industries in the BGP can

\footnotetext{
${ }^{22}$ No closed form solutions exist for $T_{i t}^{\omega}$ in terms of primitives except for the autarky case.

${ }^{23}$ The relationship between $T_{i t}^{\omega}$ and $\iota_{i}^{\omega}$ in (20) captures only the direct effect of $\iota_{i}^{\omega}$ on $T_{i t}^{\omega}$, without considering the potential indirect effects through $\beta_{i}^{R, \omega} V_{t}^{\omega} / w_{i}$.

${ }^{24}$ The domestic frontier is determined by the most efficient techniques discovered in the country of reference.
} 
be seen with the help of the next equation

$$
\delta_{i}^{\omega}=\frac{\beta_{i}^{R, \omega}}{\beta_{i}^{R}} \alpha^{\omega}=\frac{\beta_{i}^{R, \omega}}{\beta_{i}^{E, \omega}} \alpha_{i}^{\omega},
$$

where the variable $\alpha^{\omega} \equiv E_{t}^{\omega} / E_{t}$ is the share of world expenditure allocated to industry $\omega, \beta_{i}^{R} \equiv R_{i t} / R_{t}$ is the share of country $i$ in world output, and $\beta_{i}^{E, \omega} \equiv E_{i t}^{\omega} / E_{t}^{\omega}$ is the share of country $i$ 's expenditure in world expenditure in industry $\omega .^{25}$

The first equality in (22) shows the effects of specialization and world demand on manufacturing technology. On the one hand, notice that the ratio $\beta_{i}^{R, \omega} / \beta_{i}^{R}$ can be interpreted as a measure of specialization: a value of this ratio above one means that country $i$ contributes more to world output in industry $\omega$ than what it does to total world output, reflecting a specialization in production and R\&D due to more primitive supply and demand factors such as comparative advantage in innovation, geography and relatively large domestic market in the industry. On the other hand, $\alpha^{\omega}$ reflects the effects of world demand on $\delta_{i}^{\omega}$ : a greater world demand for goods in industry $\omega$-as captured by $\alpha^{\omega}$ - is associated with more production and R\&D in that industry in every country, leading to a worldwide higher BGP-level of the manufacturing technology in the industry.

The second equality in (22) is particularly useful in understanding the effects of trade on $\delta_{i}^{\omega}$ and $T_{i t}^{\omega}$. To see this consider first its implications for an autarkic economy. In autarky, a country must consume what it produces and so production must equal expenditure in every industry, i.e. $\beta_{i}^{R, \omega} / \beta_{i}^{E, \omega}=1$ for all $\omega$. In this case, the allocation of resources across industries is driven only by demand conditions in country $i$ as captured by $\alpha_{i}^{\omega}$. In contrast, when a country trades with the world, trade does not need to be balanced in each industry and the ratio $\beta_{i}^{R, \omega} / \beta_{i}^{E, \omega}$ can differ from one: if $\beta_{i}^{R, \omega} / \beta_{i}^{E, \omega}>1(<1)$, then country $i$ is a net exporter (importer) in that industry and its level of technology is higher (lower) in that industry relative to an autarkic economy that shares the same fundamental parameters.

Finally, equations (20) and (21) show how the parameter $v$ controls the importance of the endogenous adjustments of technology: the weaker the decreasing returns to $\mathrm{R} \& \mathrm{D}$ are (high $v$ ), the stronger the endogenous effects of directed research on manufacturing technology.

Existence of a Balanced Growth Path. - The next proposition gathers all the equations from which the BGP of this economy is obtained and guarantees the existence of a solution. Although the system can be simplified even further, the system of equations presented in the proposition helps identify the new elements of the model and facilitates the comparison with a benchmark model with no directed research.

Proposition 1 The balanced growth path values of trade shares $\lambda_{i j}^{\omega}$, countries' market shares $\beta_{i}^{R, \omega}$ and $\beta_{i}^{R}$, countries' expenditure shares $\beta_{i}^{E, \omega}$ and $\beta_{i}^{E}$, world-wide industry expenditure shares $\alpha^{\omega}$, countries' levels of manufacturing technology $T_{i t}^{\omega}$ and wages $w_{i}$ are obtained as a solution to the following system of equations

\footnotetext{
${ }^{25}$ In the definition of $\beta_{i}^{R}, R_{i t}$ denotes country $i$ 's total output, $R_{i t} \equiv \int_{\Omega} R_{i t}^{\omega} d \omega$; and $R_{t}$ denotes world output, $R_{t} \equiv \sum_{i=1}^{N} R_{i t}$. The letter $R$ in this notation stands for revenue.
} 


$$
\begin{aligned}
& \lambda_{i j}^{\omega}=\frac{T_{i t}^{\omega}\left(w_{i} \tau_{i j}^{\omega}\right)^{-\theta}}{\sum_{k=1}^{N} T_{k t}^{\omega}\left(w_{i} \tau_{k j}^{\omega}\right)^{-\theta}} \\
& \beta_{i}^{R, \omega}=\sum_{j=1}^{N} \lambda_{i j}^{\omega} \beta_{j}^{E, \omega} \\
& \beta_{i}^{E}=\beta_{i}^{R} \\
& T_{i t}^{\omega}=B_{T_{i}^{\prime}}^{\prime}\left[\frac{\beta_{i}^{R, \omega}}{\beta_{i}^{R}} \alpha^{\omega} L_{i t}\right]^{v}
\end{aligned}
$$

$$
\begin{aligned}
& \beta_{i}^{R}=\int_{\Omega} \alpha^{\omega} \beta_{i}^{R, \omega} d \omega \\
& \alpha^{\omega}=\sum_{j=1}^{N} \alpha_{j}^{\omega} \beta_{j}^{E} \\
& \beta_{i}^{E, \omega}=\frac{\alpha_{i}^{\omega} \beta_{i}^{E}}{\alpha^{\omega}} \\
& \beta_{i}^{R}=\frac{w_{i} L_{i t}}{\sum_{j=1}^{N} w_{i} L_{i t}}
\end{aligned}
$$

for all $i, \omega$. Moreover, for $v \in(0,1)$ a solution to the system exists with $\beta_{i}^{R, \omega}>0$ for all $i, \omega$.

\section{Proof. See Appendix C.2.5.}

The equations in the first column of the system (23) represent structural equations of the model stated previously in the text but now expressed in terms of shares: the first line reproduces the expression for trade shares obtained in (11); the second line is the market clearing condition for the output of each country in each industry (equation (15)); the third line is the balanced trade condition (18); and the fourth line combines the technology relationships (21) and (22). The equations in the second column express all the relationships between expenditure shares, $\beta_{i}^{E, \omega}, \beta_{i}^{E}$, market shares $\beta_{i}^{R, \omega}, \beta_{i}^{R}$, industries' shares in world demand $\alpha^{\omega}$ and wages $w_{i}$ that follow immediately from their definitions.

Notice that with the exception of equation (23.4), the rest of the system (23) contains the exact same equilibrium equations corresponding to a multi-industry benchmark model with no endogenous innovation, in which the distribution of firms' productivities within an industry is given by (2) for some exogenous scale parameter $T_{i t}^{\omega}$, and in which the structure of the manufacturing sector is the same as in the present model. ${ }^{26}$ Relative to such benchmark, Proposition 1 shows that the effect of the new margin of adjustment introduced by directed research on the BGP-levels of manufacturing technology is completely captured by equation (23.4).

The observations in the last paragraph have the following implications. First, the parameter $v$, that captures the contemporaneous decreasing returns in $\mathrm{R} \& \mathrm{D}$, controls the relevance of the effects of directed research on manufacturing technology. In particular, when this parameter is set to zero, all the endogenous adjustments of technology are eliminated and we are back to the no innovation benchmark model for some given initial levels of technology. In this sense, the present model nests the benchmark model with no innovation.

Second, notice that relative to the model with no innovation, the introduction of directed research adds only one parameter to the total number of parameters relevant to the BGP of the model. Moreover, armed with an estimate of $v$, any method used to estimate the manufacturing productivities $T_{i t}^{\omega}$ in the model

\footnotetext{
${ }^{26}$ The no innovation benchmark model described corresponds to the case of a multi-industry BEJK (2003) model in which the parameter $\theta$ is the same across industries. It also shares the same equilibrium equations with a multi-industry EK (2002) model with common $\theta$ across industries. Some studies using models with this structure include Costinot, Donaldson and Komunjer (2011), Chor (2010) and Shikher (2011), among others.
} 
with no innovation can be used to recover the underlying research productivities $\iota_{i}^{\omega}$ through equation (23.4). ${ }^{27}$ Consequently, all the additional estimation burden imposed by the present model is related to the estimation of $v$.

Third, the fact that the model with and without innovation share the same cross-sectional structure imply that both models perform equally well in matching trade, production and consumption data in the cross-section. Moreover, if we allow for exogenous trade deficits in (23.3), the two models can be estimated to match exactly the aforementioned data and to share all exogenous parameters and $T_{i t}^{\omega}$. Nevertheless, even if the two models are set up in this way, they still differ in their counterfactual predictions regarding the changes in trade flows, manufacturing technology and welfare associated with different shocks, all of which are relevant dimensions in policy analysis.

\subsection{Trade and Comparative Advantage in Production}

In this subsection I study the determinants of manufacturing comparative advantage in the BGP. In the analysis I emphasize the role of the decreasing returns in R\&D -captured by $v$-in controlling the extent to which trade can affect innovation, production and export specialization patterns. In addition, the analysis in this subsection provides the theoretical foundation for the estimation strategy of the parameter $v$.

Given that comparative advantage is the focus of the analysis that follows, before continuing it is convenient to precisely define it. For any two pairs of countries $i, i^{\prime}$ and any two pair of industries $\omega, \omega^{\prime}$, country $i$ has comparative advantage in production in industry $\omega$ if $T_{i t}^{\omega} / T_{i t}^{\omega^{\prime}}>T_{i^{\prime} t}^{\omega} / T_{i^{\prime} t}^{\omega^{\prime}}$. Similarly, country $i$ has comparative advantage in innovation in industry $\omega$ if $\iota_{i}^{\omega} / \iota_{i}^{\omega^{\prime}}>\iota_{i^{\prime}}^{\omega} / \iota_{i^{\prime}}^{\omega^{\prime}}$. For this reason, I refer to the distribution of the double ratios $\left(T_{i t}^{\omega} / T_{i t}^{\omega^{\prime}}\right) /\left(T_{i^{\prime} t}^{\omega} / T_{i^{\prime} t}^{\omega^{\prime}}\right)$ and $\left(\iota_{i}^{\omega} / \iota_{i}^{\omega^{\prime}}\right) /\left(\iota_{i^{\prime}}^{\omega} / \iota_{i^{\prime}}^{\omega^{\prime}}\right)$ as comparative advantage in production and innovation respectively.

Taking double ratios in equation (20) for any pair of countries $i, i^{\prime}$ and any pair of industries $\omega, \omega^{\prime}$, we can express comparative advantage in production as the product of an exogenous component given by comparative advantage in innovation, and an endogenous component that captures the effects on technology of differences in relative specialization in $\mathrm{R} \& \mathrm{D}$,

$$
\underbrace{\frac{T_{i t}^{\omega} / T_{i^{\prime} t}^{\omega}}{T_{i t}^{\omega^{\prime}} / T_{i^{\prime} t}^{\omega^{\prime}}}}_{\begin{array}{c}
\text { Comparative Adv. } \\
\text { in Production }
\end{array}}=\underbrace{\frac{\iota_{i}^{\omega} / \iota_{i^{\prime}}^{\omega}}{\iota_{i}^{\omega^{\prime}} / \iota_{i^{\prime}}^{\omega^{\prime}}}}_{\begin{array}{c}
\text { Exogenous } \\
\text { Comparative Adv. } \\
\text { in Innovation }
\end{array}} \times \underbrace{\left(\frac{\beta_{i}^{R, \omega} / \beta_{i^{\prime}}^{R, \omega}}{\beta_{i}^{R, \omega^{\prime}} / \beta_{i^{\prime}}^{R, \omega^{\prime}}}\right)^{v}}_{\begin{array}{c}
\text { Endogenous } \\
\text { Component }
\end{array}} .
$$

The last expression shows that the parameter $v$ also represents the elasticity of comparative advantage in production with respect to $R \& D$ specialization. Then, the importance of the endogenous component in the last decomposition depends negatively on the strengths of the decreasing returns in innovation -positively on $v$-, with the extreme case of $v=0$ leading to an exogenous distribution of manufacturing

\footnotetext{
${ }^{27}$ Specifically, the estimation of $T_{i t}^{\omega}$ in the BGP of this model is compatible with any method that does not assume that $\mathrm{R} \& \mathrm{D}$ and manufacturing technology are not affected by trade flows.
} 
comparative advantage.

Although the complexity of the interactions among innovation, production and prices precludes any analytic characterization of the endogenous component in (24) in terms of exogenous parameters for the general case of Proposition 1, there are two special cases in which such characterization can be obtained: the case of frictionless trade (zero gravity), in which $\tau_{i j}^{\omega}=1$ for all $i, j, \omega$; and the case in which geographic barriers are prohibitive (autarky), meaning that $\tau_{i j}^{\omega} \rightarrow \infty$ for $j \neq i .^{28}$ The characterization of comparative advantage in production in these two extreme cases is presented in the following lemma.

Lemma 1 Letting the subscripts a, zg denote autarky and zero gravity respectively, for any pair of countries $i, i^{\prime}$ and any pair of industries $\omega, \omega^{\prime}$, the comparative advantage in production is given by

(i) in autarky

$$
\frac{T_{i t, a}^{\omega} / T_{i t, a}^{\omega^{\prime}}}{T_{i^{\prime} t, a}^{\omega} / T_{i^{\prime} t, a}^{\omega^{\prime}}}=\frac{\iota_{i}^{\omega} / \iota_{i}^{\omega^{\prime}}}{\iota_{i^{\prime}}^{\omega} / \iota_{i^{\prime}}^{\omega^{\prime}}}\left[\frac{\alpha_{i}^{\omega} / \alpha_{i}^{\omega^{\prime}}}{\alpha_{i^{\prime}}^{\omega} / \alpha_{i^{\prime}}^{\omega^{\prime}}}\right]^{v}
$$

(ii) in a zero gravity world

$$
\frac{T_{i t, z g}^{\omega} / T_{i t, z g}^{\omega^{\prime}}}{T_{i^{\prime} t, z g}^{\omega} / T_{i^{\prime} t, z g}^{\omega^{\prime}}}=\frac{\iota_{i}^{\omega} / \iota_{i}^{\omega^{\prime}}}{\iota_{i^{\prime}}^{\omega} / \iota_{i^{\prime}}^{\omega^{\prime}}}\left[\frac{\iota_{i}^{\omega} / \iota_{i}^{\omega^{\prime}}}{\iota_{i^{\prime}}^{\omega} / \iota_{i^{\prime}}^{\omega^{\prime}}}\right]^{\frac{v}{1-v}}
$$

Proof. See Appendix C.2.6.

Equation (25) shows that in autarky, the endogenous component of comparative advantage depends on countries' relative expenditure shares across industries. Given that in autarky countries must produce what they consume, autarkic economies innovate more and produce more in those industries in which their domestic demand is higher. The effect of this demand-induced specialization in innovation on manufacturing comparative advantage is captured in the term in brackets in (25).

In contrast, in a zero gravity world, the relative specialization patterns of innovation and production are no longer affected by domestic demand conditions; instead, they reflect fundamental differences in innovation capabilities across industries as captured by comparative advantage in innovation. When countries open up to trade they direct their research efforts towards those industries in which they have comparative advantage in innovation. Over time, as the result of innovation efforts translates into more efficient techniques, the evolution of the distribution of manufacturing technology starts to reflect the underlying specialization in innovation, which ultimately leads to the distribution of comparative advantage in production in Lemma 1.ii.

Lemma 1 has the following implications. First, as trade costs falls and countries become more integrated, the observed dispersion in the profile of comparative advantage could rise or fall depending on the relative dispersions of relative local demand conditions and comparative advantage in innovation. ${ }^{29}$ This

\footnotetext{
${ }^{28}$ Although the case of autarky allows for a full analytic solution of the model, this is not true in the case of zero gravity, since there is no closed form solution for relative wages. However, the structure of the model implies that relative wages do not affect manufacturing comparative advantage which is what allows for a closed-form characterization.

${ }^{29}$ In particular, using log standard deviation as a measure of dispersion we get

$$
s d\left(\log \left(\frac{T_{i t, a}^{\omega} / T_{i t, a}^{\omega^{\prime}}}{T_{i^{\prime} t, a}^{\omega} / T_{i^{\prime} t, a}^{\omega^{\prime}}}\right)\right) \geq s d\left(\log \left(\frac{T_{i t, z g}^{\omega} / T_{i t, z g}^{\omega^{\prime}}}{T_{i^{\prime} t, z g}^{\omega} / T_{i^{\prime} t, z g}^{\prime}}\right)\right) \Longleftrightarrow s d\left(\log \left(\frac{\alpha_{i}^{\omega} / \alpha_{i}^{\omega^{\prime}}}{\alpha_{i^{\prime}}^{\omega} / \alpha_{i^{\prime}}^{\omega^{\prime}}}\right)\right) \geq \frac{1}{1-v} s d\left(\log \left(\frac{\iota_{i}^{\prime} / \iota_{i}^{\omega^{\prime}}}{\iota_{i^{\prime}}^{\omega} / \iota_{i^{\prime}}^{\omega^{\prime}}}\right)\right) .
$$
}


observation is especially relevant to the evaluation of the gains from trade since relative technological differences are the source of those gains in the standard Ricardian model -corresponding to $v=0-$. Then assessing the effects on the gains from trade of observed changes in comparative advantage in production through the lenses of that model may lead to incorrect conclusions if those changes are themselves the consequence of endogenous changes in innovation induced by changes in the trade environment.

Second, reductions in trade costs could potentially reverse the profile of comparative advantage across countries if the difference between relative domestic demand conditions and relative innovation capabilities across industries is sufficiently large. Moreover, if the contemporaneous decreasing returns to R\&D are not too strong, reductions in trade costs can even generate a reversal in the export profile of countries. To see this consider the effects on the trade balance as trade costs increase from a zero gravity world to autarky in the following context: for some countries $i, i^{\prime}$ and industries $\omega, \omega^{\prime}$, country $i$ has comparative advantage in innovation in industry $\omega^{\prime}$ and at the same time it has a relatively stronger demand for goods in industry $\omega$. When there are no frictions to trade, country $i$ 's relatively strong demand for goods in industry $\omega$ together with its comparative advantage in the production of goods in industry $\omega^{\prime}$ imply that the country is a net importer in industry $\omega \cdot{ }^{30}$ As transport costs increase, countries reallocate their production and innovation efforts towards those goods in which they have a strong domestic demand. In the example given, the effects of these reallocations on technology and production improve the trade balance of country $i$ in industry $\omega$. If the decreasing returns to R\&D are sufficiently week -high $v$-, then the adjustment on manufacturing technology can be strong enough such that country $i$ becomes a net exporter in industry $\omega$. The next lemma formalizes this argument for the case of two mirror symmetric countries and two industries.

Lemma 2 Consider an economy with two mirror symmetric countries $i=1,2$ and two industries $\omega, \omega^{\prime}$ in which trade costs are symmetric and uniform across industries, i.e. $\tau_{i j}^{\omega}=\tau$ for all $\omega, i, j$ such that $i \neq j .{ }^{31}$ Assume that country 1 has a relative strong demand for goods in industry $\omega$ and a comparative advantage in innovation in industry $\omega^{\prime}$ such that the following condition holds

$$
\frac{\alpha_{1}^{\omega} / \alpha_{2}^{\omega}}{\alpha_{1}^{\omega^{\prime}} / \alpha_{2}^{\omega^{\prime}}}>1>\frac{\iota_{1}^{\omega} / \iota_{2}^{\omega}}{\iota_{1}^{\omega^{\prime}} / \iota_{2}^{\omega^{\prime}}}
$$

Then, countries will display a reversal in their export profile as they move from autarky to frictionless trade if, and only if,

$$
\left(\frac{\alpha_{1}^{\omega}}{\alpha_{2}^{\omega}}\right)^{v-\frac{1}{2}}>\frac{\iota_{2}^{\omega}}{\iota_{1}^{\omega}}
$$

Proof. See Appendix C.2.7.

The possibility of reversals in the export profile of countries is closely connected to the presence of home market effects in the model. In particular, condition (28) implies that a reversal in the export profile of countries never arises if $v \in[0,1 / 2)$, which is the same range of values of $v$ for which the model

\footnotetext{
${ }^{30}$ Because of balanced trade, this implies that country $i$ is net exporter of goods in industry $\omega^{\prime}$ in a zero gravity world.

${ }^{31}$ The countries are mirror images of each other. See the proof of the Lemma in the appendix for a precise definition.
} 
does not exhibit home market effects. ${ }^{32}$ In this sense, Lemma 2 provides a theoretical threshold for the parameter $v$ above which the endogenous adjustments in technology are strong enough to allow for the possibility of home market effects and potential reversals in the export profile of countries.

Finally, Lemma 1 implies that in any trading equilibrium that is far from the extreme cases of autarky and zero gravity, we should expect the endogenous component of comparative advantage to be correlated with both comparative advantage in innovation and relative domestic demand. This observation plays an important role in the estimation of parameter $v$.

\subsection{The BGP in Changes}

When performing counterfactual analysis across BGPs, I extend the approach popularized by Dekle, Eaton and Kortum (2007) (henceforth DEK) to include the effect of innovation and directed research and solve the BGP of the model in changes. When the model is solved in changes, only a subset of parameters is needed to perform any given counterfactual evaluation. In particular, this approach does not rely on estimates of unobserved structural parameters such as innovation capabilities or trade costs. In addition, the system of equations of the model in changes encompasses the system of equations corresponding to a multi-industry EK model as a special case. This implies that armed with an estimate of the parameter capturing the decreasing returns in R\&D, performing counterfactual analysis in the model with directed research does not impose any additional data requirement over the benchmark model with no innovation.

The next corollary summarizes the extension of the DEK's method to the present model.

Corollary 1 Let $\widehat{X} \equiv X^{\prime} / X$ denote the relative change in variable $X$ from $X$ to $X^{\prime}$. Given the constant parameters $v, \theta$ and information about the endogenous trade shares $\lambda_{i j}^{\omega}$, countries' market shares $\beta_{i}^{R, \omega}$ and $\beta_{i}^{R}$, countries' expenditure shares $\beta_{i}^{E, \omega}$ and $\beta_{i}^{E}$, and world-wide industries' expenditure shares $\alpha^{\omega}$ in the initial BGP; the change in those same endogenous variables between the initial and the new BGP associated with exogenous changes in research productivities $\widehat{\iota}_{i}^{\omega}$, labor endowments $\widehat{L}_{i t}$, preference parameters $\widehat{\alpha}_{i}^{\omega}$ and trade costs $\widehat{\tau}_{i j}^{\omega}$ can be computed as

$$
\begin{aligned}
& \widehat{\lambda}_{i j}^{\omega}=\frac{\widehat{\iota}_{i}^{\omega}\left(\widehat{L}_{i t} / \widehat{\beta}_{i}^{R}\right)^{(v+\theta)}\left(\widehat{\beta}_{i}^{R, \omega}\right)^{v}\left(\widehat{\tau}_{i j}^{\omega}\right)^{-\theta}}{\sum_{k=1}^{N} \widehat{\iota}_{k}^{\omega}\left(\widehat{L}_{k t} / \widehat{\beta}_{k}^{R}\right)^{(v+\theta)}\left(\widehat{\beta}_{k}^{R, \omega}\right)^{v}\left(\widehat{\tau}_{k j}^{\omega}\right)^{-\theta} \lambda_{k j}^{\omega}} \\
& \widehat{\beta}_{i}^{R, \omega}=\sum_{j=1}^{N} \widehat{\lambda}_{i j}^{\omega} \widehat{\beta}_{j}^{E, \omega} \frac{\lambda_{i j}^{\omega} \beta_{j}^{E, \omega}}{\beta_{i}^{R, \omega}} \\
& \widehat{\beta}_{i}^{E}=\widehat{\beta}_{i}^{R}
\end{aligned}
$$

$$
\begin{aligned}
& \widehat{\beta}_{i}^{R}=\int_{\Omega} \widehat{\alpha}^{\omega} \widehat{\beta}_{i}^{R, \omega} \frac{\alpha^{\omega} \beta_{i}^{R, \omega}}{\beta_{i}^{R}} d \omega \\
& \widehat{\alpha}^{\omega}=\sum_{j=1}^{N} \widehat{\alpha}_{j}^{\omega} \widehat{\beta}_{j}^{E} \beta_{j}^{E, \omega} \\
& \widehat{\beta}_{i}^{E, \omega}=\frac{\widehat{\alpha}_{i}^{\omega} \widehat{\beta}_{i}^{E}}{\widehat{\alpha}^{\omega}}
\end{aligned}
$$

for all $i, j$ and $\omega$.

The previous system is obtained directly from the system (23) with a reduction in the total number of equations that is obtained using equations (23.4) and (23.8) in equation (23.1).

\footnotetext{
${ }^{32}$ See Appendix C.2.9 for a formal discussion of the home market effect in this model.
} 
A few comments are in order. First, notice that out of the exogenous components in the previous system, the shocks to the parameters $\left\{\hat{\iota}_{i}^{\omega}, \widehat{L}_{i t}, \widehat{\alpha}_{i}^{\omega}, \widehat{\tau}_{i j}^{\omega}\right\}$ are provided by the evaluator and the information regarding the initial BGP $\lambda_{i j}^{\omega}, \beta_{i}^{R, \omega}, \beta_{i}^{R}, \beta_{i}^{E, \omega}, \beta_{i}^{E}, \alpha^{\omega}$ is readily obtainable from the data. Consequently, the only exogenous parameters that need to be calibrated/estimated are the decreasing returns parameter $v$ and the shape parameter $\theta$. All the relevant information regarding the initial distribution of research productivities $\iota_{i}^{\omega}$, labor endowments $L_{i t}$, preference parameters $\alpha_{i}^{\omega}$ and trade costs $\tau_{i j}^{\omega}$ is summarized in the levels of trade shares $\lambda_{i j}^{\omega}$; countries' market shares $\beta_{i}^{R, \omega}$ and $\beta_{i}^{R}$, countries' expenditure shares $\beta_{i}^{E, \omega}$ and $\beta_{i}^{E}$, and world-wide industries' expenditure shares $\alpha^{\omega}$ in the initial BGP.

Second, the previous system shows the differences between the counterfactual predictions of the model with directed research and the benchmark model with no innovation, and how the decreasing returns parameter $v$ controls those differences. To see this more clearly, consider a change in parameters that are exogenous in both models, i.e., changes in labor endowments $\widehat{L}_{i t}$, preference parameters $\widehat{\alpha}_{i}^{\omega}$ and trade costs $\widehat{\tau}_{i j}^{\omega}$. To analyze the effect of those changes in the present model we only need to modify equation (29.1) setting $\widehat{\iota}_{i}^{\omega}=1$. The only difference between the system of equations in changes corresponding to a model with no innovation and (29) is equation (29.1), that captures the endogenous change in manufacturing technology. Moreover, setting $v=0$ in (29.1) yields the exact same system in changes that is obtained from applying DEK approach to the benchmark model with no innovation.

\subsection{Real Income in the Balanced Growth Path}

Country $i$ 's real income per-capita at any time $t, W_{i t}$, is given by

$$
W_{i t}=B_{P} \exp \left\{\int_{\Omega} \log \left(T_{i t}^{\omega}\right)^{\alpha_{i}^{\omega} / \theta} d \omega\right\} \exp \left\{\int_{\Omega} \log \left(\lambda_{i i}^{\omega}\right)^{-\alpha_{i}^{\omega} / \theta} d \omega\right\}
$$

The last expression is valid for all values of the $\mathrm{R} \& \mathrm{D}$ parameter $v$, including $v=0$ corresponding to the model with no innovation. However, when $v>0$ the levels of manufacturing technology endogenously adjust in response to a shock, so this has to be considered when evaluating the corresponding induced change in real income. Specifically, consider the change in real income per-capita associated with a foreign shock, defined as a change in foreign research productivities, foreign levels of labor endowment or trade costs that do not affect country $i$ 's innovation capabilities or its ability to serve its domestic market. Letting $\widehat{X} \equiv X^{\prime} / X$ denote the relative change in variable $X$, the change in the BGP-level of country $i$ 's real income induced by a foreign shock can be computed as

$$
\widehat{W}_{i t}=\exp \left\{v \int_{\Omega} \log \left(\widehat{\delta}_{i}^{\omega}\right)^{\alpha_{i}^{\omega} / \theta} d \omega\right\} \exp \left\{\int_{\Omega} \log \left(\widehat{\lambda}_{i i}^{\omega}\right)^{-\alpha_{i}^{\omega} / \theta} d \omega\right\} .
$$

The last expression offers a parsimonious way to evaluate ex-post the change in real income associated with a foreign shock. Armed with estimates of the preference parameters $\alpha_{i}^{\omega}$, the R\&D parameter $v$, and the dispersion parameter $\theta$, the ex-post evaluation of (31) only requires information on the change in the home shares of expenditure, $\hat{\lambda}_{i i}^{\omega}$, and the change in the industry shares of total output, $\widehat{\delta}_{i}^{\omega}$. In particular, it is not necessary to know the nature of the foreign shock nor its effects on innovation, production and 
trade flows around the world.

Notice that relative to the model with no innovation, the formula for $\widehat{W}_{i t}$ must be augmented by the first term in (31) to capture the endogenous adjustments in technology. ${ }^{33}$ Not incorporating this additional term in the ex-post evaluation of $\widehat{W}_{i t}$ may result in a higher or lower value as the contribution of the new term may be positive or negative. The reason for this is that the sign of the contribution of the first term in (31) is given by the sign of the integral inside the curly brackets, which cannot be determined at this level of generality.

Let us now turn to the analysis of the counterfactual predictions of the model regarding the effect of changes in trade costs on real income per-capita in the BGP. In order to evaluate the change in real income according to (31) we first need to use the model to evaluate the changes in the home share of expenditures, $\hat{\lambda}_{i i}^{\omega}$, and the share of each industry in total output, $\widehat{\delta}_{i}^{\omega}$, associated with the change in trade costs. Throughout the analysis this is done as follows: (i) I calibrate the system (29) to a baseline equilibrium using information on endogenous trade shares $\lambda_{i j}^{\omega}$, countries' market shares $\beta_{i}^{R, \omega}$ and $\beta_{i}^{R}$, countries' expenditure shares $\beta_{i}^{E, \omega}$ and $\beta_{i}^{E}$, world-wide industries' expenditure shares $\alpha^{\omega}$ and the parameter $\theta$; (ii) I solve the system in changes (29) for some value of the parameter $v$; and (iii) I compute the change in real income per capita according to (31). In this way, the differences in the predicted changes in real income per capita between the model with no innovation and the model with directed research are those that emerge from setting $v=0$ or $v>0$ in the system in changes (29). Notice that in general, the difference in the predicted change in real income per capita between the two models reflect not only the extra term in (31), but also the models' different predictions for the changes in trade flows. Proposition 2 summarizes the effects of directed research on the predicted changes in real income associated with a change in trade costs.

Proposition 2 (i) Consider a world economy of two mirror symmetric countries. ${ }^{34}$ Starting from an initial open economy equilibrium, a uniform decrease (increase) in trade costs generates a larger increase (lower reduction) in the BGP-level of real income per capita in the model with directed research than in the model with no innovation.

(ii) For the general asymmetric case, moving to autarky generates lower reductions in the BGP-level of real income per capita in the model with directed research than in the model with no innovation.

Proof. See Appendix C.2.8.

Proposition 2 compares the predictions of the models with and without innovation regarding the changes in real income per-capita conditional on observed trade shares and market shares in the original equilibrium. In this sense, this comparison is consistent with the ex-ante analysis in Arkolakis, Costinot and Rodriguez-Clare (2012). However, Proposition 1 implies that the models with and without innovation can be calibrated to share all exogenous parameters (other than $v$ ) and manufacturing technology in the

\footnotetext{
${ }^{33}$ The formula for the model with no innovation is given by the second term in (31) and it is obtained setting $v=0$ in that expression. In this case the formula reduces to the expression found in Arkolakis, Costinot and Rodriguez-Clare (2012) for the case of the multi-industry Eaton and Kortum (2002) model.

${ }^{34}$ The countries are mirror images of each other. See the proof in the Appendix for a precise definition.
} 
initial equilibrium. Consequently, the comparison in Proposition 2 is also compatible with the theoretical comparative static exercises in Melitz and Redding (2014). ${ }^{35}$ In this way, the changes in real income in the model with no innovation can be interpreted as the changes that arise in the model with innovation when technology is not allowed to adjust. Under this interpretation, the results in Proposition 2 are very intuitive. Directed research introduces a new margin through which economies can adjust to the change in trade costs. Then, a simple revealed preference argument implies that in the model with directed research, economies can enjoy a higher level of real income after the change in trade costs regardless of the direction of the change.

\section{Estimating the Decreasing Returns in R\&D}

The decreasing-returns parameter $v$ plays a central role in the model as it controls the strengths of the endogenous adjustment in technology. In this section, I estimate this key parameter from production and bilateral trade data, following a theory-consistent estimation strategy based on the structural decomposition of comparative advantage given in equation (24) and on the insights from Lemma 1.

\subsection{Data}

I identify the industries in the model with manufacturing industries corresponding roughly to two-digit ISIC Rev.3 classification, giving a total of $\Omega=18$ industries. The data on trade flows is obtained from the OECD STAN (Structural Analysis) Database while production data is sourced form the 2012 UNIDO Industrial Statistic Database INDSTAT2. The sample of countries include 25 OECD countries, 4 non-OECD countries and a constructed rest of the world aggregate, yielding a sample of $N=29$.

I map the variables in the model to the data as follows. (i) Manufacturing firms's total revenue by industry, $R_{i t}^{\omega}$, is given by gross production; (ii) exports $X_{i t}^{\omega}$ and imports $M_{i t}^{\omega}$ are obtained directly from bilateral trade data; (iii) consumption expenditure by industry, $E_{i t}^{\omega}$, is given by apparent consumption, $E_{i t}^{\omega}=A C_{i t}^{\omega} \equiv R_{i t}^{\omega}-X_{i t}^{\omega}+M_{i t}^{\omega}$. Finally, from these figures I construct all the shares relevant to the estimation and quantitative analysis directly from their definitions: (a) trade shares $\lambda_{i j}^{\omega}=X_{i j}^{\omega} / E_{i t}^{\omega}$ for $i \neq j$ and $\lambda_{i i}=$ $1-\sum_{j \neq i} \lambda_{i j}^{\omega}$; (b) market shares $\beta_{i}^{R, \omega}=R_{i}^{\omega} / \sum_{j=1}^{N} R_{j}^{\omega}$ and $\beta_{i}^{R}=\sum_{\omega=1}^{\Omega} R_{i}^{\omega} / \sum_{\omega=1}^{\Omega} \sum_{j=1}^{N} R_{j}^{\omega}$; (c) countries' expenditure shares $\beta_{i}^{E, \omega}=E_{i}^{\omega} / \sum_{j=1}^{N} E_{j}^{\omega}$ and $\beta_{i}^{E}=\sum_{\omega=1}^{\Omega} E_{i}^{\omega} / \sum_{\omega=1}^{\Omega} \sum_{j=1}^{N} E_{j}^{\omega}$; (d) Cobb-Douglas parameters $\alpha_{i}^{\omega}=E_{i t}^{\omega} / \sum_{\omega=1}^{\Omega} E_{i}^{\omega}$; (v) world-wide industry expenditure shares $\alpha^{\omega}=\sum_{j=1}^{N} E_{j}^{\omega} / \sum_{\omega=1}^{\Omega} \sum_{j=1}^{N} E_{j}^{\omega}$.

\footnotetext{
${ }^{35}$ Although these two alternative approaches yield the same results in the present model, this is not the case in general. See Melitz and Redding (2014) for a detailed discussion of these two alternative approaches.
} 


\subsection{Estimation Strategy}

Taking logs in equation (24) yields the following comparative advantage equation (CAE)

$$
\underbrace{\ln \left(\frac{T_{i t}^{\omega} / T_{i^{\prime} t}^{\omega}}{T_{i t}^{\omega^{\prime}} / T_{i^{\prime} t}^{\omega^{\prime}}}\right)}_{\text {Estimable }}=v \times \underbrace{\ln \left(\frac{\beta_{i}^{R, \omega} / \beta_{i^{\prime}}^{R, \omega}}{\beta_{i}^{R, \omega^{\prime}} / \beta_{i^{\prime}}^{R, \omega^{\prime}}}\right)}_{\text {Observable }}+\underbrace{\ln \left(\frac{\iota_{i}^{\omega} / \iota_{i^{\prime}}^{\omega}}{\iota_{i}^{\omega^{\prime}} / \iota_{i^{\prime}}^{\omega^{\prime}}}\right)}_{\text {Unobservable }} .
$$

In this equation, the only unobservable term corresponds to the log of the comparative advantage in innovation, since figures for comparative advantage in production and market shares can be obtained from production and trade data. Specifically, I construct such figures as follows: (i) I obtain markets shares $\beta_{i}^{R, \omega}$ from production data as shown in subsection 5.1; and (ii) I follow Costinot, Donaldson and Komunjer (2011) and estimate comparative advantage in production from trade flows according to a procedure that is consistent with the gravity structure of the model as reflected by equation (23.1). ${ }^{36}$ Then, (CAE) is an estimable equation that can be taken to the data to get an estimate of parameter $v$.

The estimation of the last equation presents some challenges. The structure of the model implies that estimating (CAE) by OLS, treating the unobservable term as an error, yields an inconsistent estimator for $v$. To see this more clearly it is convenient to look back at the results of Lemma 1: in autarky, the endogenous component of manufacturing comparative advantage is completely determined by relative domestic expenditure, while in a frictionless world it is completely determined by comparative advantage in innovation. Consequently, in any trading equilibrium that is in between these two extreme cases, we should expect the endogenous component of manufacturing comparative advantage to be positively correlated with both, relative domestic expenditure and comparative advantage in innovation. For this reason we should expect relative market shares to be positively correlated with the unobservable term in (CAE), implying that the OLS estimator of $v$ is biased upwards.

To address this endogeneity problem I propose to instrument relative market shares in (CAE) with the corresponding double ratios of industry preference parameters under the following assumption,

Assumption A0. Double ratios of industry preference parameters are uncorrelated with comparative advantage in innovation.

The rationale of this estimation strategy is based on three observations. (i) There is ample evidence of high trade frictions. ${ }^{37}$ (ii) As discussed above, relative market shares are positively correlated with relative domestic expenditure across industries in the presence of high trade frictions. (iii) Relative domestic expenditure is driven, in part, by underlying relative industry preference parameters. ${ }^{38}$ Observations (i)-(iii) imply that we can instrument relative market shares in (CAE) with double ratios of industry preference parameters under assumption A0.

\footnotetext{
${ }^{36}$ The details of the estimation procedure can be found in Appendix C.3.1.

${ }^{37}$ See Aderson and van Wincoop (2004) for a discussion of the empirical literature on trade costs. See Eaton and Kortum (2002) and Waugh (2010) for estimates of trade frictions in Ricardian frameworks.

${ }^{38}$ In the case of Cobb-Douglas preferences, relative domestic expenditure is completly determined by double ratios of industry preference parameters as we can see in (25). However, in more general cases relative demand is also affected by prices, as in the case of CES preferences with elasticity of substitution different from one.
} 
Following this strategy I provide a consistent estimator of $v$ under the baseline assumption of CobbDouglas preferences across industries. However, I also show that the strategy above yields a biased estimator if the elasticity of substitution across industries is incorrectly specified. Then, to address concerns of overestimation of $v$ due to potential deviations from the baseline unitary-elasticity assumption, I extend the analysis to the case of CES preferences and derive two estimators that provide upper and lower bounds for $v$ that fit in the $(0,1)$ range predicted by the theory.

Before moving to the results, I introduce some simplifying notation and a transformation of the data that I use in the sequel. In order to avoid potential concerns related to the particular choice of the country and industry relative to which comparative advantage is defined, double ratios of all variables are defined relative to an "average industry" $\bar{\omega}$ and an "average country" $\bar{k}$. The values of variable $X$ that correspond to country $k$ and industry $\bar{\omega}, X_{k t}^{\bar{\omega}}$, and to country $\bar{k}$ and industry $\omega, X_{\bar{k} t}^{\omega}$, are given by the following geometric averages,

$$
X_{k t}^{\bar{\omega}} \equiv \prod_{\omega=1}^{\Omega}\left(X_{k t}^{\omega}\right)^{\frac{1}{\Omega}}, \quad X_{\bar{k} t}^{\omega} \equiv \prod_{k=1}^{N}\left(X_{k t}^{\omega}\right)^{\frac{1}{N}} .
$$

Finally, for any variable $X$, I use $\bar{X}_{k t}^{\omega}$ to denote the log of double ratios defined relative to the "average industry" $\bar{\omega}$ and the "average country" $\bar{k}$,

$$
\bar{X}_{k t}^{\omega} \equiv \ln \frac{X_{k t}^{\omega} / X_{\bar{k} t}^{\omega}}{X_{k t}^{\bar{\omega}} / X_{\bar{k} t}^{\bar{\omega}}} .
$$

so that the estimable equation (CAE) can be expressed as $\bar{T}_{i}^{\omega}=v \bar{\beta}_{i}^{R, \omega}+\bar{\iota}_{i}^{\omega}$.

\subsection{Estimation and Results}

For the baseline case of Cobb-Douglas preferences, I follow the estimation strategy above and instrument relative market shares $\bar{\beta}_{i}^{R, \omega}$ in (CAE) with the corresponding relative industry preference parameters $\bar{\alpha}_{i}^{\omega}$, under the assumption that $\bar{\alpha}_{i}^{\omega}$ is uncorrelated with the log of comparative advantage in innovation $\bar{\iota}_{i}^{\omega} .{ }^{39}$ Computing $\bar{\alpha}_{i}^{\omega}$ as relative domestic expenditure across industries $\bar{E}_{i}^{\omega}$, I obtain the following consistent method of moments estimator of $v$,

$$
\widehat{v}_{1} \equiv \frac{\sum_{i, \omega} \bar{T}_{i}^{\omega} \bar{\alpha}_{i}^{\omega}}{\sum_{i, \omega} \bar{\beta}_{i}^{R, \omega} \bar{\alpha}_{i}^{\omega}}=\frac{\sum_{i, \omega} \bar{T}_{i}^{\omega} \bar{E}_{i}^{\omega}}{\sum_{i, \omega} \bar{\beta}_{i}^{R, \omega} \bar{E}_{i}^{\omega}}
$$

The first column of Table 1 shows the results of naively estimating (CAE) by OLS. As we can see, the OLS estimator yields a value $\widehat{v}_{O L S}=1.023$, slightly above the upper limit of 1 imposed by the theory, although not statistically different from it. However, according to the theory, we should should expect the OLS estimator to be biased upwards. The second column of the table shows the results obtained using the method of moments estimator $\widehat{v}_{1}$. As expected, the estimated value of $v$ goes down, with a

\footnotetext{
${ }^{39}$ When the context is clear, I use the word relative when referring to the log-double ratios defined in $(33)$, so that $\bar{\beta}_{i}^{R, \omega}$ are relative market shares, $\bar{\alpha}_{i}^{\omega}$ are relative industry preference parameters, etc.
} 
point estimate of $\widehat{v}_{1}=0.811$ and the corresponding $95 \%$ confidence interval included in the $(0,1)$ range predicted by the theory.

Although most of the quantitative literature assumes the elasticity of substitution to be one at this level of aggregation, there is little empirical evidence supporting this assumption. ${ }^{40}$ In this context, a concern with the estimator in (34) is that it is biased if the baseline unitary-elasticity assumption is incorrect. To see this, notice that in the case of Cobb-Douglas preferences, the indentifying assumption A0 leading to estimator $\widehat{v}_{1}, \mathbb{E}\left[\bar{\alpha}_{i}^{\omega} \bar{\iota}_{i}^{\omega}\right]=0$, is equivalent to $\mathbb{E}\left[\bar{E}_{i}^{\omega} \bar{\iota}_{i}^{\omega}\right]=0$. However, this last condition is not expected to hold if the elasticity of substitution across industries $\sigma$ differs from one, even if assumption A0 holds for the correct preferences. In particular, if $\sigma$ exceeds one then $\mathbb{E}\left[\bar{E}_{i}^{\omega} \bar{\iota}_{i}^{\omega}\right]>0$ and $\widehat{v}_{1}$ is biased upwards, leading to an overestimation of the importance of the endogenous adjustment in technology. Intuitively, a higher relative research productivity leads to a higher relative production technology, which in turn leads to a lower relative price and a higher relative domestic expenditure. Below I formalize this argument and propose a solution to address these overestimation concerns.

In what follows I assume that consumption aggregator across industries takes the following CES form

$$
C_{i t}=\left[\int_{\Omega}\left(\gamma_{i}^{\omega}\right)^{\frac{1}{\sigma}} C_{i t}^{\omega \frac{\sigma-1}{\sigma}} d \omega\right]^{\frac{\sigma}{\sigma-1}},
$$

where $\gamma_{i}^{\omega}$ are exogenous industry preference parameters and $\sigma>1$ is the elasticity of substitution across industries. I also assume that A0 holds for these preferences, i.e. $\mathbb{E}\left[\bar{\gamma}_{i}^{\omega} \bar{l}_{i}^{\omega}\right]=0$. Finally, the demand functions corresponding to preferences (35), together with equation (13) that relates price indices $P_{i t}^{\omega}$ to cost parameters $\Phi_{i t}^{\omega}$, yield the following log-linear demand equation,

$$
\bar{E}_{i}^{\omega}=\frac{\sigma-1}{\theta} \times \bar{\Phi}_{i}^{\omega}+\bar{\gamma}_{i}^{\omega}
$$

Given the new assumptions above, the presence of high trade frictions implies that the estimator $\widehat{v}_{1}$ in (34), derived under the incorrect Cobb-Douglas assumption, is biased upwards. This can be seen with the help of equations (CAE) and (DE). First, equation (CAE) implies that the log of comparative advantage in innovation $\bar{\iota}_{i}^{\omega}$ is positively correlated with log of comparative advantage in production $\bar{T}_{i}^{\omega}$. Second, equation (12) shows that in the presence of high trade costs, the main determinant of the cost parameter $\Phi_{i t}^{\omega}$ is the level of domestic manufacturing technology $T_{i t}^{\omega} \cdot{ }^{41}$ This implies that $\bar{\Phi}_{i}^{\omega}$ and $\bar{T}_{i}^{\omega}$ are positively correlated in equilibrium, an implication that is strongly confirmed by the data as we can see from Figure 2. Finally, equation (DE) and $\sigma>1$ imply that $\bar{\Phi}_{i}^{\omega}$ is positively correlated with relative domestic expenditure $\bar{E}_{i}^{\omega}$. This sequence of correlations imply that $\bar{E}_{i}^{\omega}$ and $\bar{\iota}_{i}^{\omega}$ are positively correlated, violating the identifying assumption above. Moreover, since $\bar{E}_{i}^{\omega}$ and $\bar{\beta}_{i}^{R, \omega}$ are positively correlated, it is readily seen that the estimator $\widehat{v}_{1}$ is biased upwards. ${ }^{42}$ This discussion is summarized in the next Lemma.

\footnotetext{
${ }^{40}$ See Costinot et.al. (2014) for a discussion of upper-level elasticity assumptions in the quantitative trade literature.

${ }^{41}$ The positive correlation between the $\Phi_{i t}^{\omega}$ and $T_{i t}^{\omega}$ is an implication of the gravity structure of the model in the presence of high trade frictions, and holds for all values of the elasticity of substitution $\sigma$ and of the parameter $v$ capturing the decreasing returns in $R \& D$.

${ }^{42}$ The positive correlation between $\bar{E}_{i}^{\omega}$ and $\bar{\beta}_{i}^{R, \omega}$ is another implication of the model when trade costs are high as firms sell a large part of their production domestically.
} 
Lemma 3 Suppose that preferences are given by (35) with $\sigma>1$, and that they satisfy assumption A0, i.e. $\mathbb{E}\left[\bar{\gamma}_{i}^{\omega} \bar{l}_{i}^{\omega}\right]=0$. Then the presence of high trade frictions implies that the method of moments estimator $\widehat{v}_{1}$ in (34) is biased upwards.

Proof: See appendix C.3.2.

It should be clear that if we assume specific values for $\sigma$ and $\theta$, then we could consistently estimate $v$ following the same general estimation strategy above. Specifically, armed with values for these parameters and figures for $\bar{E}_{i}^{\omega}$ and $\bar{\Phi}_{i}^{\omega}$, we could use equation (DE) to back out the relative industry preference parameters $\bar{\gamma}_{i}^{\omega}$ and use the later as instruments for relative market shares $\bar{\beta}_{i}^{R, \omega}$ in equation (CAE). However, given the uncertainty about the value of $\sigma$ at this level of aggregation, I address the overestimation concerns raised in Lemma 3 following a more robust estimation strategy that does not require assuming specific values for $\sigma$ and $\theta$. In particular, I complement the upward-biased estimator $\widehat{v}_{1}$ with a second estimator, $\widehat{v}_{2}$, that is biased downwards if $\sigma>1$, so that together they provide upper and lower bounds for $v .^{43}$

Concretely, I construct estimator $\widehat{v}_{2}$ as follows. First, I compute $\bar{\Phi}_{i}^{\omega}$ from equation (11) using estimates of comparative advantage in production and home trade shares, $\bar{\Phi}_{i}^{\omega}=\bar{T}_{i}^{\omega}-\bar{\lambda}_{i}^{\omega}$. Second, I estimate equation (DE) by OLS treating $\bar{\gamma}_{i}^{\omega}$ as the error term and compute the OLS residuals, $\widehat{\bar{\gamma}}_{i}^{\omega}$. Finally, inspired by the general estimation strategy above, I define estimator $\widehat{v}_{2}$ as follows,

$$
\widehat{v}_{2}=\frac{\sum_{i, \omega} \bar{T}_{i}^{\omega} \widehat{\bar{\gamma}}_{i}^{\omega}}{\sum_{i, \omega} \bar{\beta}_{i}^{R, \omega} \widehat{\bar{\gamma}}_{i}^{\omega}} .
$$

The bias in estimator $\widehat{v}_{2}$ reflects a bias in the estimation of $(\sigma-1) / \theta$ in the first-step regression, which in turn affects the construction of residuals $\widehat{\bar{\gamma}}_{i}^{\omega}$. Notice that if $v>0$ and $\sigma>1$, then equations (CAE) and (DE) imply positive equilibrium correlations between $\bar{\beta}_{i}^{R, \omega}$ and $\bar{T}_{i}^{\omega}$, and between $\bar{\gamma}_{i}^{\omega}$ and $\bar{E}_{i}^{\omega}$. In addition, from the discussion preceding Lemma 3 we have that high trade frictions imply positive equilibrium correlations between $\bar{E}_{i}^{\omega}$ and $\bar{\beta}_{i}^{R, \omega}$, and between $\bar{\Phi}_{i}^{\omega}$ and $\bar{T}_{i}^{\omega}$. Taken together, these correlations imply that $\bar{\Phi}_{i}^{\omega}$ and $\bar{\gamma}_{i}^{\omega}$ are positively correlated, so the OLS estimator of $(\sigma-1) / \theta$ in equation (DE) is biased upwards.

Finally, this bias in the first-step regression induces a downward bias in $\widehat{v}_{2}$. To see this, recall that the right instrument for relative market shares $\bar{\beta}_{i}^{R, \omega}$ in (CAE) are the industry preference parameters $\bar{\gamma}_{i}^{\omega}$, which, according to (DE), can be obtained adjusting relative expenditures $\bar{E}_{i}^{\omega}$ for the effect of prices, $\bar{\gamma}_{i}^{\omega}=\bar{E}_{i}^{\omega}-\frac{(\sigma-1)}{\theta} \bar{\Phi}_{i}^{\omega}$. However, from (34) and (36) we can see that the implicit "instruments" leading to $\widehat{v}_{1}$ and $\widehat{v}_{2}$ are, respectively, $\bar{E}_{i}^{\omega}$ and $\widehat{\bar{\gamma}}_{i}^{\omega}=\bar{E}_{i}^{\omega}-\widehat{c} \bar{\Phi}_{i}^{\omega}$, where $\widehat{c}$ is the upward-biased estimator of $(\sigma-1) / \theta$. Thus, relative expenditures $\bar{E}_{i}^{\omega}$ are not adjusted at all for the effect of prices in the first case while are over adjusted in the second case. As a result, the biases in estimators $\widehat{v}_{1}$ and $\widehat{v}_{2}$ run in opposite directions. These results are stated in the next Lemma.

\footnotetext{
${ }^{43}$ It can be shown that both estimators provide lower bounds for $v$ when $\sigma<1$, underestimating the mechanism proposed in this paper.
} 
Lemma 4 Suppose that preferences are given by (35) with $\sigma>1$ and that they satisfy assumption AO, i.e. $\mathbb{E}\left[\bar{\gamma}_{i}^{\omega} \bar{\iota}_{i}^{\omega}\right]=0$. If trade frictions are high and $v>0$, then the OLS estimator of $(\sigma-1) / \theta$ in equation $(D E)$ is biased upwards and the method of moments estimator $\widehat{v}_{2}$ in (34) is biased downwards.

Proof: See Appendix C.3.3.

The second and third columns of Table 1 show the results obtained using estimators $\widehat{v}_{1}$ and $\widehat{v}_{2}$, respectively. As we can see, the point estimates corresponding to these estimators $-\widehat{v}_{1}=0.811$ and $\widehat{v}_{2}=0.706$ - satisfy the inequality implied by Lemmas 3 and 4 , so together they provide upper and lower bounds for $v$ under the assumption $\sigma \geq 1$. These results suggest that there is scope for the effects of directed research to be quantitatively important as even the estimated lower bound for $v$ exceeds 0.5 , the threshold value given in Lemma 2 above which the endogenous adjustments in technology are strong enough to allow for the possibility of home market effects and potential reversals in the export profile of countries.

\section{Quantitative Analysis}

In this section I explore the quantitative relevance of the effects of directed research along two dimensions. First, I asses the importance of the endogenous adjustments in technology in the determination of manufacturing comparative advantage and explore how this process is affected by trade. Second, I investigate how the new margin affects the answer to some of the standard questions in the quantitative trade literature including the effect of trade costs on production, trade flows and real income.

\subsection{Calibration}

The mapping of variables in the model to the data and the estimation of comparative advantage in production was discussed in section 4 . In the baseline calibration of the model I set $v=0.758$, corresponding to the midpoint of the interval delimited by the estimates $\widehat{v}_{2}=0.706$ and $\widehat{v}_{1}=0.811$ obtained in section 4. As a robustness check, I also present results for values of $v$ corresponding to the endpoints of that interval. Finally I set the shape parameter $\theta$ to 4 , which is within the range of proposed values for this parameter in the literature. ${ }^{44}$

\subsection{Results}

Endogenous Comparative Advantage and Trade. - Armed with estimates of comparative advantage in production, figures for market shares and a value for $v$, equations (24) and (CAE) can be used to decompose the log of comparative advantage in production, $\bar{T}_{i}^{\omega}$, as the sum of the endogenous component $v \bar{\beta}_{i}^{R, \omega}$ and the exogenous component $\bar{\iota}_{i}^{\omega}=\bar{T}_{i}^{\omega}-v \bar{\beta}_{i}^{R, \omega}$ capturing the log of comparative advantage in innovation.

\footnotetext{
${ }^{44}$ Costinot, Donaldson and Komunjer (2011) obtain a value $\theta=6.53$ using a static multi-industry model in which $\theta$ is common across industries. However, their IV estimation procedure yields an upward biased estimator in the present model due to the two-way relationship between trade flows and R\&D that arises as a consequence of directed research.
} 
Then, a measure of the quantitative importance of the endogenous adjustments in technology is given by the contribution of the endogenous component $v \bar{\beta}_{i}^{R, \omega}$ to the total variance of $\bar{T}_{i}^{\omega} \cdot{ }^{45}$

The second row of table 2 shows the results of this variance decomposition corresponding to the observed open equilibrium in 2006. For the baseline value of $v=0.758$, the share of the endogenous component in the total variance of manufacturing comparative advantage is $52.8 \%$, indicating that the endogenous adjustments in technology play an important role in shaping comparative advantage in production. Also, the share of the endogenous component is robust with respect to the value of the parameter $v$ in the range delimited by the lower and upper bounds estimated in the last section: $51.2 \%$ for $v=0.706$ and $54.2 \%$ for $v=0.811$.

How important are the adjustments in technology induced by trade? To answer this question I analyze how the variance decomposition above is affected by trade costs. Armed with the figures for the log of comparative advantage in innovation obtained in the decomposition above and values for the CobbDouglas preference parameters, $\bar{\alpha}_{i}^{\omega}=\bar{E}_{i}^{\omega}$, I use Lemma 1 to obtain a similar variance decomposition of the log of comparative advantage in production, $\bar{T}_{i}^{\omega}$, for the cases of frictionless trade and autarky. The results are shown in the first and third rows of Table 2. For the baseline value of $v=0.758$, moving from autarky to the observed equilibrium in 2006 increases the share of the endogenous component from $26.2 \%$ to $52.8 \%$, implying that trade is responsible for about a fourth of the total variance of $\bar{T}_{i}^{\omega}$ in the observed equilibrium in 2006. In addition, the share of the endogenous component increases to $94.1 \%$ in the frictionless trade equilibrium, suggesting that there is plenty of room for further adjustments in technology as trade frictions decline. These results show that trade has a significant impact on technology.

A quick glance at table 2 shows that the share of the endogenous component in the observed equilibrium in 2006 is closer to the corresponding autarky share than to the zero gravity share, indicating that the observed equilibrium is characterized by high trade frictions. Another way to see this is to compare the endogenous components of comparative advantage in production constructed above with its counterparts in autarky and in the zero gravity equilibrium. Figure 3 shows the relationship between the endogenous components in the observed equilibrium and in autarky for the benchmark value of $v=0.758$, together with the 45 degree line in red. Each point in the figure corresponds to a country and an industry, since comparative advantage is calculated relative to an "average" country and an "average" industry according (32). As we can see, there is a tight connection between the two components. In contrast, Figure 4 shows a much weaker correlation between the endogenous components of comparative in the observed equilibrium and in the zero gravity world. Figures 3 and 4 are compatible with the presence of high impediments to trade in the actual equilibrium.

Moving to Autarky. - Here I consider the effects of raising trade costs to their autarky levels, $\tau_{i j}^{\omega} \rightarrow \infty$ for $i \neq j$. Given that in this case the effect on trade flows is trivial, I concentrate on the effects on real income. Table 3 shows the reductions in real income per-capita in the BGP as countries move to autarky, for a range of values of the decreasing returns in $\mathrm{R} \& \mathrm{D}$ parameter $v$ that include the upper and lower

\footnotetext{
${ }^{45}$ This variance decomposition is not intended to asses the relative contributions of exogenous elements of the model in the determiantion of comparative advantage in production. Instead, it is intended to asses the importance of the endogenous adjustments of technology induced by directed research, whatever the determinants of those adjustments are.
} 
bounds estimated previously. The changes in equilibrium variables needed to compute the changes in real income according to (31) are calculated using the system in changes (29), calibrated to the observed equilibrium in 2006. In the particular case we are analyzing, the change in real income across BGPs can be computed as

$$
\ln \frac{W_{i t}^{a}}{W_{i t}}=\frac{v}{\theta} \int_{\Omega} \alpha_{i}^{\omega} \ln \left(\frac{\alpha_{i}^{\omega}}{\delta_{i}^{\omega}}\right) d \omega+\frac{1}{\theta} \int_{\Omega} \alpha_{i}^{\omega} \ln \left(\lambda_{i i}^{\omega}\right) d \omega
$$

where $W_{i t}^{a}, W_{i t}$ denote the real income in autarky and in the actual equilibrium respectively.

The second term in the last expression corresponds to the change in real income predicted by the model with no innovation, $v=0$. This term is always negative and it is shown in column 1 of Table 3. In contrast, the first term in the last expression is always positive for $v>0$, and it reflects the endogenous adjustments in technology due to directed research. As discussed in section 3.4, this implies that the model with no innovation overestimates the reduction in real income associated with moving to autarky. Moreover, the predicted reduction in real income depends negatively on $v$; higher values of $v$ are associated with lower reductions in real income. The other columns in Table 3 show the changes in real income for a range of positive values of $v$ relative to the changes corresponding to the no innovation model in column 1 ,

$$
\frac{\ln W_{i t}^{a, v} / W_{i t}}{\ln W_{i t}^{a, 0} / W_{i t}}=1+v \frac{\int_{\Omega} \alpha_{i}^{\omega} \ln \left(\alpha_{i}^{\omega} / \delta_{i}^{\omega}\right) d \omega}{\int_{\Omega} \alpha_{i}^{\omega} \ln \left(\lambda_{i i}^{\omega}\right) d \omega}<1
$$

The general picture emerging from Table 3 is that the differences in the predicted changes in real income between the two models appear to be modest. For the case of the benchmark value of $v=0.758$, the reductions in real income relative to the model with no innovation range from $72 \%$ for Australia, to $98 \%$ for Belgium-Luxembourg, with a mean value for the sample of $93 \%$. To understand the reasons behind these modest differences, we have to analyze the determinants of the first term in (37) since, for this particular counterfactual, it is the only driver of the differences between the predictions of the model with no innovation and the model with directed research. Notice that the magnitude of the first term in (37) depends on the difference in the production specialization profile of the country between the actual open equilibrium and autarky. These specialization profiles are captured by $\delta_{i}^{\omega}$ and $\alpha_{i}^{\omega}$ in (37). In that equation, $\delta_{i}^{\omega}$ represents the share of industry $\omega$ in total manufacturing production in the open equilibrium. Recalling that in autarky the allocation of resources is completely driven by domestic demand, the CobbDouglas preference parameters $\alpha_{i}^{\omega}$ also represent the share of industry $\omega$ in total manufacturing output in the autarky equilibrium.

Figure 5 shows the relationship between $\alpha_{i}^{\omega}$ and $\delta_{i}^{\omega}$ in the data. Each point in the figure corresponds to a country-industry pair, where the figures for industry shares $\delta_{i}^{\omega}$ and demand parameters $\alpha_{i}^{\omega}$ are constructed using production and trade data for the year 2006. As we can see, there is a tight connection between domestic production and domestic demand; the correlation coefficient is 0.81 . As in the case of the analysis of the determinants of the endogenous component of comparative advantage in production, the close relationship between expenditure shares $\alpha_{i}^{\omega}$ and industry shares $\delta_{i}^{\omega}$ in the open equilibrium is indicative of the presence of high trade frictions in the open equilibrium. This implies that for the average country, the first term in (37) is small in absolute value. In addition, the first term tends to be important 
for those countries in which the second term is also important (in absolute terms); the correlation between the terms is -0.76 for the baseline value of $v=0.758$. This two elements are behind the modest relative differences between the predictions of the model with and without innovation.

25\% reduction in trade costs - Here I analyze how directed research affects our conclusion regarding the effects of a $25 \%$ reduction in trade costs on production, trade flows and real income. As before, the changes in equilibrium variables needed to compute the changes in real income according to (31) are calculated using the system in changes (29), calibrated to the observed equilibrium in 2006.

Let us start with the analysis of the effects of directed research on trade flows. Figure 6 shows the relationship between the predicted log-changes in trade shares in both models, together with the 45 degree line in red. The changes corresponding to the model with directed research were calculated for the benchmark calibration of the decreasing returns parameter $v=0.758$. Each point in the graph correspond to an exporter-importer-industry triplet. As we can see, there are important differences between the predictions of the models. A simple regression of the changes in trade shares in the model with directed research on the corresponding changes in trade shares in the model with no innovation yields a slope coefficient of 1.05 This implies that, on average, the direction and magnitude of the changes in trade shares are similar in both models. However, this average hides a lot of variation as we can see from the figure. The R-square corresponding to that regression is 0.378 , i.e., only a little more than a third of the variation in trade flows in the model with directed research can be explained by the corresponding changes in trade flows in the model with no innovation. In addition, in $26 \%$ of the cases the predicted changes in trade shares in both models go in opposite directions.

Let us now turn to the analysis of the changes in trade shares. Figure 7 shows a scatter plot of the predicted log-changes in market shares $\beta_{i}^{R, \omega}$ in both models, together with the 45 degree line in red. Each point in the graph corresponds to a country-industry pair. As we can see, there are small differences in the direction of the change in market shares predicted by the models; the correlation coefficient between the two variables is 0.94 . However, the standard model underestimates the magnitude of the responses in market shares relative to the model with directed research; a regression of the predicted log-changes in market shares in the model with directed research on its counterpart in the model with no innovation yield a slope coefficient of 3.37 .

Let us now turn to the analysis of the effects of the reduction in trade costs on real income per capita. The change in real income across BGPs can be computed as

$$
\ln \frac{W_{i t}^{\prime}}{W_{i t}}=\frac{v}{\theta} \int_{\Omega} \alpha_{i}^{\omega} \ln \left(\frac{\delta_{i}^{\prime \omega}}{\delta_{i}^{\omega}}\right) d \omega-\frac{1}{\theta} \int_{\Omega} \alpha_{i}^{\omega} \ln \left(\frac{\lambda_{i i}^{\prime \omega}}{\lambda_{i i}^{\omega}}\right) d \omega
$$

where $W_{i t}^{\prime}$ denotes the real income in the new counterfactual equilibrium and $W_{i t}$ denotes its counterpart in the baseline open equilibrium in 2006 respectively. Table 4 shows the changes in real income across BGPs associated with a $25 \%$ uniform reduction in trade costs across industries and countries. The changes are calculated for the same values of the decreasing returns in R\&D parameter $v$ used in the case of the previous exercise. As in Table 3, columns (2)-(4) present the predicted changes in real income relative to the corresponding predicted change for the case of no innovation $(v=0)$, shown in column 1 . 
The first thing to notice is that all countries experience an increase in their real income regardless of the degree of the decreasing returns in innovation. As anticipated, there is a general tendency for the model with no innovation to underestimate the increases in real income. In only 6 cases, the model with directed research predicts a lower increase in real income relative to the model with no innovation. However, as in the case of moving to autarky, the relative differences in the predicted changes in real income in both models seem to be modest. For the case of the benchmark value of $v=0.758$, the changes in real income relative to the model with no innovation range from $83 \%$ for China, to $108 \%$ for Japan, with a mean value for the sample of $102 \%$.

What is behind these modest effects of directed research in this case? In contrast to the case of moving to autarky, now the predicted change in trade flows depends on the degree of decreasing returns in R\&D captured by the parameter $v$. This implies that to understand the differences in the predictions of the models we have to analyze both terms in equation (38). Table 5 decomposes the total change in real income into the two terms in (38). The first and second columns show the predicted change in real income corresponding to a model with no innovation and to the model with directed research with the benchmark calibration $v=0.758$. The third and fourth columns decompose the change in real income in column 2 into the two terms in (38), such that column 2 is the sum of columns 3 and 4 . The first term in (38) is shown in column 4 (industry shares) and the second term is shown in column 3 (home shares).

Two features emerge from Table 5. First, the figures in column 3 are higher than those corresponding to column 1 for all countries. This comparison analyzes the effects of directed research on real income through its effect on trade flows in the second term of (38). Second, the first term of (38) shown in column 4 is negative for all countries. This column shows the effects of directed research on real income through its effect on the specialization patterns of the country in the first term in (38). As we can see, the effect of directed research on the two terms in (38) go in opposite directions. The intuition behind this result is very simple. Let $X^{\prime \prime}$ denote the value of variable $X$ after the $25 \%$ reduction in trade costs in the model with directed research $(v>0)$, and let $X^{\prime}$ denote the value of the same variable after the reduction in trade costs but before any endogenous adjustment in technology takes place. Then, for any country $i$ and industry $\omega$, the relationship between the price levels at these two moments is

$$
\frac{P_{i t}^{\prime \prime \omega}}{P_{i t}^{\prime \omega}} \propto\left(\Phi_{i t}^{\prime \prime \omega} / \Phi_{i t}^{\prime \omega}\right)^{-\frac{1}{\theta}}=\left(\frac{\lambda_{i t}^{\prime \prime \omega} / \lambda_{i t}^{\prime \omega}}{T_{i t}^{\prime \prime \omega} / T_{i t}^{\prime \omega}}\right)^{\frac{1}{\theta}}
$$

It should be clear that in the previous expression, the value $X^{\prime}$ for any variable $X$ corresponds to the predictions of the model with no innovation. Now consider the changes in trade flows and technology when the endogenous adjustments in technology are allowed to operate. These are the effects that are attributable to the new margin of adjustment introduced by directed research. The reduction in trade costs changes the relative expected market size for innovations across different industries. This translates into the expansion of the manufacturing technology in some sectors and the contractions in others. Suppose for a moment that more innovation takes place in industry $\omega$ in country $i$ as a consequence of the reduction in trade costs, inducing an increase in the manufacturing technology from $T_{i t}^{\prime \omega}$ to $T_{i t}^{\prime \prime \omega}$. The same specialization process induces other countries to reduce their innovation in that industry. These two 
effects together induce an increase in the home share of expenditure of country $i$ in that industry from $\lambda_{i t}^{\prime \omega}$ to $\lambda_{i i}^{\prime \prime \omega}$. A similar analysis indicates that manufacturing technology and home shares of expenditure move in the same direction when innovation reallocates away from some industry. This implies that the effects of directed research on manufacturing technology and on the home share of expenditure in (39) work in opposite directions. This explains the modest effects of directed research on real income.

\section{Conclusions}

In this paper I develop a multi-country, general equilibrium, semi-endogenous growth model of innovation and trade in which specialization in innovation and production are jointly determined. The distinctive element of the model is the ability of the agents to direct their research efforts to specific industries, in a context of heterogeneous innovation capabilities across countries and contemporaneous decreasing returns to R\&D. The model features a two-way relationship between trade and technology absent in standard quantitative Ricardian trade models.

I use the model to disentangle the effects of trade on technology and to study questions that standard Ricardian quantitative trade models are not suitable to answer. Under the baseline calibration of the model, I find that the endogenous adjustments in technology due to directed research can account for up to $52.8 \%$ of the observed variance in comparative advantage in production in the observed trading equilibrium in 2006. In addition, I find that the differences in the adjustments in trade flows and market shares in response to a $25 \%$ reduction in trade costs between the two models can be quantitatively important.

I also show that the standard model with no innovation overestimates the reduction in real income from moving to autarky and tends to underestimate the increases in real income from reductions in trade costs. However, notwithstanding the relevant effects of directed research on technology, production and trade flows, the predicted changes in real income associated with moving to autarky and with a $25 \%$ reduction in trade costs do not differ much across models. 


\section{A Figures}

Figure 1: Changes in Real Income and Trade Costs

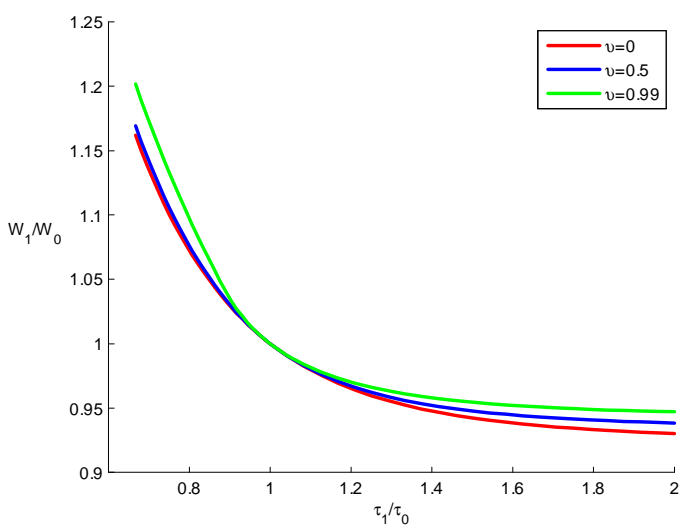

Notes: The figure shows the changes in real income across BGP as functions of changes in trade costs for alternative values of $v$. The figure was constructed for the case of two symmetric countries according to system (29) which solves the model in changes conditional on observable variables in the initial equilibrium.

Figure 2: Relationship between $\Phi_{n}$ and $T_{n}$

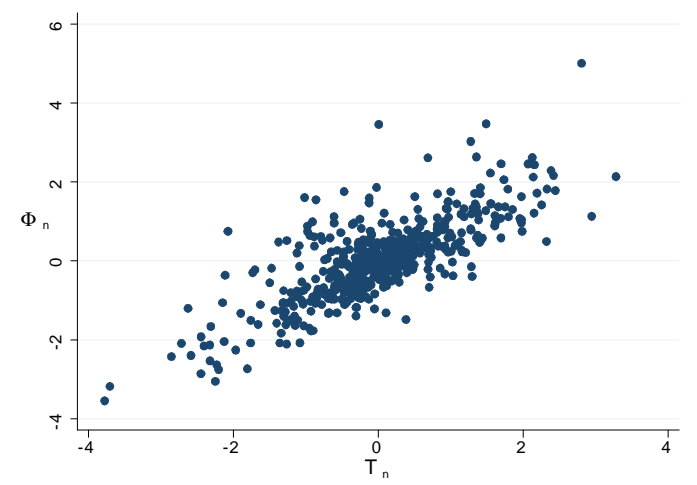

Notes: The figure shows the relationship between log-comparative advantage in production $T_{n}$ and the log-double ratio of cost parameters $\Phi_{n}$. Double ratios are taken with respect to the "average" country and "average" industry defined in the text; then each observation correspond to a country-industry pair. Trade and production data correspond to the year 2006. 
Figure 3: Endogenous Component of Comparative Advantage: Actual Equilibrium vs. Autarky

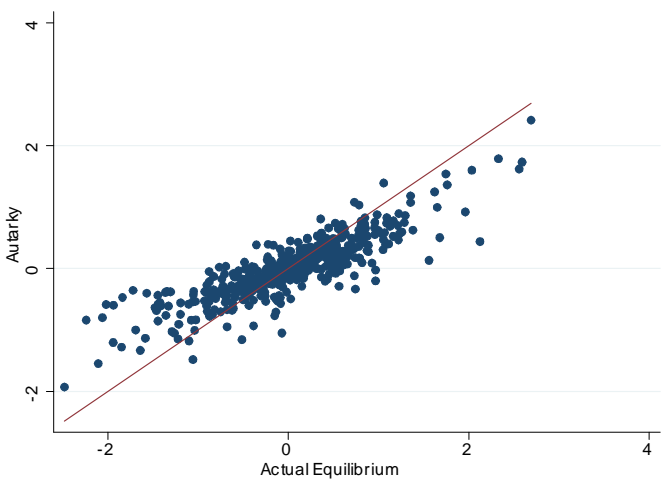

Notes: The figure shows the relationship between the endogenous components of comparative advantage in the actual equilibrium and in autarky for $v=0.758$. Double ratios are taken with respect to the "average" country and "average" industry defined in the text; then each observation correspond to a country-industry pair. In red the 45 degree line. Trade and production data correspond to the year 2006 .

Figure 4: Endogenous Component of Comparative Advantage: Actual Equilibrium vs. Zero Gravity

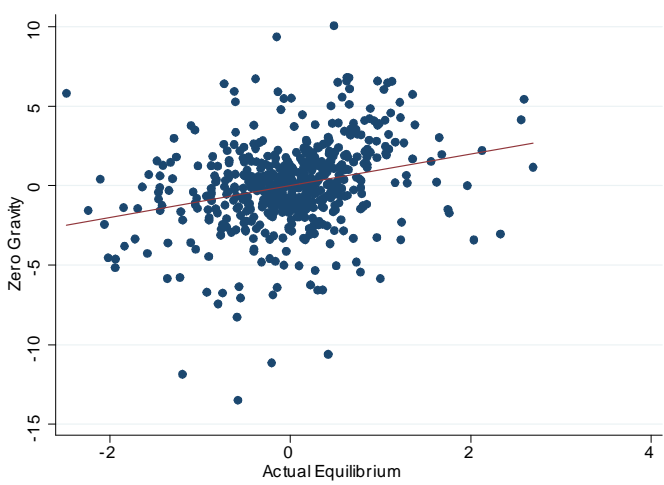

Notes: The figure shows the relationship between the endogenous components of comparative advantage in the actual equilibrium and in zero gravity for $v=0.758$. Double ratios are taken with respect to the (geometric) "average" country and "average" industry defined in the text; then each observation correspond to a country-industry pair. In red, the 45 degree line. Trade and production data correspond to the year 2006 . 
Figure 5: Allocation of Resources. Actual Equilibrium vs. Autarky

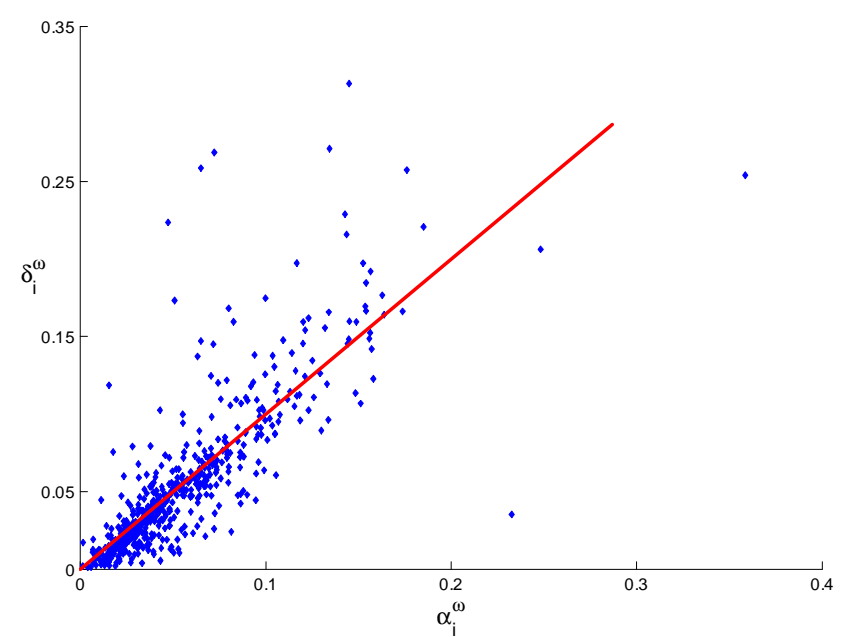

Notes: The figure shows the relationship between the allocation of resources in the actual open equilibrium and in autarky. Each dot in the figure corresponds to a country-industry pair. In red the 45 degree line. The value $\delta_{i}^{\omega}$ represents the share of industry $\omega$ in country $i$ 's total production in the actual open equilibrium and it is calculated from production data. The corresponding industry shares in autarky are given by the demand parameters $\alpha_{i}^{\omega}$, which are obtained from production and trade data as described in the Data Section. Trade and production data correspond to the year 2006.

Figure 6: Log Changes in Trade Shares. No Innovation vs. Directed Research

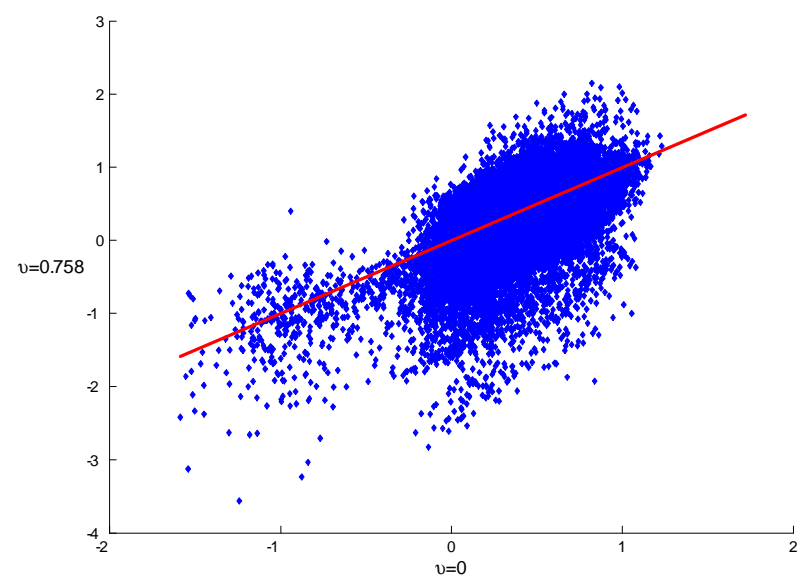

Notes: The figure shows the relationship between the predicted log-change in trade shares after a $25 \%$ reduction in trade costs corresponding to the models with no innovation and directed research. Each dot in the figure represents a exporter-importer-industry triplet, $\log \hat{\lambda}_{i j}^{\omega}$. Changes in trade shares are calculated according to the system in changes (29). Trade and production data in the baseline equilibrium correspond to the year 2006 . 
Figure 7: Log Changes in Market Shares. No Innovation vs. Directed Research

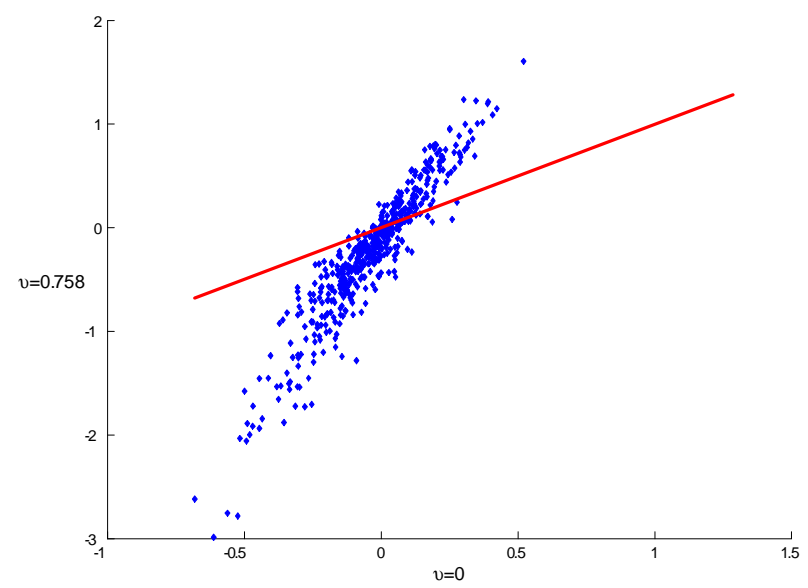

Notes: The figure shows the relationship between the predicted log-change in market shares after a $25 \%$ reduction in trade costs corresponding to the models with no innovation and directed research. Each dot in the figure represents a exporter-importer-industry triplet, $\log \widehat{\beta}_{i}^{R, \omega}$. Changes in trade shares are calculated according to the system in changes (29). Trade and production data in the baseline equilibrium correspond to the year 2006 . 


\section{B Tables}

Table 1: Estimation of $v$

\begin{tabular}{lccc}
\hline \hline $\begin{array}{l}\text { D.V. } \\
\text { log-Comp. Adv. in Prod. }\end{array}$ & OLS & $\begin{array}{c}\text { IV } \\
\text { (Expend. Shares) }\end{array}$ & $\begin{array}{c}\text { IV } \\
\text { (Residuals) }\end{array}$ \\
\hline & $(1)$ & $(2)$ & $(3)$ \\
\hline log-Market Shares & $1.023^{* * *}$ & $0.811^{* * *}$ & $0.706^{* * *}$ \\
& $(0.0386)$ & $(0.0472)$ & $(0.0506)$ \\
\hline Observations & 540 & 540 & 540 \\
R-squared & 0.566 & 0.541 & 0.512 \\
\hline \hline
\end{tabular}

Standard errors in parentheses. ${ }^{* * *} \mathrm{p}<0.01$

Notes: The table shows the results of estimating equation (CAE) according to the three different methods discussed above. Columns (1), (2), and (3) show the estimation results corresponding to OLS estimator, the method of moments estimator $\widehat{v}_{1}$ and the method of moments estimator $\widehat{v}_{2}$. An observation corresponds to a country-industry pair, since double ratios are taken with respect to the (geometric) "average" country and industry defined in the text.

Table 2: Endogenous Component of Comparative Advantage in Production

\begin{tabular}{lccc}
\hline \hline & $v=0.706$ & $v=0.758$ & $v=0.811$ \\
& $\%$ & $\%$ & $\%$ \\
\hline Zero Gravity & 91.4 & 94.1 & 96.4 \\
Actual Open Equilibrium & 51.2 & 52.8 & 54.2 \\
Autarky & 25.7 & 26.2 & 26.3 \\
\hline \hline
\end{tabular}

Notes: The table shows the share of the endogenous component in the total variance of log-comparative advantage in production for different values $v$ and for alternative assumptions about the structure of trade frictions. The selected values for the decreasing returns parameter $v$ include the estimated lower and upper bounds estimated in the text and the benchmark calibration for $v$ corresponding to the average of the bounds. 
Table 3: Changes in Real Income. Moving to Autarky (Losses.) Manufacturing Sector. 2006

\begin{tabular}{|c|c|c|c|c|}
\hline & $\begin{array}{c}v=0 \\
\text { Level \% } \\
(1)\end{array}$ & $\begin{array}{c}v=0.706 \\
\text { Rel. to }(1) \\
(2)\end{array}$ & $\begin{array}{c}v=0.758 \\
\text { Rel. to }(1) \\
(3)\end{array}$ & $\begin{array}{c}v=0.811 \\
\text { Rel. to (1) } \\
(4)\end{array}$ \\
\hline AUS & -16.67 & 0.74 & 0.72 & 0.70 \\
\hline AUT & -36.82 & 0.98 & 0.98 & 0.98 \\
\hline BLX & -41.96 & 0.99 & 0.98 & 0.98 \\
\hline BRA & -6.75 & 0.90 & 0.89 & 0.89 \\
\hline CAN & -30.55 & 0.96 & 0.95 & 0.95 \\
\hline $\mathrm{CHE}$ & -26.84 & 0.93 & 0.93 & 0.92 \\
\hline $\mathrm{CHN}$ & -12.75 & 0.83 & 0.81 & 0.80 \\
\hline $\mathrm{CZE}$ & -26.01 & 0.95 & 0.94 & 0.94 \\
\hline DEU & -20.33 & 0.98 & 0.98 & 0.97 \\
\hline DNK & -30.31 & 0.92 & 0.91 & 0.91 \\
\hline $\mathrm{ESP}$ & -14.40 & 0.97 & 0.97 & 0.97 \\
\hline FIN & -21.60 & 0.94 & 0.94 & 0.93 \\
\hline FRA & -15.76 & 0.98 & 0.98 & 0.98 \\
\hline GBR & -17.94 & 0.98 & 0.98 & 0.98 \\
\hline GRC & -28.54 & 0.85 & 0.84 & 0.83 \\
\hline HUN & -37.53 & 0.98 & 0.97 & 0.97 \\
\hline IRL & -30.43 & 0.87 & 0.86 & 0.85 \\
\hline ISR & -33.80 & 0.85 & 0.84 & 0.83 \\
\hline ITA & -13.49 & 0.91 & 0.90 & 0.90 \\
\hline JPN & -6.58 & 0.96 & 0.95 & 0.95 \\
\hline KOR & -11.61 & 0.97 & 0.97 & 0.97 \\
\hline MEX & -28.14 & 0.96 & 0.96 & 0.96 \\
\hline NLD & -31.98 & 0.97 & 0.97 & 0.97 \\
\hline NOR & -20.76 & 0.92 & 0.92 & 0.91 \\
\hline POL & -19.99 & 0.94 & 0.94 & 0.93 \\
\hline PRT & -27.88 & 0.97 & 0.96 & 0.96 \\
\hline SGP & -61.43 & 0.88 & 0.88 & 0.87 \\
\hline SWE & -23.28 & 0.96 & 0.96 & 0.95 \\
\hline USA & -8.24 & 0.96 & 0.96 & 0.95 \\
\hline mean & -24.22 & 0.93 & 0.93 & 0.92 \\
\hline median & -23.28 & 0.96 & 0.95 & 0.95 \\
\hline $\min$ & -6.58 & 0.74 & 0.72 & 0.70 \\
\hline $\max$ & -61.43 & 0.99 & 0.98 & 0.98 \\
\hline
\end{tabular}

Source: Author's calculation from the OECD STAN Database, UNIDO INDSTAT2 and the model in the

text. Notes: The levels in column (1) are calculated for a value $\theta=4$. The other columns represent the change in real income relative to the column (1); this relative measure is not affected by the value of $\theta$. 
Table 4: Changes in Real Income. 25\% Reduction in Trade Costs. Manufacturing Sector. 2006

\begin{tabular}{|c|c|c|c|c|}
\hline & $\begin{array}{c}v=0 \\
\text { Level \% } \\
(1)\end{array}$ & $\begin{array}{c}v=0.706 \\
\text { Rel. to }(1) \\
(2)\end{array}$ & $\begin{array}{c}v=0.758 \\
\text { Rel. to }(1) \\
(3)\end{array}$ & $\begin{array}{c}v=0.811 \\
\text { Rel. to (1) } \\
(4)\end{array}$ \\
\hline AUS & 13.71 & 1.02 & 1.03 & 1.05 \\
\hline AUT & 24.31 & 1.02 & 1.03 & 1.04 \\
\hline BLX & 25.45 & 1.04 & 1.05 & 1.07 \\
\hline BRA & 6.32 & 1.00 & 1.00 & 1.00 \\
\hline $\mathrm{CAN}$ & 27.35 & 1.01 & 1.01 & 1.02 \\
\hline $\mathrm{CHE}$ & 20.01 & 0.99 & 0.98 & 0.98 \\
\hline $\mathrm{CHN}$ & 8.23 & 0.86 & 0.83 & 0.79 \\
\hline $\mathrm{CZE}$ & 19.19 & 1.01 & 1.01 & 1.01 \\
\hline $\mathrm{DEU}$ & 15.34 & 1.03 & 1.04 & 1.05 \\
\hline DNK & 22.03 & 1.03 & 1.04 & 1.06 \\
\hline ESP & 12.55 & 1.01 & 1.01 & 1.01 \\
\hline FIN & 15.98 & 1.02 & 1.03 & 1.03 \\
\hline FRA & 14.18 & 1.04 & 1.05 & 1.06 \\
\hline GBR & 15.60 & 1.02 & 1.02 & 1.03 \\
\hline GRC & 16.45 & 1.01 & 1.01 & 1.01 \\
\hline HUN & 22.10 & 0.99 & 0.99 & 0.99 \\
\hline IRL & 19.81 & 1.02 & 1.03 & 1.04 \\
\hline ISR & 19.21 & 0.98 & 0.97 & 0.95 \\
\hline ITA & 11.39 & 1.03 & 1.04 & 1.05 \\
\hline JPN & 6.44 & 1.07 & 1.08 & 1.11 \\
\hline KOR & 10.49 & 1.05 & 1.06 & 1.07 \\
\hline MEX & 21.64 & 0.97 & 0.97 & 0.97 \\
\hline NLD & 23.64 & 1.05 & 1.07 & 1.09 \\
\hline NOR & 16.35 & 0.99 & 0.99 & 0.99 \\
\hline POL & 15.60 & 1.01 & 1.02 & 1.02 \\
\hline PRT & 19.54 & 1.02 & 1.02 & 1.03 \\
\hline SGP & 24.69 & 0.99 & 1.00 & 1.00 \\
\hline SWE & 18.59 & 1.02 & 1.02 & 1.02 \\
\hline $\mathrm{USA}$ & 7.59 & 1.04 & 1.05 & 1.07 \\
\hline mean & 17.03 & 1.01 & 1.02 & 1.02 \\
\hline median & 16.45 & 1.02 & 1.02 & 1.03 \\
\hline $\min$ & 6.32 & 0.86 & 0.83 & 0.79 \\
\hline $\max$ & 27.35 & 1.07 & 1.08 & 1.11 \\
\hline
\end{tabular}

Source: Author's calculation from the OECD STAN Database, UNIDO INDSTAT2 and the model in the

Notes: The levels in column (1) are calculated for a value $\theta=4$. The other columns represent the change in real income relative to the column (1). 
Table 5: Decomposition of Changes in Real Income. 25\% Reduction in Trade Costs. Manufacturing Sector. 2006

\begin{tabular}{|c|c|c|c|c|}
\hline & \multirow{2}{*}{$\begin{array}{c}v=0 \\
\text { Level \% } \\
(1)\end{array}$} & \multicolumn{3}{|c|}{$v=0.758$} \\
\hline & & $\begin{array}{l}\text { Level \% } \\
(2)\end{array}$ & $\begin{array}{c}\text { Home Shares } \\
(3)\end{array}$ & $\begin{array}{c}\text { Industry Shares } \\
(4)\end{array}$ \\
\hline AUS & 13.71 & 14.13 & 33.25 & -19.12 \\
\hline AUT & 24.31 & 25.07 & 27.84 & -2.76 \\
\hline BLX & 25.45 & 26.75 & 28.19 & -1.44 \\
\hline BRA & 6.32 & 6.32 & 9.47 & -3.15 \\
\hline $\mathrm{CAN}$ & 27.35 & 27.68 & 37.01 & -9.34 \\
\hline $\mathrm{CHE}$ & 20.01 & 19.65 & 25.55 & -5.89 \\
\hline $\mathrm{CHN}$ & 8.23 & 6.85 & 10.98 & -4.13 \\
\hline $\mathrm{CZE}$ & 19.19 & 19.36 & 22.50 & -3.14 \\
\hline DEU & 15.34 & 15.94 & 17.44 & -1.50 \\
\hline DNK & 22.03 & 22.99 & 29.05 & -6.06 \\
\hline ESP & 12.55 & 12.67 & 14.24 & -1.58 \\
\hline FIN & 15.98 & 16.42 & 20.64 & -4.22 \\
\hline FRA & 14.18 & 14.82 & 16.17 & -1.34 \\
\hline GBR & 15.60 & 15.93 & 18.02 & -2.10 \\
\hline GRC & 16.45 & 16.56 & 20.05 & -3.49 \\
\hline HUN & 22.10 & 21.91 & 24.48 & -2.57 \\
\hline IRL & 19.81 & 20.34 & 24.33 & -3.99 \\
\hline ISR & 19.21 & 18.58 & 25.97 & -7.39 \\
\hline ITA & 11.39 & 11.83 & 13.26 & -1.42 \\
\hline JPN & 6.44 & 6.99 & 8.91 & -1.92 \\
\hline KOR & 10.49 & 11.13 & 12.44 & -1.31 \\
\hline MEX & 21.64 & 20.96 & 29.90 & -8.93 \\
\hline NLD & 23.64 & 25.25 & 31.53 & -6.29 \\
\hline NOR & 16.35 & 16.14 & 20.77 & -4.63 \\
\hline POL & 15.60 & 15.87 & 18.82 & -2.95 \\
\hline PRT & 19.54 & 19.97 & 21.22 & -1.25 \\
\hline SGP & 24.69 & 24.59 & 30.25 & -5.66 \\
\hline SWE & 18.59 & 18.94 & 21.98 & -3.04 \\
\hline USA & 7.59 & 8.01 & 10.19 & -2.18 \\
\hline mean & 17.03 & 17.30 & 21.53 & -4.23 \\
\hline median & 16.45 & 16.56 & 21.22 & -3.14 \\
\hline $\min$ & 6.32 & 6.32 & 8.91 & -19.12 \\
\hline $\max$ & 27.35 & 27.68 & 37.01 & -1.25 \\
\hline
\end{tabular}

Source: Author's calculation from the OECD STAN Database, UNIDO INDSTAT2 and the model in the text.
Notes: Columns (1) and (2) show the change in real income associated with a $25 \%$ reduction in trade costs for the indicated values of $v$. The figures are calculated for a value of $\theta=4$. Columns (3) and (4) decompose column (2) into the two terms in (38) such that column 2 is the sum of columns 3 and 4. 


\section{Proofs of Theoretical Results}

\section{C.1 Section 2}

\section{C.1.1 Derivation of (2)}

Proof. The analysis that follows applies to any country $i$, good $(z, \omega)$ and time $t$, so all references to country, good and time are drop. Let $n$ be the number of techniques available up to time $t$ for good $(z, \omega)$ in country $i$. As discussed above, the efficiency of these techniques is obtained as independent draws from the Pareto distribution $H$. Let $X_{1}, \ldots, X_{n}$ be the random variables corresponding to each of these $n$ draws, and let $Y_{j}$ represent the $j$-th best draw among the $X_{i} s$. We are interested, in the joint distribution of the best and second best draws conditional on $n$, i.e., the joint distribution of $Y_{1}, Y_{2}$ conditional on $n$. Following Hogg and Craig (1995) section 4.6, the joint pdf of $Y_{1}, . ., Y_{n}$ is

$$
\begin{aligned}
g\left(y_{1}, \ldots, y_{n} \mid n\right) & =n ! h\left(y_{1}\right) h\left(y_{2}\right) \ldots h\left(y_{n}\right) \text { for } \infty>y_{1}>y_{2}>\cdots>y_{n}>1 \\
& =0 \text { elsewhere }
\end{aligned}
$$

where $h$ is the pdf corresponding to $H$. Integrating over $y_{3}, \ldots, y_{n}$, the marginal joint density of $Y_{1}, Y_{2}$ is

$$
\begin{aligned}
f\left(y_{1}, y_{2} \mid n\right) & =\int_{1}^{y_{2}} \ldots \int_{1}^{y_{n-2}} \int_{1}^{y_{n-1}} h\left(y_{n}\right) \ldots h\left(y_{1}\right) d y_{n} \ldots d y_{1} \\
& =\frac{n !}{(n-2) !} H\left(y_{2}\right)^{n-2} h\left(y_{2}\right) h\left(y_{1}\right)
\end{aligned}
$$

Once we know $f\left(y_{1}, y_{2}\right)$, the joint cdf of $Y_{1}, Y_{2}$ conditional on $n$ can be obtained as

$$
\begin{aligned}
F\left(x_{1}, x_{2} \mid n\right) & =\operatorname{Pr}\left(Y_{1} \leq x_{1}, Y_{2} \leq x_{2} \mid n\right) \\
& =\int_{1}^{x_{1}} \int_{1}^{\min \left\{x_{2}, y_{1}\right\}} g\left(y_{1}, y_{2}\right) d y_{2} d y_{1} \\
& =\int_{1}^{x_{1}} \int_{1}^{x_{2}} g\left(y_{1}, y_{2}\right) d y_{2} d y_{1}-\int_{1}^{x_{2}} \int_{1}^{y_{2}} g\left(y_{1}, y_{2}\right) d y_{1} d y_{2} \\
& =n H\left(x_{2}\right)^{n-1} H\left(x_{1}\right)-H\left(x_{2}\right)^{n}(n-1)
\end{aligned}
$$

Finally, the unconditional joint distribution of $Y_{1}, Y_{2}$ can be obtain taking expectation over $n$. Recalling that $n$ is distributed Poisson with parameter $T$, this yields

$$
\begin{aligned}
F\left(x_{1}, x_{2}\right) & =\sum_{n=0}^{\infty} \frac{F\left(x_{1}, x_{2} \mid n\right) T^{n} e^{-T}}{n !} \\
& =\sum_{n=0}^{\infty} \frac{n H\left(x_{2}\right)^{n-1} H\left(x_{1}\right) T^{n} e^{-T}}{n !}-\sum_{n=0}^{\infty} \frac{n H\left(x_{1}\right)^{n} T^{n} e^{-T}}{n !}+\sum_{n=0}^{\infty} \frac{H\left(x_{1}\right)^{n} T^{n} e^{-T}}{n !} \\
& =H\left(x_{1}\right) T e^{-T\left[1-H\left(x_{2}\right)\right]}-H\left(x_{2}\right) T e^{-T\left[1-H\left(x_{2}\right)\right]}+e^{-T\left[1-H\left(x_{2}\right)\right]} \\
& =\left[1+T\left(x_{2}^{-\theta}-x_{1}^{-\theta}\right)\right] e^{-T x_{2}^{-\theta}}
\end{aligned}
$$


and introducing the references to the country, good and time we get the result above.

Recalling that the joint distribution used in BEJK (2003) for the best and second best technique is $K\left(x_{1}, x_{2}\right)=\left[1+T\left(x_{2}^{-\theta}-x_{1}^{-\theta}\right)\right] e^{-T x_{2}^{-\theta}}$ for $x_{1} \geq x_{2} \geq 0$, notice that $F$ is almost identical to $K$ the only difference being that in this case, $F$ is only valid for $x_{2} \geq 1$. The discrepancy arises from the fact hat the minimum efficiency level in the present context is 1 , implying that $F\left(x_{1}, x_{2}\right)=0$ for $x_{2}<1$. According to $K, \operatorname{Pr}\left(x_{2} \leq 1\right)=K(\infty, 1)=[1+T] e^{-T}=\operatorname{Pr}(n \leq 1)$, i.e., the difference is attributable to the fact that at any time $t$, there is a set of goods with strictly positive mass such that no more than one technique has been discovered. However, notice that this probability approaches zero as $T \rightarrow \infty$.

Formally, $F_{T}$ converges in distribution to $K_{T}$ as $T \rightarrow \infty$, where the subscript $T$ make explicit the dependence of the distributions on the parameter $T$. Given that $T$ is growing, we need first to normalize the variables and then analyze the convergence of the normalized variables. Let $Y_{i T}^{d}$ be the random variable representing the $i$-th best technique according to distribution $d$ and for parameter $T$, and consider the variables $Z_{i T}^{d}=Y_{i}^{d} T^{1 / \theta}$ for $i=1,2$ and $d=F_{T}, K_{T}$. In what follows I show that $F_{T}, K_{T} \rightarrow K$, where $K\left(z_{1}, z_{2}\right)=\left[1+\left(z_{2}^{-\theta}-z_{1}^{-\theta}\right)\right] e^{-z_{2}^{-\theta}}$ for $z_{1} \geq z_{2} \geq 0$. Notice that

$$
\begin{aligned}
F_{T}^{Z}\left(z_{1}, z_{2}\right) & =\operatorname{Pr}\left(Z_{1 T}^{F_{T}} \leq z_{1}, Z_{2 T}^{F_{T}} \leq z_{2}\right) \\
& =\operatorname{Pr}\left(Y_{1 T}^{F_{T}} \leq T^{-1 / \theta} z_{1}, Y_{2 T}^{F_{T}} \leq T^{-1 / \theta} z_{2}\right) \\
& =\left[1+\left(z_{2}^{-\theta}-z_{1}^{-\theta}\right)\right] e^{-z_{2}^{-\theta}} \text { for } z_{1} \geq z_{2} \geq T^{-1 / \theta}
\end{aligned}
$$

and so it is clear that $F_{T}^{Z}\left(z_{1}, z_{2}\right) \rightarrow K\left(z_{1}, z_{2}\right)$ for all $z_{1} \geq z_{2} \geq 0$. Similarly,

$$
\begin{aligned}
K_{T}^{Z}\left(z_{1}, z_{2}\right) & =\operatorname{Pr}\left(Z_{1 T}^{K_{T}} \leq z_{1}, Z_{2 T}^{K_{T}} \leq z_{2}\right) \\
& =\operatorname{Pr}\left(Y_{1 T}^{K_{T}} \leq T^{-1 / \theta} z_{1}, Y_{2 T}^{K_{T}} \leq T^{-1 / \theta} z_{2}\right) \\
& =\left[1+\left(z_{2}^{-\theta}-z_{1}^{-\theta}\right)\right] e^{-z_{2}^{-\theta}} \text { for } z_{1} \geq z_{2} \geq 0
\end{aligned}
$$

and so $K_{T}^{Z}\left(z_{1}, z_{2}\right)=K\left(z_{1}, z_{2}\right)$ for all all $z_{1} \geq z_{2} \geq 0$. Both results imply that $F_{T} \rightarrow K_{T}$.

\section{C.1.2 Costs, Markups and Prices}

Firms in country $i$ produce under constant returns to scale with a unit cost of serving country $j$ given by $w_{i t} \tau_{i j}^{\omega} / x(z)$, where $x(z)$ is the efficiency of the firm. The distribution of technologies (2) has the following implications:

I.1. Let $a_{i j}^{\omega(1)}(z)$ be the unit cost of serving market $(z, \omega)$ in country $j$ for the most efficient producer of the good in country $i$. Then the cdf of $a_{i j}^{\omega(1)}(z)$ is

$$
G_{i j t}^{\omega}(a)=1-e^{-T_{i t}^{\omega}\left(w_{i t} \tau_{i j}^{\omega}\right)^{-\theta} a^{\theta}}
$$

I.2. Let $a_{j}^{\omega(1)}(z), a_{j}^{\omega(2)}(z)$ be the costs corresponding to the producers around the world with lowest 
and the second lowest unit costs of serving market $(z, \omega)$ in country $j$, respectively. The joint cdf of $a_{j}^{\omega(1)}$ and $a_{j}^{\omega(2)}$ is

$$
G_{j t}^{\omega}\left(a_{1}, a_{2}\right)=1-e^{-\Phi_{j t}^{\omega} a_{1}^{\theta}}-\Phi_{i t}^{\omega} a_{1}^{\theta} e^{-\Phi_{i t}^{\omega} a_{2}^{\theta}}
$$

where $\Phi_{j t}^{\omega}$ is given in (12). Moreover, $G_{j t}^{\omega}$ is also the joint distribution of $a_{j t}^{\omega(1)}(z), a_{j t}^{\omega(2)}(z)$ conditional on country $i$ being the lowest cost supplier.

I.3. At any given moment in time there are many alternative techniques in each country to produce a given final good $(z, \omega)$ that differ in their respective efficiencies. Bertrand competition implies that the producer with the lowest marginal cost of serving that market becomes the only supplier of the good to that market and charges the minimum between the monopoly price and the maximum price that keeps competitors at bay. Recalling that $a_{j}^{\omega(1)}(z)$ and $a_{j}^{\omega(2)}(z)$ are lowest and the second lowest unit costs of serving market $(z, \omega)$ in country $j$, the price charged by the sole supplier of good $i$ in that market is

$$
p_{j t}^{\omega}(z)=\min \left\{\bar{m}\left(\sigma^{\omega}\right) a_{j t}^{\omega(1)}(z), a_{j t}^{\omega(2)}(z)\right\}
$$

where $\bar{m}\left(\sigma^{\omega}\right)$ is the optimal monopoly markup corresponding to the iso-elastic demand for good $(z, \omega)$ which is given by $\bar{m}\left(\sigma^{\omega}\right)=\sigma^{\omega} /\left(\sigma^{\omega}-1\right)$ if $\sigma^{\omega}>1$ and $\bar{m}\left(\sigma^{\omega}\right)=\infty$ if $\sigma^{\omega} \leq 1$. Moreover, an immediate implication of (I.2) is that the distribution of prices in industry $\omega$ and country $j$ does not depend on the source country.

I.4. Let us define the cost gap in country $j, m_{j t}^{\omega}(z) \equiv a_{j t}^{\omega(2)}(z) / a_{j t}^{\omega(1)}(z)$. Then (I.2) implies that $m_{j}^{\omega}(z)$ is Pareto distributed:

$$
M_{j t}^{\omega}(m)=\operatorname{Pr}\left(m_{j t}^{\omega}(z) \leq m\right)=1-m^{-\theta}
$$

Moreover, the distribution of the cost gap is independent of the source country and of $a_{j t}^{\omega(2)}(z)$.

I.5. With the previous definitions, markups $m_{j t}^{\prime \omega}(z)$ are given by

$$
m_{j t}^{\omega}(z)=\min \left\{m_{j t}^{\omega}(z), \bar{m}\left(\sigma^{\omega}\right)\right\}
$$

I.6. The exact price index for industry $\omega$ in country $i$ is given by expression (13) in the text.

\section{C.1.3 Derivation of (13)}

Proof. In what follows I drop subscripts since the analysis applies to any time, country and industry. Starting with the definition of $P$, we have

$$
\begin{aligned}
P^{1-\sigma} & =\int_{0}^{1}\left[a^{(1)}(z) m^{\prime}(z)\right]^{1-\sigma} d z=\int_{0}^{1}\left[a^{(2)}(z) \frac{m^{\prime}(z)}{m(z)}\right]^{1-\sigma} d z \\
& =\mathbb{E}_{t}\left[\left(a^{(2)}\right)^{1-\sigma}\right] \mathbb{E}_{t}\left[\left(m^{\prime}(z) / m(z)\right)^{1-\sigma}\right]
\end{aligned}
$$


where in the first line I used the fact that price equal to cost times markup and the definition of $m(z)$, and the third line I used the fact that $m$ is independent of $a^{(2)}$ (see I.4).

Using the marginal distribution of $a^{(2)}$ we get

$$
\mathbb{E}_{t}\left[\left(a^{(2)}\right)^{1-\sigma}\right]=\Phi^{-(1-\sigma) / \theta} \Gamma\left(\frac{1-\sigma+2 \theta}{\theta}\right)
$$

Finally, (I.4) and (I.5) imply

$$
\begin{aligned}
\mathbb{E}_{t}\left[\left(m^{\prime}(z) / m(z)\right)^{1-\sigma}\right] & =\int_{1}^{\bar{m}} d M(m)+\int_{\bar{m}}^{\infty}(\bar{m} / m)^{1-\sigma} d M(m) \\
& =1+\bar{m}^{-\theta} \frac{(\sigma-1)}{[\theta-(\sigma-1)]}
\end{aligned}
$$

Using the last two results in the expression above we get the result.

\section{C.1.4 Cost Share in Revenues}

Proof. I eliminate the subscripts $\omega, i, t$ since the analysis that follows is valid for any industry, country and time. Let $\operatorname{Cost}(z) \equiv a^{(1)}(z) q(z)$ be the total cost of production of country $j$ 's demand of good $(z, \omega)$. Then

$$
\begin{aligned}
\operatorname{Cost}(z) & =\frac{E(z)}{m^{\prime}(z)}=\frac{E P^{\sigma-1}}{m^{\prime}(z)} p(z)^{1-\sigma}=\frac{E P^{\sigma-1}}{m^{\prime}(z)}\left(a^{(1)}(z) m^{\prime}(z)\right)^{1-\sigma} \\
& =\frac{E P^{\sigma-1}}{m^{\prime}(z)}\left[a^{(2)}(z)\left(\frac{m^{\prime}(z)}{m(z)}\right)\right]^{1-\sigma}
\end{aligned}
$$

and integrating over $z$ we get

$$
\text { Cost }=E P^{\sigma-1} \mathbb{E}_{t}\left[a^{(2)}(z)\right] \mathbb{E}_{t}\left[\frac{m^{\prime}(z)^{-\sigma}}{m(z)^{1-\sigma}}\right]=\frac{\theta}{1+\theta} E .
$$

\section{C.1.5 Probability of Staying in the Market}

Proof. What is the probability that a lowest cost producer in country $j$ and industry $\omega$ in period $t$ is still the state of the art in period $s>t$ ? Letting $X_{j t}^{\omega} \equiv 1 / a_{j t}^{\omega(1)}$, I.2. implies $X_{j t}^{\omega} \sim$ Fréchet $\left(\Phi_{j t}^{\omega}, \theta\right)$. The quality of the best ideas discovered between $t$ and $s$ in each country $k$ is distributed $F(x)=e^{-T_{k}^{\prime} x^{-\theta}}$ for $x \geq 1$ and where $T_{k}^{\prime \omega}=T_{k s}^{\omega}-T_{k t}^{\omega}$. Notice that this distribution is independent of the distribution of state of the art ideas at time $t$. Letting $X_{j}^{\prime}(\omega)$ denote the random variable representing the inverse of lowest costs in country $j$ at time $s$ of the ideas generated between $t$ and $s$, we know $X_{j}^{\prime \omega} \sim \operatorname{Fréchet}\left(\Phi_{j}^{\prime \omega}, \theta\right)$, where

$$
\Phi_{j}^{\prime \omega}=\sum_{k=1}^{N} T_{k}^{\prime \omega}\left(w_{k s} \tau_{i j}^{\omega}\right)^{-\theta}=\Phi_{j s}^{\omega}-\Phi_{j t}^{\omega}
$$


Since the ideas generated between period $t$ and $s$ are independent from the ideas up to time $t$, the distribution of $X_{j}^{\prime \omega}$ is also independent from the distribution of $X_{j t}^{\omega}$. Setting $w_{i t}=1$ for all $t$, the probability that an idea from country $i$ is still in the market in period $s$ conditional on being in the market in period $t$ is equal to $\operatorname{Pr}\left(X_{j t}^{\omega} \geq X_{j}^{\omega}\right)$. Given the Fréchet distribution of inverse costs we obtain

$$
\operatorname{Pr}\left(X_{j t}^{\omega} \geq X_{j}^{\omega}\right)=\frac{\Phi_{j t}^{\omega}}{\Phi_{j t}^{\omega}+\Phi_{j t}^{\prime \omega}}=\frac{\Phi_{j t}^{\omega}}{\Phi_{j s}^{\omega}} .
$$

\section{C.2 Section 3}

\section{C.2.1 Growth Rates and Research Intensity in the BGP}

Lemma 5 In any balanced growth path of this economy the following condition holds:

(i) wages, trade shares and interest rates are constant;

(ii) the interest rate is the same across countries:

$$
r_{i t}=r=[n+n v / \theta] \eta+\rho-n v / \theta
$$

(iii) growth rates are given by ${ }^{46}$

$$
\widetilde{L}_{i t}^{q, \omega}=\widetilde{L}_{i t}^{R, \omega}=\widetilde{R}_{i t}^{\omega}=\widetilde{V}_{i j t}^{\omega}=n, \quad \widetilde{T}_{i t}^{\omega}=v n, \quad \widetilde{P}_{i t}=-n v / \theta, \quad \widetilde{C}_{i t}=n+n v / \theta
$$

(iv) the research intensity $L_{i t}^{R, \omega} / L_{i t}^{\omega}$ is constant and it is the same for all industries and countries:

$$
\kappa(n, \rho, \eta, \theta, v) \equiv \frac{L_{i t}^{R, \omega}}{L_{i t}^{\omega}}=\frac{v^{2} n}{v^{2} n+\theta[r-(1-v) n]}
$$

Before getting into the formal proof of the Lemma, an informal discussion of the results. A higher rate of population growth $n$ raises the expected profits from $\mathrm{R} \& \mathrm{D}$ through a higher expected increase in the size of the market for successful ideas, leading to more innovation and growth as we can see in (iii). High values of $v$ and low values of $\theta$ are associated with better R\&D possibilities since they represent weaker decreasing returns in $\mathrm{R} \& \mathrm{D}$ and a fatter upper tail of the distribution from which the efficiency of an idea is drawn, respectively. These better R\&D possibilities are reflected in higher growth rates for the stock of ideas, and the consumption aggregator as we can see in (iii).

The first two terms in the expression for the interest rate in (ii) represent the real interest rate, while the last term is the change in the price level. Notice that the expression in brackets in the first term of (ii) is just the growth rate of the consumption aggregator, $\widetilde{C}_{i t}$. The higher $\widetilde{C}_{i t}$ is, the steeper is the

\footnotetext{
${ }^{46}$ For any variable $X, \widetilde{X}_{t} \equiv \dot{X}_{t} / X_{t}$ denotes its instantaneous growth rate.
} 
expected increase in consumption over time, which leads individuals wanting to smooth their consumption to increase their borrowing at any given rate, pushing up the equilibrium real interest rate.

Lemma 5 shows that country size, research productivity and openness have no effect on the BGPgrowth rates, i.e. all the additional effects on the innovation process brought about by the additional margin of adjustment emphasized in this paper are reflected on the levels of manufacturing technology, a topic to which I turn next.

Proof of parts (i)-(iii). $\quad L_{i t}^{q, \omega}, L_{i t}^{R, \omega}$ growing at constant rates together with $L_{i t}$ growing at the constant rate $n$, necessarily implies that there the share of labor allocated to each industry $\omega$ is constant in the BGP and so $\widetilde{L}_{i t}^{q}(\omega)=\widetilde{L}_{i t}^{R}(\omega)=n$. Differentiating (1) with respect to time yields

$$
\widetilde{T}_{i t}^{\omega}=\iota_{i}^{\omega}\left(L_{i t}^{R, \omega}\right)^{v} / T_{i t}^{\omega}
$$

Recalling that $\widetilde{T}_{i t}^{\omega}$ is constant in a BGP, log-differentiating the last expression with respect to time yields $v \widetilde{L}_{i t}^{R, \omega}=\widetilde{T}_{i t}^{\omega}$ which in turn implies $\widetilde{T}_{i t}^{\omega}=v n$.

Combining equations (11)-(15) and (18) yield

$$
w_{i t} L_{i t}^{q}=\sum_{j=1}^{N} \lambda_{i j t} w_{j t} L_{j t}^{q}
$$

with $\lambda_{i j t}=\int_{\Omega} \alpha_{j}^{\omega} \lambda_{i j t}^{\omega} d \omega$. Given the technology levels $T_{k t}^{\omega}$ and labor allocations $L_{k t}^{q, \omega}$ for all countries $k$ and industries $\omega$, the previous equation determines the equilibrium wages at time $t, w_{k t}$. It should be pretty clear that if $L_{k t}^{q, \omega}$ and $T_{k t}^{\omega}$ grow at the same constant rates across countries, then a vector of wages $w_{k}$ that solves (40) at time $t$ should also solve it at any time $s>t$. Then if we set the $w_{i}$ as the numeraire, the wages of all countries are constant in the BGP.

Once we know wages are constant then it is easy to see that $\widetilde{R}_{i t}=\widetilde{E}_{i t}=\widetilde{R}_{i t}^{\omega}=n$, from (12) we have $\widetilde{\Phi}_{k t}^{\omega}=\widetilde{T}_{k t}^{\omega}=n v$ for all $k$ and (11) imply that trade shares are constant.

From (8) and (13) we get $\widetilde{P}_{i t}=-n v / \theta$, which in turn imply that real wages in country $i$ grow at $n v / \theta$. The relations in (9) imply $\widetilde{C}_{i t}=n+n v / \theta$ and using (10) the interest rate is constant and is given by $r=n \eta+(\eta-1) \frac{n v}{\theta}+\rho$. Using this in (16) we get $\widetilde{V}_{i j t}^{\omega}=n$.

Proof of part (iv). Using the results of Lemma 5 regarding $\widetilde{T}_{i t}^{\omega}$ and $r_{i t}$ in the BGP, the expression for the value of an idea (16) yields $V_{i j t}^{\omega}=E_{t j t}^{\omega} /\{(1+\theta)[r-(1-v) n]\}$. Then

$$
\begin{aligned}
\sum_{j=1}^{N} \lambda_{i j t}^{\omega} V_{i j t}^{\omega} & =\frac{\sum_{j=1}^{N} \lambda_{i j t}^{\omega} E_{j t}^{\omega}}{(1+\theta)[r-(1-v) n]}=\frac{R_{i t}^{\omega}}{(1+\theta)[r-(1-v) n]} \\
& =\frac{w_{i t} L_{i t}^{q, \omega}}{\theta[r-(1-v) n]}
\end{aligned}
$$

where in the first line I used (15) and in the second line I used (14). Using the last expression in (17) and 
solving for $T_{i t}^{\omega}$ yields

$$
T_{i t}^{\omega}=\frac{\iota_{i}^{\omega} v\left(L_{i t}^{R, \omega}\right)^{v-1} L_{i t}^{q, \omega}}{\theta[r-(1-v) n]} .
$$

Differentiating (1) with respect to time yields $\widetilde{T}_{i t}^{\omega}=\iota_{i}^{\omega}\left(L_{i t}^{R, \omega}\right)^{v} / T_{i t}^{\omega}$, and using the result of Lemma 5 regarding $\widetilde{T}_{i t}^{\omega}$ we get

$$
T_{i t}^{\omega}=\frac{\iota_{i}^{\omega}\left(L_{i t}^{R, \omega}\right)^{v}}{v n} .
$$

The two previous expressions imply that $L_{i t}^{q, \omega} / L_{i t}^{R, \omega}=\theta[r-(1-v) n] / v^{2} n$ for all $\omega$ and $i$.

\section{C.2.2 Derivation of (20)}

Given that in the BGP the interest rate is equalized across countries, Lemma 5 and (16) imply $V_{i j t}^{\omega}=$ $\frac{E_{j t}^{\omega}}{(1+\theta)[r-n(1-v)]} \equiv V_{j t}^{\omega}$ for any country $i$. Consequently, $V_{j t}^{\omega}$ represents the expected present value of profits generated by country $j$ 's stream of expenditure in industry $\omega$.

Differentiating (1) with respect to time yields $\widehat{T}_{i t}^{\omega}=\iota_{i}^{\omega}\left(L_{i t}^{R, \omega}\right)^{v} / T_{i t}^{\omega}$, and using the result of Lemma 5 regarding $\widehat{T}_{i t}^{\omega}$ we get $\left(T_{i t}^{\omega} v n / \iota_{i}^{\omega}\right)^{\frac{v-1}{v}}=\left(L_{i t}^{R, \omega}\right)^{v-1}$, and using this back in the first order condition (17) (FOC of research firms) we get

$$
T_{i t}^{\omega}=\iota_{i}^{\omega} v^{v}(v n)^{v-1}\left[\frac{\sum_{j=1}^{N} \lambda_{i j t}^{\omega} V_{j t}^{\omega}}{w_{i}}\right]^{v}
$$

The previous equation relates the level of the stock of ideas at time $t, T_{i t}^{\omega}$, with the expected present value of the profits generated by firms in country $i$ and industry $\omega$. Notice that in the BGP, expression (16) for $V_{i j t}^{\omega}$ implies $V_{j t}^{\omega}=E_{j t}^{\omega} \zeta$, where $\zeta=\{(1+\theta)[r-n(1-v)]\}^{-1}$. Then we can write

$$
\begin{aligned}
\sum_{j=1}^{N} \lambda_{i j t}^{\omega} V_{j t}^{\omega} & =\sum_{j=1}^{N} \lambda_{i j t}^{\omega} \alpha_{j}^{\omega} E_{j t} \zeta \\
& =\left[\sum_{j=1}^{N} \lambda_{i j t}^{\omega} \frac{\alpha_{j}^{\omega} E_{j t} \zeta}{\sum_{k=1}^{N} \alpha_{k}^{\omega} E_{k t} \zeta}\right] V_{t}^{\omega} \\
& =\left[\sum_{j=1}^{N} \lambda_{i j t}^{\omega} \frac{\alpha_{j}^{\omega}\left(E_{j t} / E_{t}\right)}{\sum_{k=1}^{N} \alpha_{k}^{\omega}\left(E_{k t} / E_{t}\right)}\right] V_{t}^{\omega} \\
& =\left[\sum_{j=1}^{N} \lambda_{i j t}^{\omega} \frac{\alpha_{j}^{\omega} \beta_{j}^{E}}{\sum_{k=1}^{N} \alpha_{k}^{\omega} \beta_{k}^{E}}\right] V_{t}^{\omega} \\
& =\left[\sum_{j=1}^{N} \lambda_{i j t}^{\omega} \beta_{j}^{E, \omega}\right] V_{t}^{\omega} \\
& =\beta^{R, \omega} V_{t}^{\omega}
\end{aligned}
$$


where in the second line I divided and multiply by $V_{t}^{\omega}=\zeta \sum_{k=1}^{N} \alpha_{k}^{\omega} E_{k t}$; in the third line I divided numerator and denominator by world expenditure $E_{t} \equiv \sum_{k=1}^{N} E_{k t}$; in the forth line I used the definition $\beta_{j}^{E} \equiv E_{j t} / E_{t}$; in the fifth line I used the fact that $\beta_{j}^{E, \omega} \equiv E_{j t}^{\omega} / E_{t}^{\omega}=\alpha_{j}^{\omega} \beta_{j}^{E} /\left(\sum_{k=1}^{N} \alpha_{k}^{\omega} \beta_{k}^{E}\right)$; and in the fifth line I use the definition of $\beta^{R, \omega}$ together with (15). Using the last result in the previous expression yields the desired result.

\section{C.2.3 Derivation of (21)}

Proof. Notice that $\widetilde{T}_{i t}^{\omega}=\iota_{i}^{\omega}\left(L_{i t}^{R, \omega}\right)^{v} / T_{i t}$ and Lemma 5 imply that in the BGP we have

$$
T_{i t}^{\omega}=\iota_{i}^{\omega}\left(L_{i t}^{R, \omega}\right)^{v} / v n
$$

Dividing and multiplying the RHS of the last expression by $L_{i t}^{v}\left(L_{i t}^{\omega}\right)^{v}$ and using the fact that the research intensity is constant and the same for every industry in the BGP we get

$$
T_{i t}^{\omega}=B_{T}^{\prime} \iota_{i}^{\omega}\left[\delta_{i t}^{\omega} L_{i t}\right]^{v}
$$

where $\delta_{i}^{\omega} \equiv L_{i t}^{\omega} / L_{i t}$ denotes the share of resources allocated to industry $\omega$ and $B_{T}^{\prime} \equiv(v n)^{-1} \kappa^{v}$ is a constant.

\section{C.2.4 Derivation of (22)}

Proof. Notice that $\widetilde{T}_{i t}^{\omega}=\iota_{i}^{\omega}\left(L_{i t}^{R, \omega}\right)^{v} / T_{i t}$ and Lemma 5 imply that in the BGP, $T_{i t}^{\omega}=\iota_{i}^{\omega}\left(L_{i t}^{R, \omega}\right)^{v} / v n$. Combining this with (21) we get

$$
\left(L_{i t}^{R, \omega}\right)^{v}=v n B_{T}\left[\beta_{i}^{R, \omega} V_{t}^{\omega} / w_{i}\right]^{v}
$$

Recalling that $\alpha^{\omega} \equiv E_{t}^{\omega} / E_{t}$ denotes the share of world expenditure allocated to industry $\omega$, the CobbDouglas upper tier utility function implies that we can write $\alpha^{\omega}=\sum_{k=1}^{N} \alpha_{k}^{\omega} \beta_{k t}^{E}$. Then from the definition of $V_{t}^{\omega}$ we get $V_{t}^{\omega}=\zeta \alpha^{\omega} E_{t}$, where $\zeta$ is the same constant defined above. With this last relationship in mind, we can take the ratio of the last equation for two industries $\omega$ and $\omega^{\prime}$ to get

$$
\frac{L_{i t}^{R, \omega^{\prime}}}{L_{i t}^{R, \omega}}=\frac{\beta_{i}^{R, \omega^{\prime}} \alpha^{\omega^{\prime}}}{\beta_{i}^{R, \omega} \alpha^{\omega}}
$$

This immediately implies that

$$
\frac{L_{i t}^{R, \omega}}{L_{i t}^{R}}=\frac{\beta_{i}^{R, \omega} \alpha^{\omega}}{\int_{\Omega} \beta_{i}^{R, \omega} \alpha^{\omega} d \omega}=\frac{\beta_{i}^{R, \omega} \alpha^{\omega}}{\beta_{i}^{R}}
$$

Recalling that the research intensity is constant in the BGP we get

$$
\delta_{t}^{\omega} \equiv \frac{L_{i t}^{\omega}}{L_{i t}}=\frac{\beta_{i}^{R, \omega} \alpha^{\omega}}{\beta_{i}^{R}}=\frac{\beta_{i}^{R, \omega}}{\beta_{i}^{E, \omega}} \alpha_{i}^{\omega}
$$


where the last equality is obtained using the balanced trade condition, $\beta_{i}^{E, \omega}=\alpha_{i}^{\omega} \beta_{i}^{E} / \sum_{k=1}^{N} \alpha_{k}^{\omega} \beta_{k}^{E}$ and $\alpha^{\omega}=\sum_{k=1}^{N} \alpha_{k}^{\omega} \beta_{k}^{E}$.

\section{C.2.5 Proof of Proposition 1}

The description of equations (23.1)-(23.4) can be found in the text. Here I concentrate on the description of the remaining equations and on the proof of the existence of a BGP in which all market shares are strictly positive.

Starting from from $R_{i t}=\int_{\Omega} R_{i t}^{\omega} d \omega$, I obtain (23.5) dividing both sides by world output $R_{t}$ and using the facts $E_{t}=R_{t}$ and $R_{i t}^{\omega}=\beta_{i}^{R, \omega} \alpha^{\omega} E_{t}$. Starting from the definition of world expenditure in industry $\omega, E_{t}^{\omega}=\sum_{j=1}^{N} \alpha_{j}^{\omega} E_{j t}^{\omega}$, I obtain (23.6) dividing both sides of this expression by total world expenditure $E_{t}$. Starting from $E_{i t}^{\omega}=\alpha_{i}^{\omega} E_{i t}$, I obtain (23.7) dividing both sides by world expenditure in industry $\omega$. Finally, I obtain equation (23.8) using the fact that labor income is proportional to total output.

Let us now turn to proof of the existence of a solution to the system (23). In order to obtain this existence result, it is convenient to reduce the system of equations (23) as follows. Using (23.7) and (23.4) in $(23.1)$ and the result in $(23.2)$ we get

$$
\beta_{i}^{R, \omega}=\sum_{j=1}^{N} \frac{\iota_{i}^{\omega}\left(\tau_{i j}^{\omega}\right)^{-\theta}\left(L_{i t} / \beta_{i}^{R}\right)^{\theta+v}\left(\beta_{i}^{R, \omega}\right)^{v}}{\sum_{k=1}^{N} \iota_{k}^{\omega}\left(\tau_{k j}^{\omega}\right)^{-\theta}\left(L_{k t} / \beta_{k}^{R}\right)^{\theta+v}\left(\beta_{k}^{R, \omega}\right)^{v}} \beta_{j}^{E, \omega} .
$$

Given this reduction of the system, we need to prove that the system of equations given by (41), (23.3) and (23.5)-(23.8) has a solution. The goal is to show that a solution to the reduced system can be express as a fixed point of a continuous self-map defined over a compact and convex set (the simplex $\Delta^{N}$ ). Once we do this we can apply Brouwer's Fixed Point Theorem to obtain the result.

Notice that for a given set of countries' total expenditure shares $\beta_{i}^{E}$, equations (23.3) pin down total revenue shares $\beta_{i}^{R}\left(\beta_{1}^{E}, \ldots, \beta_{N}^{E}\right)$ and equations (23.7) pin down countries's expenditure shares in each industry, $\beta_{i}^{E, \omega}\left(\beta_{1}^{E}, \ldots, \beta_{N}^{E}\right)$. This means that for any given set of $\beta_{i}^{E}$, equations (41) represent a system of $N$ equations in the $N$ unknowns ( $N$ is the number of countries) for each industry $\omega$ that can be used to solve for markets shares $\beta_{i}^{R, \omega}$ as functions of expenditure shares $\left(\beta_{1}^{E}, \ldots, \beta_{N}^{E}\right)$. As I state formally in the following Lemma, (41) has a unique interior solution.

Lemma 6 For $v \in(0,1)$, the system (41) has a unique solution with $\beta_{i}^{R, \omega}>0$ for all $i=1, \ldots, N$.

Proof. The main idea behind the proof is to show that the system of equations (41) characterizes the solution of a maximization problem for which there exists a unique solution. Before getting into the details of the proof, it is convenient to simplify notation. Given that the proof is valid for any industry, in what follows I eliminate industry references (whenever it does not crease confusion) and I use $x_{i} \equiv \beta_{i}^{R, \omega}$ 
and $\delta_{i j} \equiv \iota_{i}^{\omega}\left(\tau_{i j}^{\omega}\right)^{-\theta}\left(L_{i t} / \beta_{i}^{R}\right)^{\theta+v}$. With this notation, the system (41) can be written as

$$
x_{i}=\sum_{j=1}^{N} \lambda_{i j}\left(x_{1, \ldots,} x_{N}\right) \beta_{j}^{E, \omega}=\sum_{j=1}^{N} \frac{\delta_{i j} x_{i}^{v}}{\sum_{k=1}^{N} \delta_{k j} x_{k}^{v}} \beta_{j}^{E, \omega}
$$

Consider the following maximization problem

$$
\max _{x_{1}, \ldots, x_{N}} \sum_{j=1}^{N} \beta_{j}^{E, \omega} \ln \left(\sum_{i=1}^{N} \delta_{i j} x_{i}^{v}\right) \text { subject to } x_{k} \geq 0 \text { and } \sum_{k=1}^{N} x_{k}=1 \text {. }
$$

A few remarks about this problem are in order. (i) The problem has at least one solution. The objective function is continuous and the feasible set is compact. (ii) There can be at most one solution. The objective function is strictly concave when $v \in(0,1)$ and the feasible set is convex. (iii) The solution must be interior. Notice that the objective function satisfies Inada conditions in each variable when $v \in(0,1)$.

In addition, given that the objective function is differentiable and strictly concave, $\left(x_{1}, \ldots, x_{N}\right)$ is a solution to $\mathrm{P} 1$ if and only if $\left(x_{1}, \ldots, x_{N}\right)$ satisfies the first order conditions (FOC) for an interior solution. This, together with points (i)-(iii) above, implies that there exists a unique solution to the system of equations determined by the FOC of this problem. Consequently, the Lemma is proved if we show that (42) corresponds to the FOC of P1, which I do next.

Letting $\mu$ be Lagrange multiplier associated with the constraint, the FOC of the previous problem can be written (after rearrangement) as

$$
\sum_{j=1}^{N} \beta_{j}^{E, \omega} \frac{\delta_{i j} x_{i}^{v}}{\sum_{k=1}^{N} \delta_{k j} x_{k}^{v}}=\frac{\mu}{v} x_{i} \text { for } i=1, \ldots, N
$$

Summing the FOCs side by side and recalling that $\sum_{k=1}^{N} x_{k}=1$ we get

$$
\sum_{i=1}^{N} \sum_{j=1}^{N} \beta_{j}^{E, \omega} \frac{\delta_{i j} x_{i}^{v}}{\sum_{k=1}^{N} \delta_{k j} x_{k}^{v}}=\frac{\mu}{v} \Rightarrow \frac{\mu}{v}=1
$$

Comparing the systems (42) and (FOC) with $\mu / v=1$ and we can see that they are identical, which is the desired result.

The last Lemma shows that for a given set of countries' total expenditure shares $\left(\beta_{1}^{E}, \ldots, \beta_{N}^{E}\right)$, there exists a unique set of market shares $\beta_{i}^{R, \omega}\left(\beta_{1}^{E}, \ldots, \beta_{N}^{E}\right)$ that solves (41). In addition it is not hard to see that the function $\left(\beta_{1}^{E}, . ., \beta_{N}^{E}\right) \rightarrow \beta_{i}^{R, \omega}$ defined in this way is continuous. Finally, once we have a set of market shares $\beta_{i}^{R, \omega}$, we can use equations (23.5) to obtain $\beta_{i}^{R}\left(\beta_{1}^{E}, . ., \beta_{N}^{E}\right)$ and then the balanced trade condition (23.3) to obtain a new set of countries' expenditure shares $\beta_{i}^{\prime E}\left(\beta_{1}^{E}, . ., \beta_{N}^{E}\right)$. In other words, we have defined in this way a continuous self-map $\left(\beta_{1}^{E}, . ., \beta_{N}^{E}\right) \rightarrow\left(\beta_{1}^{E}, . ., \beta_{N}^{\prime E}\right)$ on the $N$-dimensional simplex. Then, Brouwer's Fixed Point Theorem implies that there exist a $\left(\beta_{1}^{* E}, . ., \beta_{N}^{* E}\right)$ that is a fixed point of this self-map. Notice 
that by construction of this self-map, $\left\{\beta_{i}^{* E}, \beta_{i}^{R}\left(\beta_{1}^{* E}, . ., \beta_{N}^{* E}\right), \beta_{i}^{R, \omega}\left(\beta_{1}^{* E}, . ., \beta_{N}^{* E}\right), \beta_{i}^{E, \omega}\left(\beta_{1}^{* E}, \ldots, \beta_{N}^{* E}\right)\right\}$ is a solution to the reduced system given by equations (41), (23.3) and (23.5)-(23.8).

\section{C.2.6 Proof of Lemma 1}

Proof. The characterization under autarky is obtained combining equations (21) and (22) together with the fact that in autarky $\beta_{i}^{R, \omega} / \beta_{i}^{E, \omega}=1$ for all countries and industries.

Let us turn now to the characterization corresponding to a zero gravity world. Using equations (23.4) and (23.8) in (23.1) and specializing it for the zero gravity case yield

$$
\lambda_{i j}^{\omega}=\frac{\iota_{i}^{\omega}\left(\beta_{i}^{R, \omega}\right)^{v} w_{i}^{-(\theta+v)}}{\sum_{k} \iota_{k}^{\omega}\left(\beta_{k}^{R, \omega}\right)^{v} w_{k}^{-(\theta+v)}}
$$

As we can see from the last expression, $\lambda_{i j}^{\omega}$ does not depend on the importer $j$, implying a zero gravity world the exports of a country represent the same share of any importer's expenditure, i.e., $\lambda_{i j}^{\omega}=\lambda_{i j^{\prime}}^{\omega}$ for all $i, j, j^{\prime}$. This together with equation (23.2) imply that $\beta_{i}^{R, \omega}=\lambda_{i i}^{\omega}$ for all country $i$. Consequently, the ratio of the market shares of two countries $i, j$ is given by

$$
\frac{\beta_{i}^{R, \omega}}{\beta_{j}^{R, \omega}}=\frac{\lambda_{i i}^{\omega}}{\lambda_{j j}^{\omega}}=\frac{\iota_{i}^{\omega}\left(\beta_{i}^{R, \omega}\right)^{v} w_{i}^{-(\theta+v)}}{\iota_{j}^{\omega}\left(\beta_{j}^{R, \omega}\right)^{v} w_{j}^{-(\theta+v)}}
$$

and solving for $\beta_{i}^{R, \omega} / \beta_{j}^{R, \omega}$ yields

$$
\frac{\beta_{i}^{R, \omega}}{\beta_{j}^{R, \omega}}=\left[\frac{\iota_{i}^{\omega}}{\iota_{j}^{\omega}}\right]^{\frac{1}{1-v}}\left[\frac{w_{i}}{w_{j}}\right]^{-\frac{(\theta+v)}{1-v}}
$$

Finally, taking double ratios in equation (23.4) and using the last expression yields the result in the text

$$
\frac{T_{i t}^{\omega} / T_{i t}^{\omega^{\prime}}}{T_{j t}^{\omega} / T_{j t}^{\omega^{\prime}}}=\left[\frac{\iota_{i}^{\omega} / \iota_{i}^{\omega^{\prime}}}{\iota_{j}^{\omega} / \iota_{j}^{\omega^{\prime}}}\right]\left[\frac{\beta_{i}^{R, \omega} / \beta_{i}^{R, \omega^{\prime}}}{\beta_{j}^{R, \omega} / \beta_{j}^{R, \omega^{\prime}}}\right]^{v}=\left[\frac{\iota_{i}^{\omega} / \iota_{i}^{\omega^{\prime}}}{\iota_{j}^{\omega} / \iota_{j}^{\omega^{\prime}}}\right]^{1+\frac{v}{1-v}} .
$$

\section{C.2.7 Proof of Lemma 2}

Proof. Before turning to the proof of Lemma, it is convenient to first find an expression for the market shares in the case of frictionless trade, i.e. $\tau=1$. In this case, equation (23.1) implies that $\lambda_{i j}^{\omega}=\lambda_{i j^{\prime}}^{\omega}$ for all $i, j, j^{\prime}$. Combining this with equation (23.2) we get $\lambda_{i j}^{\omega}=\lambda_{i j^{\prime}}^{\omega}=\beta_{i}^{R, \omega}$ for all $i$. Using this together with 
expression resulting from using equation (23.4) in (23.1) we get

$$
\begin{aligned}
\beta_{i}^{R, \omega} & =\frac{\iota_{i}^{\omega}\left(\beta_{i}^{R, \omega}\right)^{v} w_{i}^{-(\theta+v)}}{\sum_{k=1}^{2} \iota_{k}^{\omega}\left(\beta_{k}^{R, \omega}\right)^{v} w_{k}^{-(\theta+v)}} \\
& =\frac{\left(\iota_{i}^{\omega}\right)^{\frac{1}{1-v}} w_{i}^{-\frac{\theta+v}{1-v}}}{\left[\sum_{k=1}^{2} \iota_{k}^{\omega}\left(\beta_{k}^{R, \omega}\right)^{v} w_{k}^{-(\theta+v)}\right]^{\frac{1}{1-v}}}
\end{aligned}
$$

The last condition implies $\beta_{i}^{R, \omega} / \beta_{j}^{R, \omega}=\left(\iota_{i}^{\omega} / \iota_{j}^{\omega}\right)^{\frac{1}{1-v}}\left(w_{i} / w_{j}\right)^{-\frac{\theta+v}{1-v}}$, and using this together with the fact that $\sum_{k} \beta_{k}^{R, \omega}=1$ we get

$$
\beta_{i}^{R, \omega}=\frac{\left(\iota_{i}^{\omega}\right)^{\frac{1}{1-v}} w_{i}^{-\frac{\theta+v}{1-v}}}{\sum_{k=1}^{N}\left(\iota_{k}^{\omega}\right)^{\frac{1}{1-v}} w_{k}^{-\frac{\theta+v}{1-v}}}
$$

Let us now turn to the derivation of the results in the Lemma which I prove with the next three results.

Condition (28) implies that country 1 is a net importer in industry $\omega$ when $\tau=1$ - Letting $N X_{i}^{\omega}$ denote country $i$ 's net exports in industry $\omega$, we have that $N X_{1}^{\omega}<0$ if and only if $X_{12}^{\omega} / X_{21}^{\omega}<1$, where $X_{i j}^{\omega}$ denote the total exports from country $i$ to country $j$ in industry $\omega$. When $\tau=1$, we have

$$
\frac{X_{12}^{\omega}}{X_{21}^{\omega}}=\frac{\lambda_{12}^{\omega} \alpha_{2}^{\omega} E_{2}}{\lambda_{21}^{\omega} \alpha_{1}^{\omega} E_{1}}=\left(\frac{\iota_{1}^{\omega}}{\iota_{2}^{\omega}}\right)^{\frac{1}{1-v}} \frac{\alpha_{2}^{\omega}}{\alpha_{1}^{\omega}}
$$

where the second equality is obtained using the fact that with frictionless trade $\lambda_{i j}^{\omega}=\beta_{i}^{R, \omega}, E_{1}=E_{2}$ from the symmetry assumption and equation (43). Consequently,

$$
N X_{1}^{\omega}<0 \Longleftrightarrow\left(\frac{\iota_{1}^{\omega}}{\iota_{2}^{\omega}}\right)^{\frac{1}{1-v}}<\frac{\alpha_{1}^{\omega}}{\alpha_{2}^{\omega}}
$$

Due to the fact that the expenditure shares of each country across industries must add up to one, condition (27) implies $\alpha_{1}^{\omega} / \alpha_{2}^{\omega}>1$ and $\alpha_{1}^{\omega^{\prime}} / \alpha_{2}^{\omega^{\prime}}<1$. In a similar way, the assumption about symmetric countries and condition (27) imply $\left(\iota_{1}^{\omega} / \iota_{2}^{\omega}\right)<1$ and $\left(\iota_{1}^{\omega^{\prime}} / \iota_{2}^{\omega^{\prime}}\right)>1$. The last two conditions together with condition (44) yield $N X_{1}^{\omega}<0$, i.e., country 1 is a net importer in industry $\omega$ when there are no frictions to trade.

Condition (27) implies that country 1 is a net exporter in industry $\omega$ for a sufficiently high value of $\tau$ - As before, $N X_{1}^{\omega}>0$ if and only if $X_{12}^{\omega} / X_{21}^{\omega}>1$. For the general case of $\tau>1$, we have

$$
\frac{X_{12}^{\omega}}{X_{21}^{\omega}}=\frac{\lambda_{12}^{\omega} \alpha_{2}^{\omega}}{\lambda_{21}^{\omega} \alpha_{1}^{\omega}}=\frac{\alpha_{2}^{\omega}}{\alpha_{1}^{\omega}} \frac{\iota_{1}^{\omega}}{\iota_{2}^{\omega}}\left(\frac{\beta_{1}^{R, \omega}}{\beta_{2}^{R, \omega}}\right)^{v} \frac{\left[\iota_{1}^{\omega}\left(\beta_{1}^{R, \omega}\right)^{v}+\iota_{2}^{\omega}\left(\beta_{2}^{R, \omega}\right)^{v} \tau^{-\theta}\right]}{\left[\iota_{1}^{\omega}\left(\beta_{1}^{R, \omega}\right)^{v} \tau^{-\theta}+\iota_{2}^{\omega}\left(\beta_{2}^{R, \omega}\right)^{v}\right]},
$$

where the second equality is obtained using the definitions of $\lambda_{i j}^{\omega}$ given in equation (23.1) together with 
equation (23.4). In autarky $\beta_{i}^{R, \omega}=\beta_{i}^{E, \omega}$, which in turn implies that $\beta_{1}^{R, \omega} / \beta_{2}^{R, \omega}=\alpha_{1}^{\omega} / \alpha_{2}^{\omega}$. Taking the limit as $\tau \rightarrow \infty$ in the last expression and we get

$$
\lim _{\tau \rightarrow \infty} \frac{X_{12}^{\omega}}{X_{21}^{\omega}}>1 \Longleftrightarrow\left(\frac{\alpha_{1}^{\omega}}{\alpha_{2}^{\omega}}\right)^{v-\frac{1}{2}}>\frac{\iota_{2}^{\omega}}{\iota_{1}^{\omega}} .
$$

Notice that the RHS of the last equivalence is just condition (27). This implies that if condition (27) holds, then there is a value $\bar{\tau}$ such that for all $\tau>\bar{\tau}$, country 1 is a net exporter in industry $\omega$.

There is only one level of transport costs $\tau \in(0,1)$ such that trade is balanced in each industry- Notice that if trade is balanced in industry $\omega$, then $\beta_{i}^{R, \omega}=\beta_{i}^{E, \omega}$, which in turn implies that $\beta_{1}^{R, \omega} / \beta_{2}^{R, \omega}=\alpha_{1}^{\omega} / \alpha_{2}^{\omega}$. Using this in (45), and letting $z \equiv \tau^{-\theta}$, trade is balanced for some $z \in(0,1)$ if, and only if,

$$
f(z) \equiv c \frac{[a+b z]}{[a z+b]}=1
$$

where $c \equiv\left(\frac{\alpha_{2}^{\omega}}{\alpha_{1}^{\omega}}\right)^{1-v} \frac{\iota_{1}^{\omega}}{\iota_{2}^{\omega}}, a \equiv \iota_{1}^{\omega}\left(\alpha_{1}^{\omega} / \alpha_{2}^{\omega}\right)^{v}$, and $b \equiv \iota_{2}^{\omega}$. Let us now analyze the behavior of the function $f(z)$. First, condition (46) implies that $f(0)>1$. Second, $f(1)=c<1$ since $\alpha_{2}^{\omega} / \alpha_{1}^{\omega}<1$ and $\iota_{1}^{\omega} / \iota_{2}^{\omega}<1$. Finally, notice that

$$
f^{\prime}(z)=c \frac{\left[b^{2}-a^{2}\right]}{[a z+b]^{2}}<0
$$

for all $z \in(0,1)$, since condition (28) implies $b \equiv \iota_{2}^{\omega}<\iota_{1}^{\omega}\left(\alpha_{1}^{\omega} / \alpha_{2}^{\omega}\right)^{v} \equiv a$. Consequently, there is at most one $z \in(0,1)$ such that trade is balanced in industry $\omega$.

The results proved above imply that as countries move from autarky to trade, they display a unique reversal in their export profile.

\section{C.2.8 Proof of Proposition 2}

Proof of part (i). To simplify the exposition I consider the case of two symmetric countries that have the same preferences and two industries. However, nothing in the proof depends on countries having the same preferences or in the number of industries. The only requirement is that countries are mirror images of each other.

Countries differ in their research productivities across two industries $\omega=1,2$. The mirror symmetry assumption for the two countries imply that research productivities satisfy $\iota_{i}^{\omega}=\iota_{j}^{\omega^{\prime}}$ and for $i \neq j$. Let us now consider the BGP of this world economy. The system of equations (23) to obtain the BGP of the economy reduces to

$$
\lambda_{i j}^{\omega}=\frac{\iota_{i}^{\omega}\left(\beta_{i}^{R, \omega}\right)^{v}\left(\tau_{i j}^{\omega}\right)^{-\theta}}{\sum_{k=1}^{2} \iota_{k}^{\omega}\left(\beta_{k}^{R, \omega}\right)^{v}\left(\tau_{k j}^{\omega}\right)^{-\theta}} ; \quad \beta_{i}^{R, \omega}=\sum_{j=1}^{N} \lambda_{i j}^{\omega} \frac{1}{2}
$$

where $\tau_{k j}^{\omega}=\tau$ for $k \neq j$, and $\beta_{j}^{E, \omega}=1 / 2$ due to symmetry and equal preferences. Given that $\beta_{i}^{R, \omega}=$ $1-\beta_{j}^{R, \omega}$, with the previous set of equations we can solve for $\beta_{i}^{R, \omega}$. The symmetry assumption together with $\tau_{k j}^{\omega}=\tau$ for $k \neq j$ imply that market shares in the other industry satisfy $\beta_{i}^{R, \omega}=\beta_{j}^{R, \omega^{\prime}}$. In addition, 
symmetry implies that this solution satisfies the balanced trade condition. From the solution to this system, we can back out the manufacturing technology levels

$$
T_{i}^{\omega}=B_{T}^{\prime} \iota_{i}^{\omega}\left[\beta_{i}^{R, \omega} L\right]^{v}
$$

where $L$ denotes the labor endowment in both countries.

Now consider the following maximization problem (P2),

$$
U(\tau)=\max \frac{1}{2} \frac{1}{\theta} \sum_{i=1}^{2} \sum_{\omega=1}^{2} \ln \Phi_{i}^{\omega}
$$

subject to

$$
\begin{array}{ll}
\Phi_{i}^{\omega}=T_{i}^{\omega}+T_{j}^{\omega} \tau^{-\theta} & \lambda_{i j}^{\omega}=\frac{T_{i}^{\omega} \tau^{-\theta}}{\Phi_{j}^{\omega}} \\
T_{i}^{\omega}=B_{T_{i}^{\prime}}^{\prime}\left(L_{i}^{R, \omega}\right)^{v} & \beta_{i}^{R, \omega}=\sum_{j=1}^{2} \lambda_{i j}^{\omega} \frac{1}{2} \\
\sum_{\omega=1}^{2} L_{i}^{R, \omega}=L &
\end{array}
$$

for all $\omega, i$. The objective function in this problem is proportional to the geometric average of the inverse of the price levels in each country. The proof of the Lemma is based is based on the following claim.

Claim 1 The solution to the equations in (47) and (48) are a solution to problem P2.

Proof. The first order condition with respect to $L_{i}^{R, \omega}$ yields

$$
L_{i}^{R, \omega}=\frac{v}{\mu_{i} \theta}\left[\frac{1}{2} \lambda_{i i}^{\omega}+\frac{1}{2} \lambda_{i j}^{\omega}\right]=\frac{v}{\mu_{i} \theta} \beta_{i}^{R, \omega}
$$

where $\mu_{i}$ is the Lagrange multiplier associated with the labor feasibility constraint, and the second equality is obtained using constraint the definition of $T_{i}^{\omega}$ in the constraints. Using this back in the definition of $T_{i}^{\omega}$ and in the expression for $\lambda_{i j}^{\omega}$, and recalling that symmetry implies $\mu_{i}=\mu_{j}$, we arrive to system (47) above. All the symmetry assumptions made imply that for any variable $X$, the solution to the previous problem satisfies $X_{i}^{\omega}=X_{j}^{\omega^{\prime}}$. Consequently, from the solution of the system we can obtain the rest of the variables corresponding to the solution on the previous problem. In particular, the technology levels are given by

$$
T_{i}^{\omega}=B_{T}^{\prime} \iota_{i}^{\omega}\left[\frac{\beta_{i}^{R, \omega}}{\beta_{i}^{R, \omega}+\beta_{i}^{R, \omega^{\prime}}} L\right]^{v}=B_{T}^{\prime} \iota_{i}^{\omega}\left[\beta_{i}^{R, \omega} L\right]^{v}
$$

since $\beta_{i}^{R, \omega}+\beta_{i}^{R, \omega^{\prime}}=1$.

Armed with the last claim, we are ready to prove the Lemma. Consider a change in real income associated with a change in trade cots $\widehat{\tau}$. We are interested in comparing the predicted changes in real income between the model with innovation $(v>0)$ and the model with no innovation $(v=0)$, as predicted by solving the system in changes (29) specialized to the symmetric case under consideration, i.e., we are 
interested in the predicted changes in real income conditional on observed trade shares and market shares in the original equilibrium. These conditional changes are in line with the analysis in Arkolakis, Costinot and Rodriguez-Clare (2012). However, given that the model with and without innovation share the same cross-section structure, we can always assume that the set of exogenous parameters and manufacturing technologies generating the observed initial equilibrium is the same in both models. In this way, this comparison is also compatible with the comparative static exercises in Melitz and Redding (2014). When the two models are set up in this way, real income is also the same across models in the original equilibrium.

Claim 1 implies that the changes in real income associated with the change in trade costs in the model with directed research, $\widehat{W}_{v>0}$, corresponds to the change in the objective function in problem P2, i.e., $\widehat{W}_{v>0}=U\left(\tau^{\prime}\right) / U(\tau)$. In addition, the change in real income in the model with no innovation, $\widehat{W}_{v=0}$, corresponds to the change in the objective function in problem P2 when technology levels are kept at their initial levels. A straight forward revealed preference argument implies that $\widehat{W}_{v>0}(\widehat{\tau})>\widehat{W}_{v=0}(\widehat{\tau})$ for all $\widehat{\tau} \neq 1$.

Proof of part (ii). Consider the effects of raising trade costs to their autarky levels, $\tau_{i j}^{\omega} \rightarrow \infty$ for $i \neq j$. For this particular shock, evaluating (31) is straight forward. In autarky, the home share of expenditure must be equal to one in every industry, while the share of each industry in total output must be equal to the share of consumers' total expenditure allocated to the industry i.e., $\lambda_{i i}^{\omega}=1$ and $\delta_{i}^{\omega}=\alpha_{i}^{\omega}$. ${ }^{47}$ Consequently, for any $v \in[0,1)$, the change in real income associated with moving to autarky, can be computed as

$$
\frac{W_{i t}}{W_{i t}^{a}}=\exp \left\{\int_{\Omega} \log \left(\frac{\delta_{i}^{\omega}}{\alpha_{i}^{\omega}}\right)^{v \alpha_{i}^{\omega} / \theta} d \omega\right\} \exp \left\{\int_{\Omega} \log \left(\lambda_{i i}^{\omega}\right)^{-\alpha_{i}^{\omega} / \theta} d \omega\right\}
$$

where $W_{i t}^{a}$ denotes the real income per capita in autarky. Noticing that Jensen's inequality implies

$$
\int_{\Omega} \alpha_{i}^{\omega} \log \left(\frac{\delta_{i}^{\omega}}{\alpha_{i}^{\omega}}\right) d \omega<\log \left(\int_{\Omega} \alpha_{i}^{\omega} \frac{\delta_{i}^{\omega}}{\alpha^{\omega}} d \omega\right)=\log \left(\int_{\Omega} \delta_{i}^{\omega} d \omega\right)=0
$$

we can write (49) as follows

$$
W_{i t} / W_{i t}^{a}=A_{i}^{\frac{v}{\theta}} \exp \left\{\int_{\Omega} \log \left(\lambda_{i i}^{\omega}\right)^{-\alpha_{i}^{\omega} / \theta} d \omega\right\}
$$

where $A_{i}=\exp \left\{\int_{\Omega} \alpha^{\omega} \log \left(\frac{\delta_{i}^{\omega}}{\alpha_{i}^{\omega}}\right) d \omega\right\}<1$. In other words, the benchmark model with no innovation overestimates the reductions in real income per capita from moving to autarky relative to the model with directed research.

\footnotetext{
${ }^{47}$ Recall that $\delta_{i}^{\omega}=\frac{\beta_{i}^{R, \omega}}{\beta_{i}^{E} \cdot \omega} \alpha_{i}^{\omega}$, which can differ from $\alpha_{i}^{\omega}$ only if $\beta_{i}^{R, \omega} / \beta_{i}^{E, \omega} \neq 1$, i.e., only if trade is not balanced in the industry.
} 


\section{C.2.9 Home Market Effect}

In this section, I follow Krugman (1980) and define the home market effect as the situation in which the country with the relatively larger domestic market in an industry becomes the net exporter in that industry.

To analyze the home market effect, it is convenient to consider a world with only two countries and two industries, $\Omega=2$. Countries are mirror images of each other and they only differ in their preferences. In particular, (i) countries have the same research productivity across industries, eliminating any specialization due to comparative advantage; (ii) countries have the same size as captured by population size, eliminating weak scale effects on technology; (iii) $\tau_{i j}^{\omega}=\tau_{j i}^{\omega}=\tau$. Their preferences satisfy $\alpha_{i}^{\omega}=\alpha_{j}^{\omega^{\prime}}$, and of course $\alpha_{i}^{\omega^{\prime}}=\left(1-\alpha_{i}^{\omega}\right)$.

In what follows I show how the difference in preferences stated above affects the trade patterns for different values of the decreasing returns parameter $v$. The previous conditions guarantee that in equilibrium both countries have the same wage -which I normalize to one- which implies that both countries also have the same total expenditure. Moreover, we only need to focus on one industry since the other industry will just be mirror image of it.

Under these conditions we have

$$
\begin{aligned}
\beta_{i}^{R, \omega} & =\lambda_{i i}^{\omega} \beta_{i}^{E, \omega}+\lambda_{i j}^{\omega} \beta_{j}^{E, \omega} \\
& =\frac{\left(\beta_{i}^{R, \omega}\right)^{v}}{\left(\beta_{i}^{R, \omega}\right)^{v}+\left(\beta_{j}^{R, \omega}\right)^{v} \tau^{-\theta}} \frac{\alpha_{i}^{\omega}}{\alpha_{i}^{\omega}+\alpha_{j}^{\omega}}+\frac{\left(\beta_{i}^{R, \omega}\right)^{v} \tau^{-\theta}}{\left(\beta_{i}^{R, \omega}\right)^{v} \tau^{-\theta}+\left(\beta_{j}^{R, \omega}\right)^{v}} \frac{\alpha_{j}^{\omega}}{\alpha_{i}^{\omega}+\alpha_{j}^{\omega}}
\end{aligned}
$$

for $i=1,2$ and $j \neq i$, and where in the second line I used the definition of $\beta_{1}^{E, \omega}$ and the fact that $E_{1}=E_{2}$.

Dividing dividing each side of the last equation by $\beta_{i}^{R, \omega}$, subtracting the equation corresponding to $i=2$ from the one corresponding to $i=1$, and solving for $\alpha_{2}^{\omega} / \alpha_{1}^{\omega}$ we obtain

$$
\frac{\alpha_{2}^{\omega}}{\alpha_{1}^{\omega}}=\frac{\left[\left(\beta_{1}^{R, \omega} / \beta_{2}^{R, \omega}\right)^{v} \tau^{-\theta}+1\right]}{\left[\left(\beta_{1}^{R, \omega} / \beta_{2}^{R, \omega}\right)^{v}+\tau^{-\theta}\right]} \frac{\left[1-\left(\beta_{1}^{R, \omega} / \beta_{2}^{R, \omega}\right)^{1-v} \tau^{-\theta}\right]}{\left[\left(\beta_{1}^{R, \omega} / \beta_{2}^{R, \omega}\right)^{1-v}-\tau^{-\theta}\right]}
$$

Defining $\beta \equiv \beta_{1}^{R, \omega} / \beta_{2}^{R, \omega}$ and $\alpha \equiv \alpha_{2}^{\omega} / \alpha_{1}^{\omega}$, the last equation defines $\beta$ as an implicit function of $\alpha, \beta(\alpha)$. Noticing that in the range $\left(\tau^{-\frac{\theta}{1-v}}, \tau^{\frac{\theta}{1-v}}\right)$, the right hand side of (50) is strictly decreasing in $\beta$ and varies from infinity to zero, the function $\beta(\alpha)$ satisfies

(50.i) $d \beta / d \alpha<0$ for any value of $v \in[0,1]$ and $\tau>1$.

(50.ii) $\beta=1$ for $\alpha=1$ for any value of $v \in[0,1]$ and $\tau>1$

(50.iii) $\beta(\alpha) \in\left(\tau^{-\frac{\theta}{1-v}}, \tau^{\frac{\theta}{1-v}}\right)$ for any $\alpha \in[0, \infty)$.

Now let us consider the trade balance (net exports) of country 2 in industry $\omega$. We have

$$
T B_{2}^{\omega}=\alpha_{1}^{\omega} E_{1} \lambda_{21}^{\omega}-\alpha_{2}^{\omega} E_{2} \lambda_{12}^{\omega}
$$

where the first term are country 2's exports to country 1 and the second term are country 2's imports 
from country 1. Using the definitions of $\lambda_{i j}^{\omega}$, (50) and the fact that in equilibrium we must have $E_{1}=E_{2}$, we can write the above equation

$$
T B_{2}^{\omega}=\frac{\alpha_{1}^{\omega} E_{1} \tau^{-\theta}}{\left[\beta^{v}+\tau^{-\theta}\right]}\left[1-\beta^{v} \frac{\left[1-\beta^{1-v} \tau^{-\theta}\right]}{\left[\beta^{1-v}-\tau^{-\theta}\right]}\right]
$$

To analyze the effect of the domestic market size on trade patterns it is instructive to consider first the extreme cases of $v=0$ and $v=1$. When $v=0$ there are no R\&D possibilities in the model and the model becomes essentially a two industry version of Eaton and Kortum (2002) (specifically, a two industry version of BEJK). In this case (51) becomes

$$
T B_{2}^{\omega}=\frac{\alpha_{1}^{\omega} E_{1} \tau^{-\theta}}{\left[1+\tau^{-\theta}\right]}\left[1-\frac{\left[1-\beta \tau^{-\theta}\right]}{\left[\beta-\tau^{-\theta}\right]}\right]
$$

Now consider the case in which country 2 has a larger domestic market for industry $\omega$, i.e., $\alpha>1$. Conditions (50.i) and (50.ii) above imply that $\beta<1$ if $\alpha>1$, and using this in the last expression we get $T B_{2}^{\omega}<0$. In other words, when $v=0$, the country with the larger home market in a given industry is a net importer in that industry.

When $v=1$ there are constant returns to $\mathrm{R} \& \mathrm{D}$. In this case (51) becomes

$$
T B_{2}^{\omega}=\frac{\alpha_{1}^{\omega} E_{1} \tau^{-\theta}}{\left[\beta+\tau^{-\theta}\right]}[1-\beta]
$$

As before, if country 2 has a larger home country for industry $\omega$, then $\alpha>1$ and $\beta<1$, which in turn imply $T B_{2}^{\omega}>0$. As in Krugman (1980), the country with the larger home market in a given industry is a net exporter in that industry.

Let us now turn to the intermediate cases when $v \in(0,1)$. As before, I consider differences in domestic market size in which country 2 has a relatively larger domestic market in industry $\omega$-which correspond to values of $\alpha$ in the range [0,1)- and I focus on how this difference affects country 2 's net exports in that industry. Equations (50) and (51) define the balance of trade as a function of $\alpha, T B_{2}^{\omega}(\alpha)$, and according to our definition, a home market effect is present if $T B_{2}^{\omega}(\alpha)>0$ for $\alpha \in[0,1)$. Consequently, to analyze the home market effect, we need to study the sign of $T B_{2}^{\omega}(\alpha)$ for values of $\alpha$ in the range $[0,1)$.

It is convenient to start with the analysis of the effects of small deviations from the benchmark case of no differences in home market size, $\alpha=1$. In this case, (50) and (51) imply trade is balanced at the industry level, $T B_{2}^{\omega}(1)=0$. A home market effect is present for small differences in market size if $d T B_{2}^{\omega} /\left.d \alpha\right|_{\alpha=1}>0$, i.e., a small relative increase in the size of country 2's domestic market in industry $\omega$ induces a trade surplus in that industry. Recalling that

$$
\frac{d T B_{2}^{\omega}}{d \alpha}=\frac{\partial T B_{2}^{\omega}}{\partial \beta} \frac{\partial \beta}{\partial \alpha}
$$

(50.i) and (50.ii) imply that $d T B_{2}^{\omega} /\left.d \alpha\right|_{\alpha=1}>0$ if, and only if, $\partial T B_{2}^{\omega} /\left.\partial \beta\right|_{\beta=1}<0$. Deriving (51) with respect to $\beta$ and evaluating at $\beta=1$ we get that $T B_{2}^{\omega} /\left.\partial \beta\right|_{\beta=1}<0$ if, and only if, $v>\left(1+\tau^{-\theta}\right) / 2$. In other words, if the decreasing returns to $\mathrm{R} \& \mathrm{D}$ are sufficiently weak ( $v$ sufficiently high), then there is a 
home market effect for small differences in the relative size of the home market.

However, from (50) we can see that as the relative size of the domestic market in country 2 approaches infinity, $\alpha \rightarrow \infty$, the relative market share of country 1 approaches its lower bound, $\beta \rightarrow \tau^{-\frac{\theta}{1-v}}$. This implies that the denominator of the second term of the expression in brackets in (51) approaches zero, which in turn implies that $T B_{2}^{\omega}<0$ for sufficiently large $\alpha$. This means that even for those values of $v$ at which there is a home market effect for small differences in domestic markets' sizes, a sufficiently (relative) large domestic market eventually translates into a trade deficit in the corresponding industry.

The intuition of this result is simple. When a country has a relatively larger domestic market in industry $\omega$ and $\tau>1$, relatively more domestic resources are allocated to that industry for any value of $v$. When there are no $\mathrm{R} \& \mathrm{D}$ possibilities $(v=0)$ those additional resources allocated to production do not compensate the larger domestic demand in the industry, and as a result there is a trade deficit in the industry.

When $v>0$, the reallocation of resources also involves the redirection of R\&D efforts towards industry $\omega$, which endogenously increases the level of technology in that industry giving the country a comparative advantage in production that industry. Notice that the greater domestic demand and the endogenous increase in technology generated by a large domestic market have opposite effects on the trade balance, and consequently, the net effect depends of the relative strength of these two effects.

When $v=1$ there are constant returns to $\mathrm{R} \& \mathrm{D}$ and the effect of a larger domestic market on technology is strongest. In this case, the greater technology effect always dominates the greater demand effect, generating a home market effect for any difference in relative domestic market size.

When $v>\left(1+\tau^{-\theta}\right) / 2$, the effect on technology is strong enough to generate a home market effect for small differences in relative domestic market size. However, as the differences in domestic market size increase and more resources are allocated to industry $\omega$ in country 2 , the decreasing returns in $R \& D$ kick in and the endogenous changes in technology cannot compensate the greater domestic demand.

Finally, when $v \leq\left(1+\tau^{-\theta}\right) / 2$ the decreasing returns to $\mathrm{R} \& \mathrm{D}$ are so strong that there is no home market effect for any difference in relative market size. Notice that this means that if $v \leq 1 / 2$, then there are no home market affects regardless of the level of trade costs.

With the previous analysis we have proved the following Lemma.

Lemma 7 Let $\alpha \equiv \alpha_{2}^{\omega} / \alpha_{1}^{\omega}$ be the relative market size and let $T B_{2}^{\omega}(\alpha)$ the net exports of country 2 in industry $\omega$. In the economy described above the following holds:

(i) If $v=1, T B_{2}^{\omega}(\alpha)>0$ for all $\alpha \in(0,1)$.

(ii) If $\left(1+\tau^{-\theta}\right) / 2<v<1$, there is a $\alpha_{v}^{*} \in(0,1)$ such that (a) $T B_{2}^{\omega}(\alpha)>0$ for $\alpha \in\left(\alpha_{v}^{*}, 1\right)$; (b) $T B_{2}^{\omega}\left(\alpha_{v}^{*}\right)=0$; and (c) $T B_{2}^{\omega}(\alpha)<0$ if $\alpha \in\left(0, \alpha_{v}^{*}\right){ }^{48}$

(iii) If $v \leq\left(1+\tau^{-\theta}\right) / 2, T B_{2}^{\omega}(\alpha)<0$ for all $\alpha \in(0,1)$.

\footnotetext{
${ }^{48}$ The subscript in $\alpha_{v}^{*}$ emphasizes the dependence of the cutoff value on the paramtere $v$.
} 


\section{C.3 Section 5}

\section{C.3.1 Estimation of Comparative Advantage in Production}

I will follow Costinot, Donaldson and Komunjer (2012) to estimate comparative advantage across countries. Equation (23.1) can be express as follows:

$$
x_{i j t}^{\omega}=\frac{T_{i t}^{\omega} w_{i t}^{-\theta}\left(\tau_{i j}^{\omega}\right)^{-\theta}}{\Phi_{j t}^{\omega}} E_{j t}^{\omega}
$$

where the only new variable $x_{i j t}^{\omega}$ represents country $i$ 's total exports of goods in industry $\omega$ to country $j$ in period $t$.

Writing $\ln \tau_{i j}^{\omega}=\mathbb{E}_{\Omega}\left[\ln \tau_{i j}^{\omega}\right]+\left(\ln \tau_{i j}^{\omega}-\mathbb{E}_{\Omega}\left[\ln \tau_{i j}^{\omega}\right]\right)$, we can write the previous expressions as

$$
\log x_{i j t}^{\omega}=\log T_{i t}^{\omega} w_{i t}^{-\theta}+\log \frac{E_{j t}^{\omega}}{\Phi_{j t}^{\omega}}-\theta \log \tau_{i j}^{\omega}
$$

Using $\ln \tau_{i j}^{\omega}=\mathbb{E}_{\Omega}\left[\ln \tau_{i j}^{\omega}\right]+\left(\ln \tau_{i j}^{\omega}-\mathbb{E}_{\Omega}\left[\ln \tau_{i j}^{\omega}\right]\right)$ in the last equation, the resulting expression it can be estimated as

$$
\log x_{i j}^{\omega}=\xi_{i}^{\omega}+\psi_{j}^{\omega}+\xi_{i j}+\varepsilon_{i j}^{\omega}
$$

where $\xi_{i}^{\omega}, \psi_{j}^{\omega}, \xi_{i j}$ are exporter-industry, importer-industry and importer-exporter fixed effects, and $\varepsilon_{i j}^{\omega}$ is an error term:

$$
\begin{array}{rlrl}
\xi_{i}^{\omega} & =\log T_{i t}^{\omega} w_{i t}^{-\theta} ; & \psi_{j}^{\omega}=\log E_{j t}^{\omega} / \Phi_{j t}^{\omega} \\
\xi_{i j}=\mathbb{E}_{\Omega}\left[\ln \tau_{i j}^{\omega}\right] ; & \varepsilon_{i j}^{\omega}=\ln \tau_{i j}^{\omega}-\mathbb{E}_{\Omega}\left[\ln \tau_{i j}^{\omega}\right]
\end{array}
$$

Given the structure of the fixed effects, the regression can only identify $\left(\xi_{i}^{\omega^{\prime}}-\xi_{i}^{\omega}\right)-\left(\xi_{j}^{\omega^{\prime}}-\xi_{j}^{\omega}\right)$, which can be use to construct measures of revealed comparative advantage

$$
C A_{i, i^{\prime} t}^{\omega, \omega^{\prime}} \equiv \frac{T_{i t}^{\omega} / T_{i t}^{\omega^{\prime}}}{T_{i^{\prime} t}^{\omega} / T_{i^{\prime} t}^{\omega^{\prime}}}=\exp \left\{\left(\xi_{i}^{\omega}-\xi_{i}^{\omega^{\prime}}\right)-\left(\xi_{i^{\prime}}^{\omega}-\xi_{i^{\prime}}^{\omega^{\prime}}\right)\right\}
$$

In order to avoid issues related to the particular choice of base year and base industry, I define comparative advantage relative to an "average" industry and country as in the text. Then, starting from a base country $i^{\prime}$ and a base industry $\omega^{\prime}$

$$
C A_{i, i^{\prime} t}^{\omega, \bar{\omega}} \equiv \frac{C A_{i, i^{\prime} t}^{\omega, \omega^{\prime}}}{\prod_{\omega=1}^{\Omega}\left[C A_{i, i^{\prime} t}^{\omega, \omega^{\prime}}\right]^{\frac{1}{\Omega}}}
$$


Finally, we can define comparative advantage relative to "average" industry $\bar{\omega}$ and country $\bar{\imath}$ as follows:

$$
C A_{i t}^{\omega} \equiv \frac{T_{i t}^{\omega} / T_{i t}^{\bar{\omega}}}{T_{\bar{\imath} t}^{\omega} / T_{\bar{\imath} t}^{\bar{\omega}}}=\frac{C A_{i, i^{\prime} t}^{\omega, \bar{\omega}}}{\prod_{i=1}^{N}\left[C A_{i, i^{\prime} t}^{\omega, \bar{\omega}}\right]^{\frac{1}{N}}}
$$

\section{C.3.2 Proof of Lemma 3}

Proof. Multiplying both sides of equations (CAE) and (DE) by $\bar{E}_{i}^{\omega}$ and $\bar{\iota}_{i}^{\omega}$ respectively and taking expectations yields

$$
\begin{aligned}
\mathbb{E}\left[\bar{T}_{i}^{\omega} \bar{E}_{i}^{\omega}\right] & =v \mathbb{E}\left[\bar{\beta}_{i}^{R, \omega} \bar{E}_{i}^{\omega}\right]+\mathbb{E}\left[\bar{\iota}_{i}^{\omega} \bar{E}_{i}^{\omega}\right] \\
\mathbb{E}\left[\bar{\iota}_{i}^{\omega} \bar{E}_{i}^{\omega}\right] & =\frac{\sigma-1}{\theta} \mathbb{E}\left[\bar{\iota}_{i}^{\omega} \bar{\Phi}_{i}^{\omega}\right]
\end{aligned}
$$

where in the second line (equation (DE)) I used $\mathbb{E}\left[\bar{\iota}_{i}^{\omega} \bar{\gamma}_{i}^{\omega}\right]=0$. As discussed in the text, the presence of high trade frictions implies $\mathbb{E}\left[\bar{\iota}_{i}^{\omega} \bar{\Phi}_{i}^{\omega}\right]>0$ and $\mathbb{E}\left[\bar{\beta}_{i}^{R, \omega} \bar{E}_{i}^{\omega}\right]>0$. Using these results and $\sigma>1$ after taking probability limits in (34) yields

$$
\operatorname{plim}\left(\widehat{v}_{1}\right)=\frac{\mathbb{E}\left[\bar{T}_{i}^{\omega} \bar{E}_{i}^{\omega}\right]}{\mathbb{E}\left[\bar{\beta}_{i}^{R, \omega} \bar{E}_{i}^{\omega}\right]}=v+\frac{\sigma-1}{\theta} \frac{\mathbb{E}\left[\bar{\iota}_{i}^{\omega} \bar{\Phi}_{i}^{\omega}\right]}{\mathbb{E}\left[\bar{\beta}_{i}^{R, \omega} \bar{E}_{i}^{\omega}\right]}>v
$$

which is the desired result.

\section{C.3.3 Proof of Lemma 4}

The estimator $\widehat{v}_{2}$ involves the following steps: $\bar{\gamma}_{i}^{\omega}, \bar{\Phi}_{i}^{\omega}, \bar{T}_{i}^{\omega} \bar{\beta}_{i}^{R, \omega}, \widehat{\bar{\gamma}}_{i}^{\omega}$

Proof. As the first step, I show that the OLS estimator of $(\sigma-1) / \theta$ in equation (DE) is biased upwards. Let $c \equiv(\sigma-1) / \theta$ and let $\widehat{c}$ be the OLS estimator of $c$. Notice that (i) equation (DE) implies that $\bar{\gamma}_{i}^{\omega}$ and $\bar{E}_{i}^{\omega}$ are positively correlated; (ii) high trade costs imply that $\bar{E}_{i}^{\omega}$ and $\bar{\beta}_{i}^{R, \omega}$ are positively correlated; (iii) equation (CAE) implies that $\bar{\beta}_{i}^{R, \omega}$ and $\bar{T}_{i}^{\omega}$ are positively correlated if $v>0$; and (iv) as discussed above $\bar{\Phi}_{i}^{\omega}$ and $\bar{T}_{i}^{\omega}$ are positively correlated if trade frictions are high. This sequence of correlations imply that $\bar{\gamma}_{i}^{\omega}$ and $\bar{\Phi}_{i}^{\omega}$ are positively correlated, so the OLS estimator $\widehat{c}$ is biased upwards:

$$
\bar{c} \equiv \operatorname{plim}(\widehat{c})=c+\frac{\mathbb{E}\left[\bar{\Phi}_{i}^{\omega} \bar{\gamma}_{i}^{\omega}\right]}{\mathbb{E}\left[\left(\bar{\Phi}_{i}^{\omega}\right)^{2}\right]}>c
$$

Now I show the last result implies that $\widehat{v}_{2}$ is biased downwards. By construction, $\widehat{\bar{\gamma}}_{i}^{\omega}=(c-\widehat{c}) \bar{\Phi}_{i}^{\omega}+\bar{\gamma}_{i}^{\omega}$, and taking probability limits yields $\operatorname{plim}\left(\hat{\bar{\gamma}}_{i}^{\omega}\right)=(c-\bar{c}) \bar{\Phi}_{i}^{\omega}+\bar{\gamma}_{i}^{\omega}$. Using this and (CAE), the probability limit of estimator $\widehat{v}_{2}$ is given by

$$
\operatorname{plim}\left(\widehat{v}_{2}\right)=\frac{\mathbb{E}\left[\bar{T}_{i}^{\omega} \times \operatorname{plim}\left(\hat{\bar{\gamma}}_{i}^{\omega}\right)\right]}{\mathbb{E}\left[\bar{\beta}_{i}^{R, \omega} \times \operatorname{plim}\left(\hat{\bar{\gamma}}_{i}^{\omega}\right)\right]}=v+(c-\bar{c}) \frac{\mathbb{E}\left[\bar{\iota}_{i}^{\omega} \bar{\Phi}_{i}^{\omega}\right]}{\mathbb{E}\left[\bar{\beta}_{i}^{R, \omega} \times p \operatorname{plim}\left(\hat{\bar{\gamma}}_{i}^{\omega}\right)\right]}
$$


As discussed above, the structure of the model implies $(c-\bar{c})<0$ and $\mathbb{E}\left[\bar{\iota}_{i}^{\omega} \bar{\Phi}_{i}^{\omega}\right]>0$. In addition, $\widehat{b} \equiv \frac{1}{\Omega N} \sum_{i, \omega} \bar{\beta}_{i}^{R, \omega} \widehat{\bar{\gamma}}_{i}^{\omega}$ is a consistent estimator of $\mathbb{E}\left[\bar{\beta}_{i}^{R, \omega} \times p \lim \left(\widehat{\gamma}_{n}\right)\right]$ and from the data we have $\widehat{b}>0$. Then $\operatorname{plim}\left(\widehat{v}_{2}\right)<v$, which is the desired result. 


\section{References}

[1] Acemoglu, D. and J. Linn (2004): "Market Size in Innovation: Theory and Evidence from the Pharmaceutical Industry," Quarterly Journal of Economics, 119(3), 1049-1090.

[2] Aghion, Philippe, and Peter Howitt (1992): "A Model of Growth through Creative Destruction," Econometrica, 60(2), 323-351.

[3] Arkolakis, C., A. Costinot, and A. Rodriguez-Clare (2012): "New Trade Models, Same Old Gains?," American Economic Review, 102(1), 94-130.

[4] Arkolakis, C., N. Ramondo, A.Rodriguez-Clare, and S. Yeaple (2012): "Innovation and Production in the Global Economy," mimeo.

[5] Atkeson, A, and Burstein (2010): "Innovation, Firm Dyanamics, and International Trade," Journal of Political Economy, 118(3), 433-489.

[6] Bernard A., J. Eaton, J. B. Jensen and S. Kortum (2003): "Plants and Productivity in International Trade," American Economic Review, 93(4), 1268-1290.

[7] Bustos, P. (2011): "Trade Liberalization, Exports, and Technology Upgrading: Evidence on the Impact of MERCOSUR on Argentinean Firms," American Economic Reveiw, 101(1), 304-340.

[8] Caliendo, L. and F. Parro (forthcoming): "Estimates of the Trade and Welfare Effects of NAFTA," Review of Economic Studies.

[9] Cerda, R. (2007): "Endogenous Innovations in the Pharmaceutical Industry," Journal of of Evolutionary Economics, 17(4):473-515.

[10] Chor, D. (2010): "Unpacking Sources of Comparative Advantage: A Quantitative Approach," Journal of International Economics, 82(2010), 152-167.

[11] Costinot, A., D. Donaldson and I. Komunjer (2012): "What Goods Do Coutries Trade? A Quantitative Exploration of Ricardo's Ideas," Review of Economic Studies, 79, 581-608.

[12] Dekle, R., J. Eaton, and S. Kortum (2008): "Global Rebalancing with Gravity: Measuring the Burden of Adjustment," IMF Staff Papers, 55(3), 511-540.

[13] Eaton, J. and S. Kortum (2001): "Technology, Trade and Growth: A Unified Framework," European Economic Review, 45(2001), 742-755.

[14] Eaton, J. and S. Kortum (2002): "Technology, Geography and Trade," Econometrica, 70(5), 17411779.

[15] Eaton, J. and S. Kortum (2012): "Putting Ricardo to Work," Journal of Economic Perspectives, 26(2), 65-90. 
[16] Grossman, G. and E. Helpman (1991): "Innovation and Growth in the Global Economy," The MIT Press.

[17] Grossman, G. and E. Helpman (1995): "Technology and Trade," Handbook of International Economics, vol III, 1279-1337.

[18] Hsieh C.-T., and R. Ossa (2012): "A Global View of Productivity Growth in China," NBER Working Paper.

[19] Jaffe, A., G. Newell and R. Stavins (1999): "The Induced Innovation Hypothesis And Energy-Saving Technological Change," Quarterly Journal of Economics, 114(3): 941-975.

[20] Jones, C. (1995a): "Times Series Tests of Endogenous Growth Models," Quarterly Journal of Economics, 110(2), 495-525.

[21] Jones, C. (1995b): "R\&D-Based Models of Economic Growth," Journal of Political Economy, 103(4), 759-784.

[22] Krugman, P. (1980): "Scale Economies, Product Differentiation, and the Pattern of Trade," American Economic Review, 70(5), 950-959.

[23] Kucheryavvy, K., G. Lyn and A. Rodriguez-Clare (2016): "Grounded by Gravity: A Well-Behaved Trade Model with External Economies," Working Paper.

[24] Levchenko, A., and J. Zhang (2013): "The Evolution of Comparative Advantage: Measurement and Welfare Implications," mimeo Universtity of Michigan.

[25] Lileeva, A. and D. Trefler (2010): "Improved Access to Foreign Markets Raises Plant-Level Productivity... For Some Plants," Quarterly Journal of Economics, 125(3): 1051-99.

[26] Melitz, M. (2003): "The Impact of Trade on Intra-Industry Reallocations and Aggregate Industry Productivity," Econometrica, 71(6), 1695-1725.

[27] Rivera-Batiz, L. and P. Romer (1991): "Economic Integration and Endogenous Growth," Quarterly Journal of Economics, 106(2), 531-555.

[28] Romer P., (1990): "Endogenous Technical Change," Journal of Political Economy, 98(5): S71-102.

[29] Schmookler, J. (1966): "Invention and Economic Growth," Harvard University Press, Cambridge, MA.

[30] Shikher, S. "Putting Industries into the Eaton-Kortum Model," Journal of International Trade and Economic Development, 21:6, 807-837.

[31] Shikher, S. "Capital, Technology and Specialization in the Neoclassical Model," Journal of International Economics, 83(2), 229-242. 
[32] Simonovska, I., and M. Waugh (2014a): "The Elasticity of Trade: Estimates and Evidence," Journal of International Economics, 92(1), 34-50.

[33] Simonovska, I., and M. Waugh (2014b): "Trade Models, Trade Elasticity and the Gains from Trade," mimeo. 